\title{
Flow Sheet Development for the Dissolution of Unirradiated Mark 42 Fuel Tubes in F-Canyon, Part II
}

by

A. M. Murray

Westinghouse Savannah River Company

Savannah River Site

Aiken, South Carolina 29808

W. J. Crooks III

This paper was prepared in connection with work done under the above contract number with the U. S.

Department of Energy. By acceptance of this paper, the publisher and/or recipient acknowledges the U. S.

Government's right to retain a nonexclusive, royalty-free license in and to any copyright covering this paper, along with the right to reproduce and to authorize others to reproduce all or part of the copyrighted paper. 
WSRC-TR-99-00196

Flow Sheet Development for the

Dissolution of Unirradiated Mark 42 Fuel Tubes in F-Canyon

Part II

\author{
Alice M. Murray \\ William J. Crooks III
}

Strategic Materials Technology Development

Savannah River Technology Center

June 28, 1999

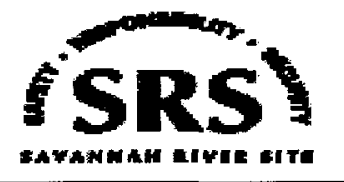


Flow Sheet Development for the Dissolution of Unirradiated Mark 42 Fuel Tubes in F-Canyon

\title{
Part II
}

Alice M. Murray

William J. Crooks III

\section{Strategic Materials Technology Development \\ Savannah River Technology Center}

\author{
June 28, 1999
}

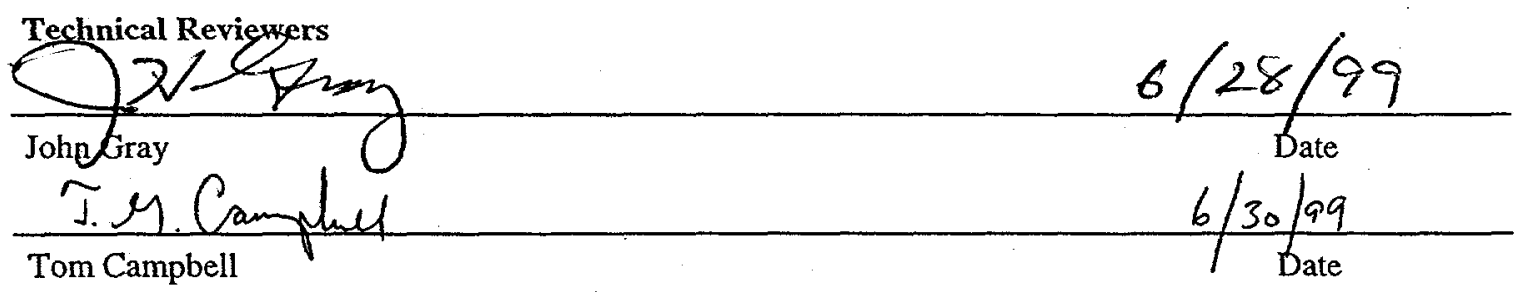




\section{DISCLAIMER}

This report was prepared as an account of work sponsored by an agency of the United States Government. Neither the United States Government nor any agency thereof, nor any of their employees, makes any warranty, express or implied, or assumes any legal liability or responsibility for the accuracy, completeness, or usefulness of any information, apparatus, product or process disclosed, or represents that its use would not infringe privately owned rights. Reference herein to any specific commercial product, process or service by trade name, trademark, manufacturer, or otherwise does not necessarily constitute or imply its endorsement, recommendation, or favoring by the United States Government or any agency thereof. The views and opinions of authors expressed herein do not necessarily state or reflect those of the United States Government or any agency thereof.

This report has been reproduced directly from the best available copy.

Available for sale to the public, in paper, from: U.S. Department of Commerce, National Technical Information Service, 5285 Port Royal Road, Springfield, VA 22161, phone: (800) 553-6847

fax: (703) 605-6900

email: orders@ntis.fedworld.gov

online ordering: http://www.ntis.gov/ordering.htm

Available electronically at http://www.doe.gov/bridge

Available for a processing fee to U.S. Department of Energy and its contractors, in paper, from: U.S. Department of Energy, Office of Scientific and Technical Information, P.O. Box 62, Oak Ridge, TN 37831-0062, phone: (865) 576-8401

fax: (865) 576-5728

email: reports@adonis.osti.gov 


\section{DISCLAIMER}

Portions of this document may be illegible in electronic image products. Images are produced from the best available original document. 


\section{Executive Summary}

Two sets of tests were done to establish dissolution conditions for the unirradiated Mark 42 fuel tubes. Extended dissolution tests were done using $0.15 \mathrm{M}$ and $0.20 \mathrm{M}$ fluoride/ $8 \mathrm{M}$ nitric acid/ $/ 2.20 \mathrm{M}$ boron solutions. Higher fluoride concentrations were used (i.e., $0.25 \mathrm{M}, 0.275$, and $0.30 \mathrm{M}$ ) in another set of tests. Reject Mark 42 compact material was used as the surrogate for the Mark 42 fuel tube cores.

Aluminum nitrate nonahydrate was used as the surrogate for the aluminum from the can and cladding.

The extended dissolution tests were premised on a flow sheet in which 10.3 kilograms of plutonium and 96.3 kilograms of aluminum would be dissolved per batch in 6500 liters of solution. Potassium fluoride was used as the fluoride source, and the fluoride concentrations were $0.15 \mathrm{M}$ and $0.20 \mathrm{M}$. The extendeddissolution tests showed that about $96-98 \%$ of the plutonium was dissolved after 195 hours at $85^{\circ} \mathrm{C}$.

A different processing scheme for the unirradiated Mark 42 fuel tubes was used for the next set of tests. In that scheme, 6.2 kilograms of plutonium and 80.2 kilograms of aluminum would be dissolved per batch. Tests were done with $0.25 \mathrm{M}, 0.275 \mathrm{M}$, and $0.30 \mathrm{M}$ fluoride with calcium fluoride as the fluoride source. There were two tests using $0.30 \mathrm{M}$ fluoride. Those two tests simulated dissolutions that were done in 6500 liters and in 10,000 liters. Dissolution of the reject Mark 42 compact material was completed in seven to 25 hours, depending on the fluoride concentrations and on the dissolver solution volume.

The most effective dissolution conditions used $0.30 \mathrm{M}$ fluoride based on a dissolver solution of 10,000 liters. Under those conditions, the reject Mark 42 compact material dissolved in less than six hours. A parallel experiment was done based on 6500 liters in the dissolver solution. That dissolution was completed within 14 hours. The rapid dissolution of the 10,000 -liter test conditions is not unexpected because the aluminum:fluoride mole ratio was 1:1.

The dissolution of the unirradiated Mark 42 fuel tubes is expected to be longer than the reject compact material. Although the Mark 42 reject compact material is chemically similar to the fuel core in the fuel tubes (i.e., plutonium oxide and aluminum), the compact material is crushed whereas the fuel core is a bulk material. That physical difference favors the dissolution of the compact material compared to the bulk material. Furthermore, the tests on the Mark 42 reject compact material did not assess the time required for the dissolution of the bulk aluminum in the can and the cladding.

No mercury was used in these tests. The aluminum dissolution proceeded rapidly anyway. Initially, that behavior was attributed to the physical form of the Mark 42 reject compact material; it was crushed. The higher surface area of the crushed material would facilitate dissolution compared to bulk material. An article in the literature indicated that there might be an alternate reason: the presence of $\mathrm{HBF}_{4}$ in the solution might serve to enhance the dissolution. The dissolution of an aluminum coupon was tested in a nitric acid solution to which $\mathrm{HBF}_{4}$ was added, in the dissolver solution (nitric acid, boric acid, and calcium fluoride), and in a nitric acid solution. Those tests showed that aluminum dissolution in the $\mathrm{HBF}_{4}$ solution and in the dissolver solution proceeded readily and to completion within a few hours whereas the aluminum dissolution in the nitric acid solution was very slow and incomplete after 10 hours. The presence of $\mathrm{HBF}_{4}$ in the dissolver solution is not an unreasonable expectation because of the equilibria among the boron, fluoride, and acid species. Mercury should continue to be used to promote the dissolution of aluminum in the unirradiated Mark 42 material because these tests do not provide sufficient information to recommend not using mercury. However, as the use the mercury catalyst poses environmental issues, continued work on the use of the $\mathrm{HBF}_{4}$ instead of a mercury catalyst for aluminum dissolution should be pursued.

The corrosive effect of the higher-fluoride concentrations is important to the acceptance of those fluoride concentrations for F-Canyon processing solutions. A study is being done by the Materials Applications and Technology Group to determine the corrosion effects of fluoride concentrations in the range of 0.2 to $0.4 \mathrm{M}$ using the Mark 42 dissolution flow sheet. Those results will be published in a separate report. As part of that corrosion study, the effective free-fluoride concentrations will be measured. 


\section{Recommendation}

The flow sheet recommendation is based on the addition of 6.2 kilograms of plutonium and 80.2 kilograms aluminum from the unirradiated Mark 42 fuel tubes to the dissolver solution per batch. Under those conditions, a 6500 -liter dissolver solution of 8 molar nitric acid, 2.2 grams boron per liter, and 0.125 to $0.15 \mathrm{M}$ calcium fluoride (fluoride concentration is 0.25 to $0.30 \mathrm{M}$ ) should dissolve the plutonium oxide in the unirradiated Mark 42 fuel tubes. Mercury should be added for the aluminum dissolution. 


\section{Acknowledgments}

The authors acknowledge the technical assistance of John Gray, Elaine Pearson, and Patrick Westover (Chemical Technology Group) and of Cecilia Diprete, David Diprete, June Hart, Art Jurgensen, David Missimer, and Mike Summer (Analytical Development Section).

$\therefore . .$. 


\section{Table of Contents}

Introduction 1

2 Background

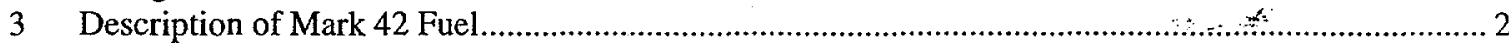

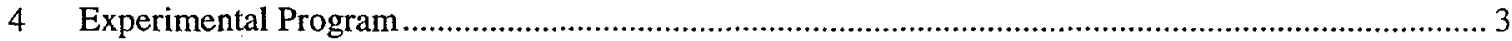

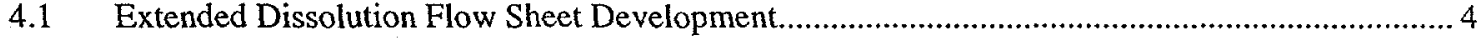

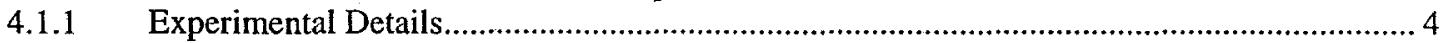

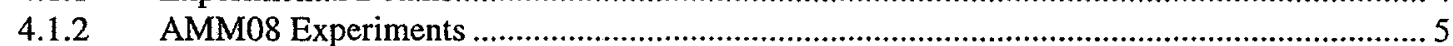

4.1.2.1 Analytical Results for AMM08 Experiments ...........................................................6

4.1.2.2 Discussion of Results for AMM08 Experiments ................................................... 7

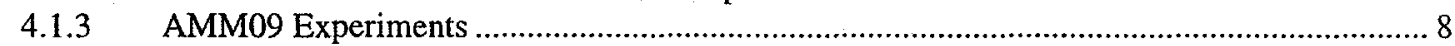

4.1.3.1 Analytical Results for AMM09 Experiments ....................................................... 10

4.1.3.2 Discussion of Results for AMM09 Experiments ....................................................... 10

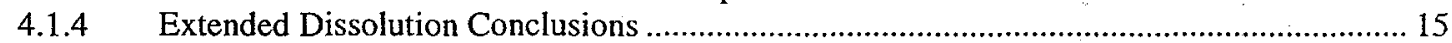

$4.2 \mathrm{CaF}_{2}$ Dissolution Flow Sheet Development

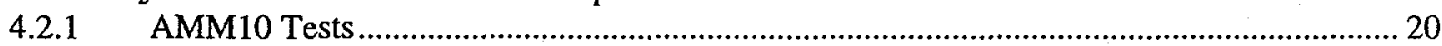

4.2.1.1 Analytical Results for AMM10 Experiments ............................................................ 21

4.2.1.2 Discussion of Results for AMM10 Experiments ........................................................2 21

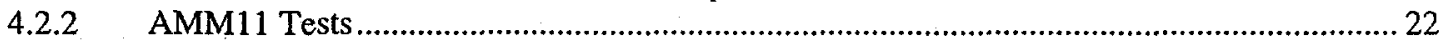

4.2.2.1 Analytical Results for AMM11 Experiments ....................................................... 22

4.2.2.2 Discussion of Results for AMM11 Experiments .........................................................2 23

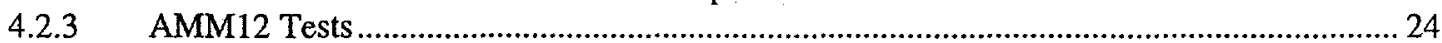

4.2.3.1 Analytical Results for AMM12 Experiments ............................................................. 25

4.2.3.2 Discussion of Results for AMM12 Experiment.......................................................... 25

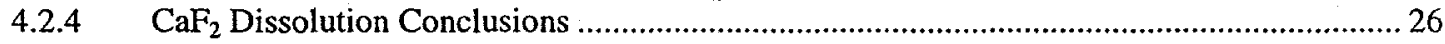

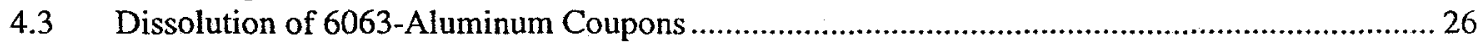

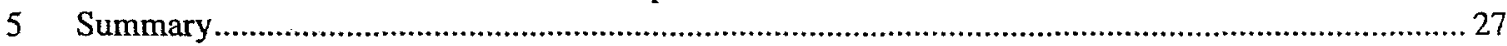

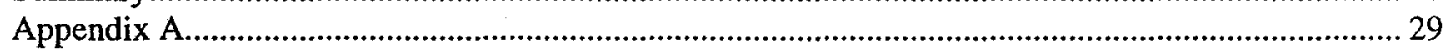

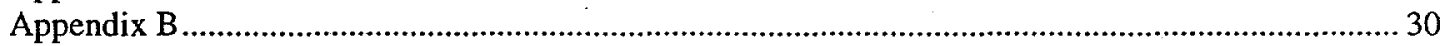


List of Tables

Table 1. Initial Distribution of Plutonium Isotopes in the Mark 42 Fuel .................................................... 2

Table 2. Initial Composition of Mark 42 Fuel Core that Met Specifications (by weight) ............................. 2

Table 3. Distribution of Plutonium Isotopes in Mark 42 Reject Compact Material ................................ 3

Table 4. Relative Plutonium-238 Alpha Activity ............................................................................... 3

Table 5. Composition of Worst Case Scenario for Dissolution of Two Batches of Mark 42 Fuel Tubes ..... 4

Table 6. Experimental Conditions for the Extended Dissolution Flow Sheet Tests …….............................5

Table 7. Rad Screen and Gamma Scan Results for AMM08 Solutions .................................................... 6

Table 8. Plutonium and Americium in AMM08 Solutions as a Function of Dissolution Time...................... 7

Table 9. Progress of Plutonium and Americium Dissolution in AMM08 Experiments ............................... 8

Table 10. Rad Screen and Gamma Scan Results for AMM09a and AMM09c Solutions........................... 11

Table 11. Rad Screen and Gamma Scan Results for AMM09b and AMM09d Solutions ........................... 12

Table 12. Plutonium and Americium in AMM09a and AMM09c Solutions as a Function of Dissolution Time.

Table 13. Plutonium and Americium in AMM09b and AMM09d Solutions as a Function of Dissolution Time.

Table 14. Progress of Plutonium and Americium Dissolution in AMMOS

Table 15. Progress of Plutonium and Americium Dissolution in AMM09b Experiment ............................ 17

Table 16. Experimental Conditions for the $\mathrm{CaF}_{2}$ Dissolution Flow Sheet Tests ...................................... 20

Table 17. Rad Screen and Gamma Scan Results for AMM10 Solutions....................................................... 21

Table 18. Plutonium and Americium in AMM10 Solutions as a Function of Dissolution Time.................. 21

Table 19. Plutonium and Americium Dissolved in AMM10 Experiments................................................2

Table 20. Rad Screen and Gamma Scan Results for AMM11 Solutions..................................................... 23

Table 21. Plutonium and Americium in AMM11 Solutions as a Function of Dissolution Time ..................24

Table 22. Plutonium and Americium Dissolved in AMM11 Experiments .................................................. 24

Table 23. Rad Screen and Gamma Scan Results for AMM12 Solution ..................................................... 25

Table 24. Plutonium and Americium in AMM12 Solution as a Function of Dissolution Time ...................226

Table 25. Plutonium and Americium Dissolved in AMM12 Experiments............................................... 26 


\section{Introduction}

Two dissolution flow sheets were tested for the dissolution of unirradiated Mark 42 fuel tubes. Both the aluminum (from the can, cladding, and fuel core) and the plutonium oxide $\left(\mathrm{PuO}_{2}\right)$ are dissólved simultaneously, i.e., a co-dissolution flow sheet. In the first series of tests, 0.15 and 0.20 molar (M) potassium fluoride (KF) solutions were used and the dissolution extended over several days. In the other series of tests, solutions with higher concentrations of fluoride $(0.25$ to $0.30 \mathrm{M})$ were used. Calcium fluoride $\left(\mathrm{CaF}_{2}\right)$ was used in those tests as the fluoride source.

\section{Background}

There are 38 unirradiated Mark 42 fuel tubes stored in the Receiving Basin for Offsite Fuel (RBOF). Those unirradiated fuel tubes failed to meet the $\mathrm{PuO}_{2}$ density specifications after fabrication in the late 1970s and early 1980s. ${ }^{1,2,3}$ The Nuclear Materials Stabilization and Storage (NMSS) Division plans to dissolve the Mark 42 fuel tubes in F-Canyon and would like to use the resulting solutions to blend with solutions from the dissolution of Experimental Breeder Reactor II (EBR-II) spent nuclear fuel. The blended solution will be processed through the F-Canyon PUREX process flow sheet with the dissolved plutonium converted to metal in FB-Line.

Based on a literature review, the Chemical Technology (CT) Group concluded that the H-Canyon flow sheet for the dissolution of irradiated Mark 42 fuel tubes was not applicable to the dissolution of the unirradiated Mark 42 fuel tubes. ${ }^{4}$ The main issue was the solubility of the $\mathrm{PuO}_{2}$ that is present in the Mark 42 fuel core. Unirradiated $\mathrm{PuO}_{2}$ is more difficult to dissolve than irradiated $\mathrm{PuO}_{2}$. Uncomplexed fluoride ions are needed in the solution to facilitate the dissolution of the unirradiated $\mathrm{PuO}_{2}$. The simple inclusion of sufficient fluoride into the $\mathrm{H}$-Canyon flow sheet is complicated by the presence of boron in the $\mathrm{F}$. Canyon dissolver solution. The boron is required for nuclear criticality safety because the plutonium in the unirradiated Mark 42 fuel tubes is about $78 \%$ plutonium- 239 and $2 \%$ plutonium-241. Boron complexes fluoride ions, thus reducing the amount of free fluoride available to assist with the $\mathrm{PuO}_{2}$ dissolution. The amount of free fluoride ions is further reduced by the dissolved aluminum from the packaged Mark 42 fuel tubes (can, cladding, and core) because aluminum also complexes with fluoride ions. An experimental program was recommended to ascertain the requisite fluoride concentration for the successful dissolution of the $\mathrm{PuO}_{2}$ in the unirradiated Mark 42 fuel tubes.

Experiments were done to determine the flow sheet requirements for the dissolution of the unirradiated Mark 42 fuel tubes. One series of tests focused on a dissolution flow sheet in which the aluminum and $\mathrm{PuO}_{2}$ dissolve simultaneously. The fluoride requirements for the $\mathrm{PuO}_{2}$ dissolution were examined. The results indicated that the required fluoride concentrations would be sufficiently high that there might be serious corrosion issues and the potential for the precipitation of the boron as potassium tetrafluoroborate $\left(\mathrm{KBF}_{4}\right)$ if $\mathrm{KF}$ were used as the fluoride source. The other series of tests considered a two-step acid dissolution in which the aluminum was dissolved in the first step and the $\mathrm{PuO}_{2}$ was dissolved in the second step. The two-step flow sheet presented issues regarding the undissolved $\mathrm{PuO}_{2}$, specifically the transfer of those solids into the holding tank and criticality safety issues. The details of those experiments are reported in WSRC-TR-98-00457. ${ }^{5}$

\footnotetext{
${ }^{1}$ R: L. Frontroth, "Mark 42 Billet Fabrication" memorandum to G. F. Merz, Savannah River Plant, February 11, 1980.

${ }^{2}$ H. B. Peacock, "Inspection of Mark 42 Tubes" memorandum to W. G. Winn, Savannah River Plant, April 14, 1980.

${ }^{3}$ W. G. Winn, Appraisal of High Density Spots in Mark 42 Fuel Tubes, Savannah River Plant Report DPST-80-398, June 13, 1980

${ }^{4}$ A. M. Murray, Evaluation of Proposed Flow Sheet for the F-Canyon Dissolution of Unirradiated Mark 42 Fuel Tubes, Savannah River Site Report WSRC-TR-98-00304, September 4, 1998.

${ }^{5}$ Alice M. Murray and William J. Crooks III; Flow Sheet Development for the Dissolution of Unirradiated Mark 42 Fuel Tubes in F-Canyon; Savannah River Site Report WSRC-TR-98-00457, April 30, 1999.
} 
The NMSS Division approved additional tests on the dissolution of the Mark 42 fuel tubes. Those tests included longer dissolution times at lower fluoride concentrations for the dissolution flow sheet. Other dissolution tests involved the use of $\mathrm{CaF}_{2}$ as the fluoride source so that higher fluoride concentrations could be tested without precipitation of boron-containing salts. The tests on extended dissolution and dissolution with $\mathrm{CaF}_{2}$ are presented in this report.

\section{Description of Mark 42 Fuel}

A good description of the reject Mark 42 fuel tubes and packaging is critical to the development of the dissolution flow sheet. The Mark 42 fuel assembly contained three concentric fuel tubes: the inner, middle, and outer tubes. A cermet (ceramic/metal) of aluminum powder and $\mathrm{PuO}_{2}$ was used for the fuel core. The initial distribution of plutonium isotopes in the Mark 42 fuel core is given in Table 1. More than half of the plutonium-241 has decayed over the past 18 years because the plutonium-241 half-life is about 14.4 years.

Table 1. Initial Distribution of Plutonium Isotopes in the Mark 42 Fuel $^{6}$

\begin{tabular}{|c|c|}
\hline $\begin{array}{c}\text { Plutonium } \\
\text { Isotope }\end{array}$ & $\begin{array}{c}\text { Percent of Total } \\
\text { Plutonium }\end{array}$ \\
\hline Plutonium-238 & $0.15 \%$ \\
\hline Plutonium-239 & $78.28 \%$ \\
\hline Plutonium-240 & $18.58 \%$ \\
\hline Plutonium-241 & $2.27 \%$ \\
\hline Plutonium-242 & $0.71 \%$ \\
\hline
\end{tabular}

The aluminum $/ \mathrm{PuO}_{2}$ composition of the Mark 42 fuel core that met specifications is given in Table 2. The composition of the reject Mark 42 fuel core should be within 5\% of the Mark 42 fuel core that met specifications based on information given in Frontroth's report. ' For example, the plutonium density for the inner fuel tube that met specifications was $61.6 \mathrm{grams} /$ foot. According to Frontroth's report, the reject inner fuel tube had an average plutonium density of $63.5 \mathrm{grams} / \mathrm{foot}$. Thus, there will be less aluminum in the fuel core of the reject inner fuel tubes than predicted by the specifications.

The cladding (Aluminum 6063) was extruded with core material. An estimate of the cladding can be made from information in a report by $M$. $J$. Beckum in which the amount of aluminum associated with a particular package (can + cladding + core) is given. ${ }^{7}$ The estimated amounts of aluminum cladding for the inner, middle, and outer fuel tubes are 3.40 kilograms, 3.23 kilograms, and 3.29 kilograms, respectively. Details of the estimate are given in Appendix A. The unirradiated Mark 42 fuel tubes are in storage in the RBOF. They will be packaged in aluminum General Purpose Cans (GPCs). Each GPC weighs 6.67 kilograms.

Table 2. Initial Composition of Mark 42 Fuel Core that Met Specifications (by weight)

\begin{tabular}{|l|c|c|c|}
\hline Fuel Tube & Percent Plutonium & Percent $\mathrm{PuO}_{2}$ & Percent Aluminum \\
\hline Inner Tube Core & $18.7 \%$ & $21.2 \%$ & $78.8 \%$ \\
\hline Middle Tube Core & $21.8 \%$ & $24.7 \%$ & $75.3 \%$ \\
\hline Outer Tube Core & $15.4 \%$ & $17.5 \%$ & $82.5 \%$ \\
\hline
\end{tabular}

${ }^{6}$ L. Traver, Internal Communication: Mark 42 Facts, August 10, 1998.

${ }^{7}$ M. J. Beckum, Mk-42 Packaging Report, Savannah River Report NMP-SRB-92-0048, January 29, 1992. 


\section{Experimental Program}

Two co-dissolution flow sheets were investigated: an extended dissolution flow sheet with KF as the fluoride source and a dissolution flow sheet that used $\mathrm{CaF}_{2}$ as the fluoride source. Actualmaterial from the unirradiated Mark 42 fuel tubes was not available for the experiments. Instead, crushed reject compact material from the Mark 42 program was used. As part of the formation of the Mark 42 fuel cores, aluminum powder and $\mathrm{PuO}_{2}$ were compacted. Some of that compact material was rejected. That reject compact material has been stored in F-Area (initially the F-Area 410 vault and then in the FB-Line facility). The reject compacts were crushed prior to storage. One can of the reject compact material was sent to the CT Group for use in the Mark 42 flow sheet development. That material is nominally 12.24 weight\% plutonium based on the Material Control and Accountability (MC\&A) records. X-ray diffraction analyses of the Mark 42 reject compact material confirmed the presence of $\mathrm{PuO}_{2}$ and aluminum. The distribution of plutonium isotopes in the Mark 42 reject compact material was determined by inductively-coupled plasma (ICP)/mass spectrometry (MS). Those results are given in Table 3.

Table 3. Distribution of Plutonium Isotopes in Mark 42 Reject Compact Material

\begin{tabular}{|c|c|}
\hline $\begin{array}{c}\text { Plutonium } \\
\text { Isotope }\end{array}$ & $\begin{array}{c}\text { Percent of Total } \\
\text { Plutonium }\end{array}$ \\
\hline Plutonium-238 & $0.14 \%$ \\
\hline Plutonium-239 & $77 \%$ \\
\hline Plutonium-240 & $19 \%$ \\
\hline $\begin{array}{c}\text { Plutonium-241/ } \\
\text { Americium241 }\end{array}$ & $3 \%$ \\
\hline Plutonium-242 & $0.71 \%$ \\
\hline
\end{tabular}

The amount of plutonium-238 alpha activity in the material relative to the total plutonium alpha activity in the material was determined experimentally and is given in Table 4. A thenoyltrifluoroacetone extraction was used to separate the plutonium from the americium to eliminate the americium alpha activity from the solution. Analyses were done on samples reported in WSRC-TR-98-00457. ${ }^{5}$

Table 4. Relative Plutonium-238 Alpha Activity

\begin{tabular}{|c|c|c|c|}
\hline Experiment from WSRC-TR-98-00457 & \multirow[t]{2}{*}{ AMM05c ${ }^{5}$} & \multirow[t]{2}{*}{$\mathrm{AMM} \mathrm{Cg}^{5}$} & \multirow[t]{2}{*}{$A M M 06 h^{5}$} \\
\hline Alpha Activity Ratios & & & \\
\hline $\mathrm{Pu}-238 /(\mathrm{Pu}-239$ and $\mathrm{Pu}-240)$ & 0.166 & 0.165 & 0.168 \\
\hline Pu-238 / Total Pu Alpha Activity & 0.142 & 0.142 & 0.144 \\
\hline
\end{tabular}

The dissolution rate for the crushed compact material is expected to be different from that of actual Mark 42 fuel tubes and is only applicable to the Mark 42 fuel core. Even that applicability has limitations. The large surface area of the crushed compact material enhances that material's dissolution rate compared to intact compact material, i.e., the physical form of the Mark 42 fuel core. The crushed material has a relative large surface area compared to the bulk fuel core, and thus, dissolution of the crushed material is expected to occur more readily. Typically, mercuric nitrate $\left(\mathrm{Hg}\left[\mathrm{NO}_{3}\right]_{2}\right)$ is added to the dissolver solutions to facilitate the dissolution of bulk aluminum. However, in these experiments with the crushed Mark 42 reject compact material, the dissolution proceeded readily without the addition of mercury. 


\subsection{Extended Dissolution Flow Sheet Development}

The goal of this series of tests was to determine if the dissolution flow sheet could be successful at 0.15 or 0.20 molar fluoride if the dissolution was allowed to proceed over several days. Tests were done using the Mark 42 reject compact material.

The amount of Mark 42 reject compact material used in the extended dissolution experiments was based on the worst-case charging scenario that was described in WSRC-TR-98-00457. According to that scenario, the unirradiated Mark 42 fuel tubes will be repackaged in RBOF so that only two fuel tubes are in each GPC that is sent to F-Canyon for dissolution. A worst case scenario for dissolution was developed in which an outer fuel tube and a middle fuel tube are packaged together. This scenario has the highest amount of plutonium and aluminum for a combination of two unirradiated Mark 42 fuel tubes (Table A1, Appendix A). The first dissolution batch would involve four packages, each with an outer and a middle fuel tube. The second dissolution batch would be similarly composed. Table 5 contains the details for that worst case scenario.

Table 5. Composition of Worst Case Scenario for Dissolution of Two Batches of Mark 42 Fuel Tubes

\begin{tabular}{|l|l|l|l|l|}
\hline Batch & Plutonium & $\begin{array}{l}\text { Aluminum in } \\
\text { Cermet }\end{array}$ & $\begin{array}{l}\text { Aluminum from } \\
\text { Cladding }\end{array}$ & $\begin{array}{l}\text { Aluminum from } \\
\text { Can }\end{array}$ \\
\hline 1 & 10.27 kilograms & 43.55 kilograms & 26.08 kilograms & 26.68 kilograms \\
\hline 2 & 10.26 kilograms & 43.53 kilograms & 26.08 kilograms & 26.68 kilograms \\
\hline
\end{tabular}

For the extended dissolution experiments, sufficient Mark 42 reject compact material was added to 250 milliliters of dissolver solution to duplicate the plutonium concentrations of the addition of the first batch in the worst-case scenario to 6,500 liters of dissolver solutions, i.e., 1.6 grams plutonium/liter and $0.55 \mathrm{M}$ aluminum. There were four extended dissolution tests done. In two tests (AMM08a and AMM08b), the material was allowed to dissolve 48 hours before the aluminum-laden solutions were decanted and fresh solutions were added to complete the dissolution of the $\mathrm{PuO}_{2}(\mathrm{AMM08 \textrm {c }}$ and AMM08d). The other two tests (AMM09a and AMM09b) had dissolution times of 196 hours. Not all of the $\mathrm{PuO} 2$ had dissolved in those solutions. The aluminum-laden solutions were decanted and fresh solutions were added to complete the dissolution of the $\mathrm{PuO}_{2}$ (AMM09c and AMM09d).

Aluminum nitrate nonahydrate (ANN) was added to the solutions to provide the aluminum expected from the dissolution of the cladding and the GPC. From Table 5, 52.76 kilograms of aluminum are expected from the dissolution of the cladding and the can in the first batch. In 6,500 liters, that amount of dissolved aluminum would have a concentration of $0.30 \mathrm{M}$.

Fluoride concentrations of $0.15 \mathrm{M}$ and $0.20 \mathrm{M}$ were tested. Potassium fluoride was the fluoride source. The aluminum:fluoride molar ratios were 3.7 and 2.7 , respectively.

The detailed description of the test solutions is given in Table 6. All tests were done in $8 \mathrm{M} \mathrm{HNO}_{3}$ and 2.2 grams boron/liter solutions ( 2.2 grams boron/liter is equivalent to $0.20 \mathrm{M}$ boron).

\subsubsection{Experimental Details}

The experiments on the Mark 42 reject compacts were done in a glovebox with leaded-glass windows because of radiation exposure concerns. The dissolver solutions were prepared outside of the glovebox. Typically, the experiments were done with 250 milliliters of dissolver solution. The Mark 42 reject compact material was weighed in the glovebox and was added to a 600-milliliter Teflon beaker: Next, the dissolver solution was poured into the beaker. The solution was stirred and heated to $85^{\circ} \mathrm{C}$. The solution was kept at $85^{\circ} \mathrm{C}$ during the day shift and allowed to cool overnight. Samples were taken the next day and 
Table 6. Experimental Conditions for the Extended Dissolution Flow Sheet Tests

\begin{tabular}{|l|c|c|c|c|c|}
\hline Test & $\begin{array}{c}\text { Mark 42 } \\
\text { Reject Compact }\end{array}$ & Fluoride & $\begin{array}{c}\text { Fluoride } \\
\text { Source }\end{array}$ & $\begin{array}{c}\text { Dissolution } \\
\text { Time at } \\
850 \mathrm{OC}\end{array}$ & Comments \\
\hline AMM08a & 3.38 grams & 0.15 Molar & $\mathrm{KF}$ & 48 hours & Solution decanted \\
\hline AMM08b & 3.39 grams & 0.20 Molar & $\mathrm{KF}$ & 48 hours & Solution decanted \\
\hline AMM08c* & $\begin{array}{c}\text { Residual solids } \\
\text { from AMM08a }\end{array}$ & 0.15 Molar & $\mathrm{KF}$ & 8 hours & $\begin{array}{c}\text { Solids completely } \\
\text { dissolved }\end{array}$ \\
\hline AMM08d* & $\begin{array}{c}\text { Residual solids } \\
\text { from AMM08b }\end{array}$ & 0.15 Molar & $\mathrm{KF}$ & 8 hours & $\begin{array}{c}\text { Solids completely } \\
\text { dissolved }\end{array}$ \\
\hline AMM09a & 3.40 grams & 0.15 Molar & $\mathrm{KF}$ & 215 hours & Solution decanted \\
\hline AMM09b & 3.39 grams & 0.20 Molar & $\mathrm{KF}$ & 215 hours & Solution decanted \\
\hline AMM09c & $\begin{array}{c}\text { Residual solids } \\
\text { from AMM09a }\end{array}$ & 0.15 Molar & $\mathrm{KF}$ & 7 hours & $\begin{array}{c}\text { Solids completely } \\
\text { dissolved }\end{array}$ \\
\hline AMM09d & $\begin{array}{c}\text { Residual solids } \\
\text { from AMM09b }\end{array}$ & 0.15 Molar & $\mathrm{KF}$ & 7 hours & $\begin{array}{c}\text { Solids completely } \\
\text { dissolved }\end{array}$ \\
\hline
\end{tabular}

* No boric acid added to those solutions.

the volume of the solution was measured. The heating/cooling/sampling cycle was repeated until the experiment was stopped. At that point, the aluminum-laden solution was decanted and fresh solution was added to complete the dissolution of the $\mathrm{PuO}_{2}$.

No mercury was needed for the dissolution of the aluminum in Mark 42 reject compact material. The aluminum dissolution proceeded quite readily as the solution was heated to $85^{\circ} \mathrm{C}$. The aluminum dissolution was accompanied by the evolution of $\mathrm{NO}_{x}$ fumes. The aluminum dissolution was essentially completed in about 30 minutes, as noted by the decrease in $\mathrm{NO}_{\mathrm{x}}$ fumes. The solutions were stirred ( 300 rpm) until the heating was stopped. The undissolved solids were allowed to settle overnight as the solution cooled.

Samples were taken from the cooled solutions at periodic intervals. Typical analyses of the dissolver solutions included rad screen ${ }^{8}$ and gamma scan so that the progress of the plutonium dissolution could be monitored. Less frequently, samples were taken to monitor other constituents in the solution such as fluoride, aluminum, boron, and acid concentrations. Fluoride concentration was determined with ionselective electrodes, total- and free-acid concentrations were determined by titration, and aluminum and boron concentrations were obtained from the ICP/atomic emission spectroscopy (AES) analysis. Results of the fluoride concentration analyses, acid concentration analyses, and ICP/AES analyses are discussed in Appendix B. Some undissolved solids were sampled for $x$-ray diffraction.

\subsubsection{AMM08 Experiments}

The first extended dissolution tests were done for 48 hours. Two fluoride concentrations were tested: $0.15 \mathrm{M}$ and $0.20 \mathrm{M}$. Those two experiments were AMM08a and AMM08b, respectively. Potassium fluoride was the source of fluoride. After the solutions had been heated for 48 hours, the aluminum-laden solutions were decanted. About 250 milliliters of an $8 \mathrm{M} \mathrm{HNO}_{3} / 0.15 \mathrm{M} \mathrm{KF}$ solution was added to dissolve the, remaining residues from experiments AMM08a and AMM08b. The new experiments were AMM08c and AMM08d, respectively. The remaining residues were dissolved after seven hours.

${ }^{8} \mathrm{Rad}$ screen refers to the liquid scintillation analysis in which pulse-shaped discrimination is used to differentiate the alpha events from the beta events. 
It is important to note that a significant fraction of the AMM08a and AMM08b solutions had evaporated during the 48-hour dissolution. Solution AMM08a went from 250 milliliters to 130 milliliters (a $48 \%$ loss of volume) and solution AMM08b lost $36 \%$ of its volume: from 250 milliliters to 160 milliliters. Solids were noted on the walls of the beakers and of the sample vials after about 32 hours of heating. Thus, the evaporation caused some species in the solution to precipitate.

\subsubsection{Analytical Results for AMM08 Experiments}

Periodic samples for rad screen and gamma scan analyses were taken to establish the plutonium and americium dissolution profile in the dissolver solutions. Total alpha activity (plutonium-238, plutonium239, plutonium-240, and americium-241) and total beta activity (plutonium-241) were determined by rad screen. To determine the americium-241 contribution to the total alpha activity, gamma scans were done. The results for the rad screen and gamma scan analyses are given in Table 7. A correction factor was applied to the alpha activity because the rad screen protocol uses a conservative alpha efficiency of $90 \%$. The actual alpha efficiency of the liquid scintillation counter was measured as $97.2 \%$. Therefore, a correction factor of $(0.9 / 0.972)$ was applied to the reported values. The corrected values are given in Table 7.

Table 7. Rad Screen and Gamma Scan Results for AMM08 Solutions

\begin{tabular}{|c|c|c|c|c|c|c|}
\hline Experiment & $\begin{array}{c}\text { Volume of } \\
\text { Solution } \\
\text { Before } \\
\text { Sampling }\end{array}$ & $\begin{array}{c}\text { Time in } \\
\text { Dissolution } \\
\text { Sample } \\
\text { Taken }\end{array}$ & $\begin{array}{c}\text { Beta Activity } \\
\text { dpm/ml - } \\
\text { assumed to } \\
\text { be Pu-241 }\end{array}$ & $\begin{array}{c}\text { Alpha } \\
\text { Activity } \\
\text { dpm/ml }\end{array}$ & $\begin{array}{c}\text { Corrected } \\
\text { Alpha } \\
\text { Activity } \\
\text { dpm/ml }\end{array}$ & $\begin{array}{c}\text { Americium- } \\
241 \\
\text { Alpha } \\
\text { Activity } \\
\text { dpm/ml }\end{array}$ \\
\hline AMM08a-1 & $245 \mathrm{ml}$ & 1.2 hours & $8.80 \times 10^{8}$ & $2.07 \times 10^{8}$ & $1.92 \times 10^{8}$ & $5.22 \times 10^{7}$ \\
\hline AMM08a-2 & $215 \mathrm{ml}$ & Not Taken & - & - & - & - \\
\hline AMM08a-3 & $195 \mathrm{ml}$ & 16.3 hours & $1.67 \times 10^{9}$ & $3.85 \times 10^{8}$ & $3.57 \times 10^{8}$ & $1.02 \times 10^{8}$ \\
\hline AMM08a-4 & $185 \mathrm{ml}$ & 24.1 hours & $1.92 \times 10^{9}$ & $4.39 \times 10^{8}$ & $4.07 \times 10^{8}$ & $1.14 \times 10^{8}$ \\
\hline AMM08a-5 & $170 \mathrm{ml}$ & 31.6 hours & $1.81 \times 10^{9}$ & $4.54 \times 10^{8}$ & $4.20 \times 10^{8}$ & $1.44 \times 10^{8}$ \\
\hline AMM08a-6 & $160 \mathrm{ml}$ & 39.8 hours & $2.52 \times 10^{9}$ & $5.97 \times 10^{8}$ & $5.53 \times 10^{8}$ & $1.68 \times 10^{8}$ \\
\hline AMM08a-7 & $130 \mathrm{ml}$ & 48.0 hours & $3.25 \times 10^{9}$ & $7.39 \times 10^{8}$ & $6.84 \times 10^{8}$ & $2.08 \times 10^{8}$ \\
\hline AMM08c & $235 \mathrm{ml}$ & 7.0 hours & $4.90 \times 10^{8}$ & $1.12 \times 10^{8}$ & $1.04 \times 10^{8}$ & $2.81 \times 10^{7}$ \\
\hline & & & & & & $9.73 \times 10^{7}$ \\
\hline AMM08b-1 & $245 \mathrm{ml}$ & 1.2 hours & $1.59 \times 10^{9}$ & $3.65 \times 10^{8}$ & $3.38 \times 10^{8}$ & - \\
\hline AMM08b-2 & $225 \mathrm{ml}$ & Not Taken & - & - & - & - \\
\hline AMM08b-3 & $200 \mathrm{ml}$ & 16.3 hours & $1.84 \times 10^{9}$ & $4.24 \times 10^{8}$ & $3.93 \times 10^{8}$ & $1.12 \times 10^{8}$ \\
\hline AMM08b-4 & $190 \mathrm{ml}$ & 24.1 hours & $2.26 \times 10^{9}$ & $4.85 \times 10^{8}$ & $4.49 \times 10^{8}$ & $1.25 \times 10^{8}$ \\
\hline AMM08b-5 & $180 \mathrm{ml}$ & 31.6 hours & $1.77 \times 10^{9}$ & $4.49 \times 10^{8}$ & $4.16 \times 10^{8}$ & $1.45 \times 10^{8}$ \\
\hline AMM08b-6 & $170 \mathrm{ml}$ & 39.8 hours & $2.35 \times 10^{9}$ & $5.69 \times 10^{8}$ & $5.27 \times 10^{8}$ & $1.72 \times 10^{8}$ \\
\hline AMM08b-7 & $160 \mathrm{ml}$ & 48.0 hours & $2.93 \times 10^{9}$ & $7.02 \times 10^{8}$ & $6.50 \times 10^{8}$ & $1.99 \times 10^{8}$ \\
\hline AMM08d & $160 \mathrm{ml}$ & 7.0 hours & $2.64 \times 10^{8}$ & $6.08 \times 10^{7}$ & $5.63 \times 10^{7}$ & $1.98 \times 10^{8}$ \\
\hline
\end{tabular}

White solids were observed in some of the sample vials taken from AMM08a and AMM08b for rad screen analyses for the 5,6 , and 7 sets. The samples with solids were filtered through a disk using a syringe. The solids were submitted from $x$-ray diffraction analyses. Those results are discussed in Appendix B. The x-ray diffraction analyses identified $\mathrm{ANN}$ and $\mathrm{H}_{3} \mathrm{BO}_{3}$.

As mentioned previously, the results of the fluoride concentration analyses, acid analyses, and ICP/AES analyses are discussed in Appendix B. 


\subsubsection{Discussion of Results for AMM08 Experiments}

The dissolution of the plutonium and americium in the Mark 42 reject compact material was monitored during the 48 hours at $85^{\circ} \mathrm{C}$. The amount of dissolved plutonium and americium was calculated using the information in Table 3, Table 4, and Table 7 . The grams of plutonium-241/milliliter were calculated assuming that the beta activity was due to the plutonium-241. The grams of americium-241/milliliter were calculated using the results of the gamma scan. Subtracting the americium alpha activity from the total alpha activity gave the plutonium activity. The contribution of plutonium-238 to the plutonium alpha activity was calculated based on the information from the thenoyltrifluoroacetone extraction and was subtracted from the plutonium alpha activity. The remaining plutonium alpha activity was from plutonium239 and plutonium-240. The isotopic ratios from the ICP/MS analysis allowed the relative amounts of those isotopes to be determined. The results of the calculations are given in Table 8 . The thenoyltrifluoroacetone extraction and the ICP/MS tests were done to support the first phase of the flow sheet work for the unirradiated Mark 42 fuel tubes. ${ }^{5}$

Table 8. Plutonium and Americium in AMM08 Solutions as a Function of Dissolution Time

\begin{tabular}{|c|c|c|c|c|c|c|}
\hline Experiment & $\begin{array}{c}\text { Dissolution } \\
\text { Time }\end{array}$ & $\begin{array}{c}\text { Plutonium-241 } \\
\mathrm{g} / \mathrm{ml}\end{array}$ & $\begin{array}{c}\text { Americium- } \\
241 \\
\mathrm{~g} / \mathrm{ml}\end{array}$ & $\begin{array}{c}\text { Plutonium-238 } \\
\mathrm{g} / \mathrm{ml}\end{array}$ & $\begin{array}{c}\text { Plutonium-239 } \\
\mathrm{g} / \mathrm{ml}\end{array}$ & $\begin{array}{c}\text { Plutonium-240 } \\
\mathrm{g} / \mathrm{ml}\end{array}$ \\
\hline AMM08a-1 & 1.2 hours & $3.84 \times 10^{-6}$ & $6.86 \times 10^{-6}$ & $5.20 \times 10^{-7}$ & $4.53 \times 10^{-4}$ & $1.14 \times 10^{-4}$ \\
\hline AMM08a-3 & 16.3 hours & $7.29 \times 10^{-6}$ & $1.34 \times 10^{-5}$ & $9.49 \times 10^{-7}$ & $8.27 \times 10^{-4}$ & $2.07 \times 10^{-4}$ \\
\hline AMM08a-4 & 24.1 hours & $8.38 \times 10^{-6}$ & $1.50 \times 10^{-5}$ & $1.09 \times 10^{-6}$ & $9.50 \times 10^{-4}$ & $2.38 \times 10^{-4}$ \\
\hline AMM08a-5 & 31.6 hours & $7.90 \times 10^{-6}$ & $1.89 \times 10^{-5}$ & $1.03 \times 10^{-6}$ & $8.98 \times 10^{-4}$ & $2.25 \times 10^{-4}$ \\
\hline AMM08a-6 & 39.8 hours & $1.10 \times 10^{-5}$ & $2.21 \times 10^{-5}$ & $1.43 \times 10^{-6}$ & $1.25 \times 10^{-3}$ & $3.14 \times 10^{-4}$ \\
\hline AMM08a-7 & 48.0 hours & $1.42 \times 10^{-5}$ & $2.73 \times 10^{-5}$ & $1.78 \times 10^{-6}$ & $1.55 \times 10^{-3}$ & $3.88 \times 10^{-4}$ \\
\hline AMM08c & 7.0 hours & $2.14 \times 10^{-6}$ & $3.70 \times 10^{-6}$ & $2.82 \times 10^{-7}$ & $2.46 \times 10^{-4}$ & $6.16 \times 10^{-5}$ \\
\hline & & & & & & \\
\hline AMM08b-1 & 1.2 hours & $6.94 \times 10^{-6}$ & $1.28 \times 10^{-5}$ & $8.97 \times 10^{-7}$ & $7.82 \times 10^{-4}$ & $1.96 \times 10^{-4}$ \\
\hline AMM08b-3 & 16.3 hours & $8.03 \times 10^{-6}$ & $1.47 \times 10^{-5}$ & $1.05 \times 10^{-6}$ & $9.11 \times 10^{-4}$ & $2.29 \times 10^{-4}$ \\
\hline AMM08b-4 & 24.1 hours & $9.87 \times 10^{-6}$ & $1.64 \times 10^{-5}$ & $1.21 \times 10^{-6}$ & $1.05 \times 10^{-3}$ & $2.64 \times 10^{-4}$ \\
\hline AMM08b-5 & 31.6 hours & $7.73 \times 10^{-6}$ & $1.91 \times 10^{-5}$ & $1.01 \times 10^{-6}$ & $8.79 \times 10^{-4}$ & $2.21 \times 10^{-4}$ \\
\hline AMM08b-6 & 39.8 hours & $1.03 \times 10^{-5}$ & $2.26 \times 10^{-5}$ & $1.32 \times 10^{-6}$ & $1.15 \times 10^{-3}$ & $2.89 \times 10^{-4}$ \\
\hline AMM08b-7* & 48.0 hours & $1.28 \times 10^{-5}$ & $2.61 \times 10^{-5}$ & $1.68 \times 10^{-6}$ & $1.46 \times 10^{-3}$ & $3.68 \times 10^{-4}$ \\
\hline AMM08d & 7.0 hours & $1.15 \times 10^{-5}$ & $1.96 \times 10^{-6}$ & $1.54 \times 10^{-7}$ & $1.34 \times 10^{-4}$ & $3.37 \times 10^{-5}$ \\
\hline
\end{tabular}

*Based on the average of the americium-241dpm/ml measurements given in Table 7 .

The progress of the dissolution of the plutonium and americium was calculated using the information in Table 8 and the volumes in Table 7. The amounts of plutonium and americium that had dissolved at specific times during the dissolution are given in Table 9. Both the absolute amount and the fraction of the total plutonium and americium are given. The fraction of plutonium and americium was determined using the plutonium and americium values from the AMM08a-7 and AMM08c solutions and from the AMM08b7 and AMM08d solutions. The loss of plutonium and americium from the periodic sampling was incorporated into the calculation. A plot of the progress of the plutonium and americium dissolution in AMM08a is given in Figure 1. 
Table 9. Progress of Plutonium and Americium Dissolution in AMM08 Experiments

\begin{tabular}{|c|c|c|c|}
\hline Experiment & $\begin{array}{c}\text { Dissolution } \\
\text { Time }\end{array}$ & $\begin{array}{c}\text { Plutonium and } \\
\text { Americum-241 } \\
\text { in Solution } \\
\text { (grams) }\end{array}$ & $\begin{array}{c}\text { Fraction of } \\
\text { Plutonium and } \\
\text { Amercium-241 } \\
\text { in Solution }\end{array}$ \\
\hline AMM08a-1 & 1.2 hours & 0.14 & 0.42 \\
\hline AMM08a-3 & 16.3 hours & 0.21 & 0.61 \\
\hline AMM08a-4 & 24.1 hours & 0.23 & 0.67 \\
\hline AMM08a-5 & 31.6 hours & 0.20 & 0.59 \\
\hline AMM08a-6 & 39.8 hours & 0.26 & 0.78 \\
\hline AMM08a-7 & 48.0 hours & 0.26 & 0.78 \\
\hline AMM08c & 7.0 hours & 0.074 & 0.22 \\
\hline & & & \\
\hline AMM08b-1 & 1.2 hours & 0.25 & 0.71 \\
\hline AMM08b-3 & 16.3 hours & 0.23 & 0.68 \\
\hline AMM08b-4 & 24.1 hours & 0.26 & 0.74 \\
\hline AMM08b-5 & 31.6 hours & 0.21 & 0.60 \\
\hline AMM08b-6 & 39.8 hours & 0.26 & 0.76 \\
\hline AMM08b-7* & 48.0 hours & 0.31 & 0.88 \\
\hline AMM08d & 7.0 hours & 0.040 & 0.12 \\
\hline
\end{tabular}

The $0.20 \mathrm{M} \mathrm{KF}$ solution (AMM08b) was more effective dissolving the plutonium and americium than the $0.15 \mathrm{M} \mathrm{KF}$ solution (AMM08a). Neither set of fluoride conditions was able to dissolve all of the plutonium and americium in the Mark 42 reject compact material. The fractions of plutonium and americium that were dissolved in AMM08a and AMM08b are $78 \%$ and $88 \%$, respectively.

Based on the amount of the plutonium and americium that was dissolved in AMM08a-7 and AMM08c and in AMM08b-7 and AMM08d, the percent of plutonium and americium in the Mark 42 reject compact material was calculated. Both sets of solutions gave $10 \%$ as the plutonium and americium content. That value is in agreement with the MC\&A value (12.24 weight\%) and with previous experiments. ${ }^{5}$

The x-ray diffraction analyses of the solids showed that both $\mathrm{ANN}$ and $\mathrm{H}_{3} \mathrm{BO}_{3}$ were present. As expected, no $\mathrm{PuO}_{2}$ was shown in the $\mathrm{x}$-ray diffraction analysis. The solids had precipitated from the sample solutions. None of the undissolved $\mathrm{PuO}_{2}$ solids from the beaker were included in the $\mathrm{x}$-ray diffraction sample.

\subsubsection{AMM09 Experiments}

The second set of extended dissolution tests was done for approximately 215 hours. Two fluoride concentrations were tested: $0.15 \mathrm{M}$ and $0.20 \mathrm{M}$. Those two experiments were AMM09a and AMM09b, respectively. Potassium fluoride was the source of fluoride. During this extended dissolution, the AMM09a and AMM09b solutions were replenished to 250 milliliters with $5 \mathrm{M} \mathrm{HNO}_{3}$ solution if the AMM09a and AMM09b solutions reduced to 200 milliliters. The $5 \mathrm{M} \mathrm{HNO}_{3}$ solution was added to prevent the $\mathrm{ANN}$ and $\mathrm{H}_{3} \mathrm{BO}_{3}$ precipitation that was observed during the AMM08 experiments. The solutions were replenished after about 74 hours and 159 hours at $85^{\circ} \mathrm{C}$. After 195 hours at $85^{\circ} \mathrm{C}, \mathrm{CaF}_{2}$ was added to the solutions to see if the $\mathrm{PuO}_{2}$ dissolution could be enhanced. Sufficient $\mathrm{CaF}_{2}$ was added to AMM09a and AMM09b to increase the fluoride content in each solution by 0.0257 moles. The resulting solutions would be $0.25 \mathrm{M}$ (AMM09a) and $0.30 \mathrm{M}$ (AMM09b) based on 250 milliliters of solution and if all of the original fluoride were still present. 
Figure 1. 48-Hour Dissolution with $0.15 \mathrm{M} \mathrm{KF}$

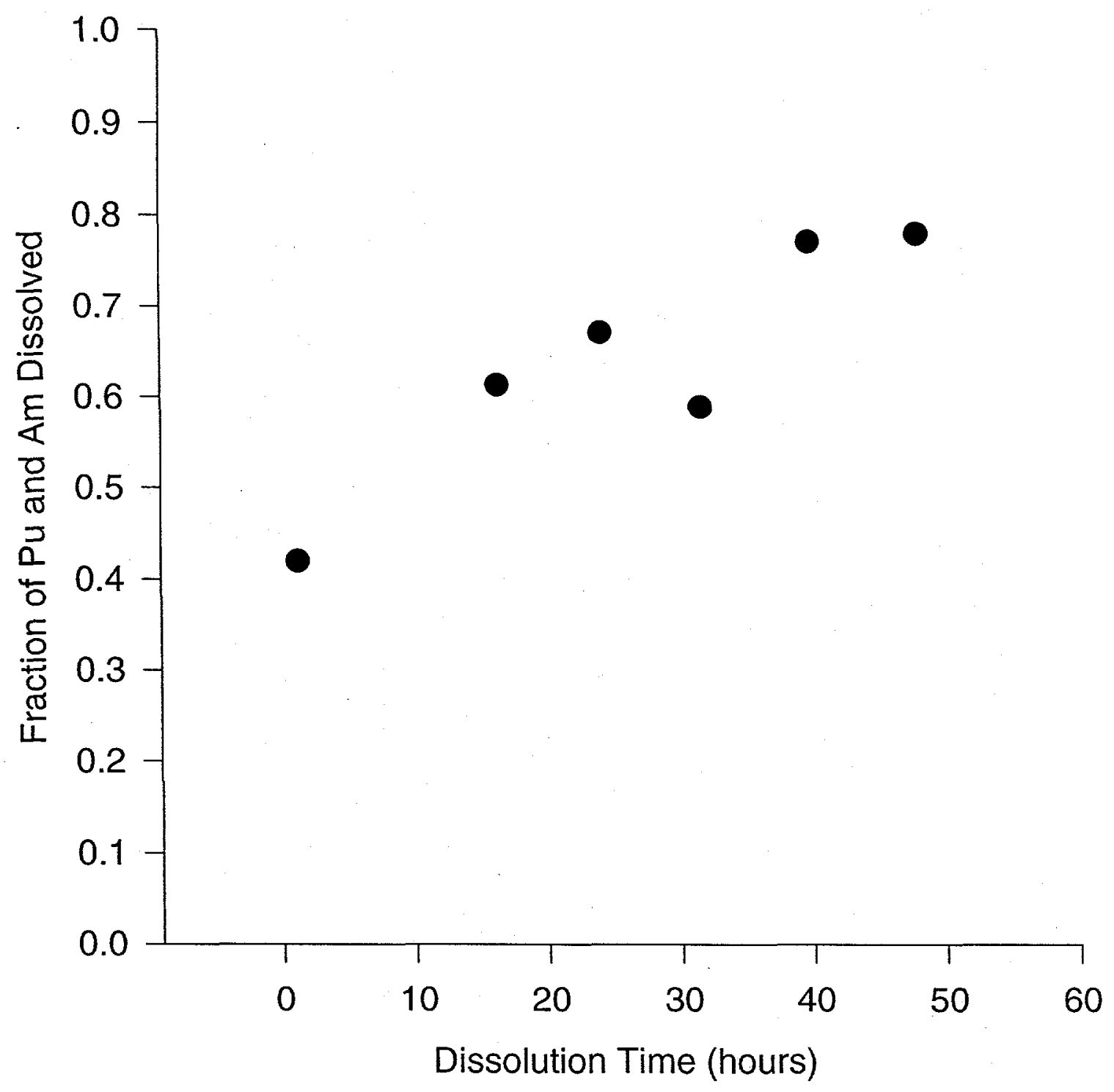


After the solutions had been heated for 215 hours, the aluminum-laden solutions were decanted. About 250 milliliters of an $8 \mathrm{M} \mathrm{HNO}_{3} / 0.20 \mathrm{M} \mathrm{H}_{3} \mathrm{BO}_{3} / 0.15 \mathrm{M} \mathrm{KF}$ solution were added to dissolve the remaining residues from experiments AMM09a and AMM09b. The new experiments were AMM09c and AMM09d, respectively. The remaining residues were dissolved after 6.3 hours at $85^{\circ} \mathrm{C}$.

\subsubsection{Analytical Results for AMM09 Experiments}

Just as with the AMM08 experiments, periodic samples for rad screen and gamma scan were obtained from the AMM09 solutions. Total alpha activity (plutonium-238, plutonium-239, plutonium-240, and americium-241) and total beta activity (plutonium-241) were determined by rad screen. To determine the americium-241 contribution to the total alpha activity, gamma scans were done. The results for the rad screen and gamma scan analyses are given in Table 10 and Table 11. As mentioned in Section 4.1.2.1, a correction factor was applied to the alpha activity because the rad screen protocol uses a conservative alpha efficiency of $90 \%$. The measured alpha-emitter counting efficiency was $97.2 \%$. Therefore, a correction factor of (0.9/0.972) was applied to the reported values. The corrected values also are given Table 10 and Table 11. The samples taken for AMM09a-19 and AMM09b-19 are duplicates of AMM09a-20 and AMM09b-20, respectively. The samples for AMM09a-23 and AMM09b-23 were taken immediately after the $5 \mathrm{M} \mathrm{HNO}_{3}$ solution was added to replenish solutions AMM09a and AMM09b to 250 milliliters. Thus, a dilution factor should relate the results of those two samples to the results from samples AMM09a-22 and AMM09b-22, respectively.

A sample of the remaining solids was taken after 54 hours at $85^{\circ} \mathrm{C}$. That sample was submitted for $\mathrm{x}$-ray diffraction analysis.

Samples were taken less frequently for the ICP/AES analyses for aluminum and boron, ion-selective electrode analysis for fluoride concentration, and the analysis for total- and free-acid concentrations Those results are discussed in Appendix B.

\subsubsection{Discussion of Results for AMM09 Experiments}

The dissolution of the plutonium and americium in the Mark 42 reject compact material was monitored during the 215 hours at $85^{\circ} \mathrm{C}$. The amount of dissolved plutonium and americium was calculated using the information in Table 3, Table 4, Table 10, and Table 11. The grams of plutonium-241/milliliter were calculated assuming that the beta activity was due to the plutonium-241. The grams of americium$241 /$ milliliter were calculated using the results of the gamma scan. Subtracting the americium alpha activity from the total alpha activity gave the plutonium alpha activity. The contribution of plutonium-238 to the plutonium alpha activity was calculated based on the information from the thenoyltrifluoroacetone extraction and was subtracted from the plutonium alpha activity. The remaining plutonium alpha activity was from plutonium-239 and plutonium-240. The isotopic ratios from the ICP/MS analysis allowed the relative amounts of those isotopes to be determined. The results of the calculations are given in Table 12 and Table 13. The thenoyltrifluoroacetone extraction and the ICP/MS tests were done to support the first phase of the flow sheet work for the unirradiated Mark 42 fuel tubes. ${ }^{5}$

The total amount of plutonium and americium dissolved was corrected to account for the amount of plutonium and americium that was removed in the periodic samples. Although each sample only depleted the plutonium and americium by a small amount, the cumulative effect over the thirty-one days of tests was substantial - about $21 \%$ of the plutonium and americium was in the samples.

After about 98 hours, the plutonium and americium dissolution in AMM09a reached a plateau. The average amount of plutonium and americium dissolved was calculated using the sample results from 98 hours through 195 hours. The amount of plutonium and americium dissolved in AMM09a after 195 hours was calculated as 0.33 grams \pm 0.01 grams or $90 \%$ of the plutonium and americium. After the $\mathrm{CaF}_{2}$ was added to AMMO9a to increase the fluoride concentration, the amount of plutonium and americium dissolved increased to 0.36 grams \pm 0.1 grams or $98 \%$ of the amount of plutonium and americium. After decanting the aluminum-laden solution and adding 250 milliliters of a $8 \mathrm{M} \mathrm{HNO}_{3} / 0.20 \mathrm{M} \mathrm{H}_{3} \mathrm{BO}_{3} /$ 
Table 10. Rad Screen and Gamma Scan Results for AMM09a and AMM09c Solutions

\begin{tabular}{|c|c|c|c|c|c|c|}
\hline Experiment & $\begin{array}{l}\text { Volume of } \\
\text { Solution } \\
\text { Before } \\
\text { Sampling }\end{array}$ & $\begin{array}{c}\text { Time Sample } \\
\text { Taken }\end{array}$ & $\begin{array}{l}\text { Beta Activity } \\
\text { dpm/ml - } \\
\text { assumed to } \\
\text { be Pu- } 241\end{array}$ & $\begin{array}{l}\text { Alpha } \\
\text { Activity } \\
\text { dpm } / \mathrm{ml}\end{array}$ & $\begin{array}{l}\text { Corrected } \\
\text { Alpha } \\
\text { Activity } \\
\text { dpm/ml }\end{array}$ & $\begin{array}{c}\text { Americium- } \\
241 \\
\text { Alpha } \\
\text { Activity } \\
\text { dpm } / \mathrm{ml} \\
\end{array}$ \\
\hline AMM09a-1 & $230 \mathrm{ml}$ & 4.5 hours & $1.15 \times 10^{9}$ & $2.76 \times 10^{8}$ & $2.56 \times 10^{8}$ & $8.13 \times 10^{7}$ \\
\hline AMM09a-2 & $230 \mathrm{ml}$ & 12.2 hours & $1.46 \times 10^{9}$ & $3.47 \times 10^{8}$ & $3.21 \times 10^{8}$ & $9.68 \times 10^{7}$ \\
\hline AMM09a-3 & $225 \mathrm{ml}$ & 20.15 hours & $1.62 \times 10^{9}$ & $3.79 \times 10^{8}$ & $3.51 \times 10^{8}$ & $1.06 \times 10^{8}$ \\
\hline AMM09a-4 & $215 \mathrm{ml}$ & 28.35 hours & $1.77 \times 10^{9}$ & $4.15 \times 10^{8}$ & $3.84 \times 10^{8}$ & $1.15 \times 10^{8}$ \\
\hline AMM09a-5 & $210 \mathrm{ml}$ & 37.65 hours & $1.94 \times 10^{9}$ & $4.55 \times 10^{8}$ & $4.21 \times 10^{8}$ & $1.23 \times 10^{8}$ \\
\hline AMM09a-6 & $210 \mathrm{ml}$ & 45.65 hours & $2.08 \times 10^{9}$ & $4.81 \times 10^{8}$ & $4.45 \times 10^{8}$ & $1.30 \times 10^{8}$ \\
\hline AMM09a-7 & $200 \mathrm{ml}$ & 53.65 hours & $2.16 \times 10^{9}$ & $5.06 \times 10^{8}$ & $4.69 \times 10^{8}$ & $1.36 \times 10^{8}$ \\
\hline AMM09a-8 & $185 \mathrm{ml}$ & 59.65 hours & $2.23 \times 10^{9}$ & $5.17 \times 10^{8}$ & $4.79 \times 10^{8}$ & $1.37 \times 10^{8}$ \\
\hline \multirow[t]{2}{*}{ AMM09a-9 } & \multirow[t]{2}{*}{$200 \mathrm{ml}$} & \multirow[t]{2}{*}{66.45 hours } & $2.41 \times 10^{9}$ & $5.61 \times 10^{8}$ & $5.19 \times 10^{8}$ & \multirow[t]{2}{*}{$1.46 \times 10^{8}$} \\
\hline & & & $2.20 \times 10^{9}$ & $5.30 \times 10^{8}$ & $4.91 \times 10^{8}$ & \\
\hline \multirow[t]{2}{*}{ AMM09a-10 } & \multirow[t]{2}{*}{$185 \mathrm{ml}$} & \multirow[t]{2}{*}{74.2 hours } & $2.52 \times 10^{9}$ & $5.86 \times 10^{8}$ & $5.43 \times 10^{8}$ & \multirow[t]{2}{*}{$1.51 \times 10^{8}$} \\
\hline & & & $2.29 \times 10^{9}$ & $5.56 \times 10^{8}$ & $5.15 \times 10^{8}$ & \\
\hline AMM09a-11* & $240 \mathrm{ml}$ & 81 hours & $1.81 \times 10^{9}$ & $4.26 \times 10^{8}$ & $3.94 \times 10^{8}$ & $1.13 \times 10^{8}$ \\
\hline AMM09a-12 & $230 \mathrm{ml}$ & 90.6 hours & $1.92 \times 10^{9}$ & $4.45 \times 10^{8}$ & $4.12 \times 10^{8}$ & $1.16 \times 10^{8}$ \\
\hline AMM09a-13 & $230 \mathrm{ml}$ & 98.3 hours & $1.96 \times 10^{9}$ & $4.54 \times 10^{8}$ & $4.20 \times 10^{8}$ & $1.20 \times 10^{8}$ \\
\hline AMM09a-14 & $225 \mathrm{ml}$ & 105.55 hours & $2.06 \times 10^{9}$ & $4.78 \times 10^{8}$ & $4.43 \times 10^{8}$ & $1.26 \times 10^{8}$ \\
\hline \multirow[t]{2}{*}{ AMM09a-15 } & \multirow[t]{2}{*}{$220 \mathrm{ml}$} & \multirow[t]{2}{*}{111.15 hours } & $1.96 \times 10^{9}$ & $5.32 \times 10^{8}$ & $4.93 \times 10^{8}$ & \multirow[t]{2}{*}{$1.40 \times 10^{8}$} \\
\hline & & & $2.28 \times 10^{9}$ & $5.07 \times 10^{8}$ & $4.69 \times 10^{8}$ & \\
\hline AMM09a-16 & $215 \mathrm{ml}$ & 118.55 hours & $2.14 \times 10^{9}$ & $4.97 \times 10^{8}$ & $4.60 \times 10^{8}$ & $1.28 \times 10^{8}$ \\
\hline AMM09a-17 & $210 \mathrm{ml}$ & 126.65 hours & $2.20 \times 10^{9}$ & $5.08 \times 10^{8}$ & $4.70 \times 10^{8}$ & $1.34 \times 10^{8}$ \\
\hline AMM09a-18 & $205 \mathrm{ml}$ & 134.75 hours & $2.25 \times 10^{9}$ & $5.21 \times 10^{8}$ & $4.82 \times 10^{8}$ & $1.35 \times 10^{8}$ \\
\hline AMM09a-19 & $200 \mathrm{ml}$ & 142.25 hours & $2.32 \times 10^{9}$ & $5.36 \times 10^{8}$ & $4.96 \times 10^{8}$ & $1.42 \times 10^{8}$ \\
\hline \multirow[t]{2}{*}{ AMM09a-20 } & \multirow[t]{2}{*}{$200 \mathrm{ml}$} & \multirow[t]{2}{*}{142.25 hours } & $1.58 \times 10^{9 * * *}$ & $4.66 \times 10^{8 * 2 *}$ & $4.32 \times 10^{8 * * *}$ & \multirow[t]{2}{*}{$1.31 \times 10^{8}$} \\
\hline & & & $2.12 \times 10^{9}$ & $5.07 \times 10^{8}$ & $4.69 \times 10^{8}$ & \\
\hline \multirow[t]{2}{*}{ AMM09a-21 } & \multirow[t]{2}{*}{$200 \mathrm{ml}$} & \multirow[t]{2}{*}{151.05 hours } & $1.78 \times 10^{9 * * *}$ & $4.80 \times 10^{8 * *}$ & $4.44 \times 10^{8 * * * 7}$ & \multirow[t]{2}{*}{$1.43 \times 10^{8}$} \\
\hline & & & $2.22 \times 10^{9}$ & $5.40 \times 10^{8}$ & $5.00 \times 10^{8}$ & \\
\hline AMM09a-22 & $195 \mathrm{ml}$ & 159.05 hours & $2.24 \times 10^{9}$ & $5.35 \times 10^{8}$ & $4.95 \times 10^{8}$ & $1.40 \times 10^{8}$ \\
\hline \multirow[t]{2}{*}{ AMM09a-23* } & \multirow[t]{2}{*}{$250 \mathrm{ml}$} & \multirow[t]{2}{*}{159.05 hours } & $1.65 \times 10^{9}$ & $3.83 \times 10^{8}$ & $3.55 \times 10^{8}$ & $0.97 \times 10^{8}$ \\
\hline & & & $1.55 \times 10^{9}$ & $3.83 \times 10^{8}$ & $3.55 \times 10^{8}$ & $1.01 \times 10^{8}$ \\
\hline \multirow[t]{2}{*}{ AMM09a-24 } & $240 \mathrm{ml}$ & 165.75 hours & $1.66 \times 10^{9}$ & $4.08 \times 10^{8}$ & $3.78 \times 10^{8}$ & $1.04 \times 10^{8}$ \\
\hline & & & & & & $1.22 \times 10^{8}$ \\
\hline AMM09a-25 & $235 \mathrm{ml}$ & 173.55 hours & $1.78 \times 10^{9}$ & $4.22 \times 10^{8}$ & $3.91 \times 10^{8}$ & $2.48 \times 10^{8}$ \\
\hline & & & & & & $1.12 \times 10^{8}$ \\
\hline AMM09a-26 & $230 \mathrm{ml}$ & 181.35 hours & $1.72 \times 10^{9}$ & $4.36 \times 10^{8}$ & $4.04 \times 10^{8}$ & $1.16 \times 10^{8}$ \\
\hline & & & $1.78 \times 10^{9}$ & $4.40 \times 10^{8}$ & $4.07 \times 10^{8}$ & \\
\hline AMM09a-27 & $230 \mathrm{ml}$ & 189.15 hours & $1.69 \times 10^{9}$ & $4.34 \times 10^{8}$ & $4.02 \times 10^{8}$ & $1.17 \times 10^{8}$ \\
\hline AMM09a-28 & $230 \mathrm{ml}$ & 194.95 hours & $1.56 \times 10^{9}$ & $4.31 \times 10^{8}$ & $3.99 \times 10^{8}$ & $1.20 \times 10^{8}$ \\
\hline AMM09a-29** & $220 \mathrm{ml}$ & 200.55 hours & $2.22 \times 10^{9}$ & $5.11 \times 10^{8}$ & $4.73 \times 10^{8}$ & $1.33 \times 10^{8}$ \\
\hline & & & $2.07 \times 10^{9}$ & $4.91 \times 10^{8}$ & $4.55 \times 10^{8}$ & $1.36 \times 10^{8}$ \\
\hline AMM09a-30 & $215 \mathrm{ml}$ & 207.55 hours & $2.01 \times 10^{9}$ & $4.64 \times 10^{8}$ & $4.30 \times 10^{8}$ & $1.31 \times 10^{8}$ \\
\hline AMM09a-31 & $215 \mathrm{ml}$ & 214.8 hours & $2.23 \times 10^{9}$ & $5.15 \times 10^{8}$ & $4.77 \times 10^{8}$ & $1.37 \times 10^{8}$ \\
\hline & & & $2.08 \times 10^{9}$ & $4.85 \times 10^{8}$ & $4.49 \times 10^{8}$ & $1.32 \times 10^{8}$ \\
\hline AMM09c & $245 \mathrm{ml}$ & 6.3 hours & $4.31 \times 10^{7}$ & $9.92 \times 10^{6}$ & $9.19 \times 10^{6}$ & $2.54 \times 10^{6}$ \\
\hline
\end{tabular}

* 5 Molar $\mathrm{HNO}_{3}$ added to reach 250 milliliters. $* * \mathrm{CaF}_{2}$ added to solution. $* * *$ Not used. 
Table 11. Rad Screen and Gamma Scan Results for AMM09b and AMM09d Solutions

\begin{tabular}{|c|c|c|c|c|c|c|}
\hline Experiment & $\begin{array}{l}\text { Volume of } \\
\text { Solution } \\
\text { Before } \\
\text { Sampling }\end{array}$ & $\begin{array}{l}\text { Time Sample } \\
\text { Taken }\end{array}$ & $\begin{array}{c}\text { Beta Activity } \\
\mathrm{dpm} / \mathrm{ml} \text { - } \\
\text { assumed to } \\
\text { be } \mathrm{Pu}-241\end{array}$ & $\begin{array}{l}\text { Alpha } \\
\text { Activity } \\
\text { dpm/ml }\end{array}$ & $\begin{array}{l}\text { Correeted } \\
\text { Alpha } \\
\text { Activity } \\
\text { dpm/ml }\end{array}$ & $\begin{array}{c}\text { Americium- } \\
241 \\
\text { Alpha } \\
\text { Activity } \\
\text { dpm/ml }\end{array}$ \\
\hline AMM09b -1 & $230 \mathrm{ml}$ & 4.5 hours & $1.40 \times 10^{9}$ & $3.32 \times 10^{8}$ & $3.07 \times 10^{8}$ & $9.29 \times 10^{7}$ \\
\hline AMM09b-2 & $230 \mathrm{ml}$ & 12.2 hours & $1.66 \times 10^{9}$ & $3.82 \times 10^{8}$ & $3.54 \times 10^{8}$ & $1.04 \times 10^{8}$ \\
\hline AMM09b-3 & $230 \mathrm{ml}$ & 20.15 hours & $1.73 \times 10^{9}$ & $4.10 \times 10^{8}$ & $3.80 \times 10^{8}$ & $1.11 \times 10^{8}$ \\
\hline AMM09b-4 & $215 \mathrm{ml}$ & 28.35 hours & $1.98 \times 10^{9}$ & $4.61 \times 10^{8}$ & $4.27 \times 10^{8}$ & $1.17 \times 10^{8}$ \\
\hline AMM09b-5 & $210 \mathrm{ml}$ & 37.65 hours & $1.93 \times 10^{9}$ & $4.62 \times 10^{8}$ & $4.28 \times 10^{8}$ & $1.27 \times 10^{8}$ \\
\hline AMM09b-6 & $210 \mathrm{ml}$ & 45.65 hours & $2.12 \times 10^{9}$ & $4.93 \times 10^{8}$ & $4.57 \times 10^{8}$ & $1.35 \times 10^{8}$ \\
\hline AMM09b-7 & $200 \mathrm{ml}$ & 53.65 hours & $2.20 \times 10^{9}$ & $5.11 \times 10^{8}$ & $4.73 \times 10^{8}$ & $1.38 \times 10^{8}$ \\
\hline AMM09b-8 & $190 \mathrm{ml}$ & 59.65 hours & $2.22 \times 10^{9}$ & $5.14 \times 10^{8}$ & $4.76 \times 10^{8}$ & $1.38 \times 10^{8}$ \\
\hline AMM09b-9 & $200 \mathrm{ml}$ & 66.45 hours & $2.32 \times 10^{9}$ & $5.36 \times 10^{8}$ & $4.96 \times 10^{8}$ & $1.40 \times 10^{8}$ \\
\hline AMM09b-10 & $195 \mathrm{ml}$ & 74.2 hours & $2.41 \times 10^{9}$ & $5.57 \times 10^{8}$ & $5.16 \times 10^{8}$ & $1.48 \times 10^{8}$ \\
\hline AMM09b-11* & $240 \mathrm{ml}$ & 81 hours & $1.90 \times 10^{9}$ & $4.39 \times 10^{8}$ & $4.07 \times 10^{8}$ & $1.12 \times 10^{8}$ \\
\hline AMM09b-12 & $235 \mathrm{ml}$ & 90.6 hours & $1.95 \times 10^{9}$ & $4.51 \times 10^{8}$ & $4.18 \times 10^{8}$ & $1.19 \times 10^{8}$ \\
\hline AMM09b-13 & $225 \mathrm{ml}$ & 98.3 hours & $2.07 \times 10^{9}$ & $4.79 \times 10^{8}$ & $4.44 \times 10^{8}$ & $1.20 \times 10^{8}$ \\
\hline AMM09b-14 & $230 \mathrm{ml}$ & 105.55 hours & $2.08 \times 10^{9}$ & $4.76 \times 10^{8}$ & $4.41 \times 10^{8}$ & $1.22 \times 10^{8}$ \\
\hline AMM09b-15 & $225 \mathrm{ml}$ & 111.15 hours & $2.07 \times 10^{9}$ & $4.80 \times 10^{8}$ & $4.44 \times 10^{8}$ & $1.24 \times 10^{8}$ \\
\hline AMM09b-16 & $220 \mathrm{ml}$ & 118.55 hours & $2.10 \times 10^{9}$ & $4.84 \times 10^{8}$ & $4.48 \times 10^{8}$ & $1.27 \times 10^{8}$ \\
\hline AMM09b-17 & $220 \mathrm{ml}$ & 126.65 hours & $2.13 \times 10^{9}$ & $4.92 \times 10^{8}$ & $4.56 \times 10^{8}$ & $1.27 \times 10^{8}$ \\
\hline AMM09b-18 & $215 \mathrm{ml}$ & 134.75 hours & $2.13 \times 10^{9}$ & $4.92 \times 10^{8}$ & $4.56 \times 10^{8}$ & $1.33 \times 10^{8}$ \\
\hline AMM09b-19 & $210 \mathrm{ml}$ & 142.25 hours & $2.22 \times 10^{9}$ & $5.09 \times 10^{8}$ & $4.71 \times 10^{8}$ & $1.35 \times 10^{8}$ \\
\hline \multirow[t]{2}{*}{ AMM09b-20 } & \multirow[t]{2}{*}{$215 \mathrm{ml}$} & \multirow[t]{2}{*}{142.25 hours } & $1.83 \times 10^{9}$ & $4.89 \times 10^{8}$ & $4.53 \times 10^{8}$ & \multirow[t]{2}{*}{$1.28 \times 10^{8}$} \\
\hline & & & $2.08 \times 10^{9}$ & $4.90 \times 10^{8}$ & $4.54 \times 10^{8}$ & \\
\hline AMM09b-21 & $210 \mathrm{ml}$ & 151.05 hours & $1.98 \times 10^{9}$ & $5.13 \times 10^{8}$ & $4.75 \times 10^{8}$ & $1.36 \times 10^{8}$ \\
\hline AMM09b-22 & $205 \mathrm{ml}$ & 159.05 hours & $2.09 \times 10^{9}$ & $4.17 \times 10^{8}$ & $4.79 \times 10^{8}$ & $1.30 \times 10^{8}$ \\
\hline \multirow[t]{2}{*}{ AMM09b-23* } & \multirow[t]{2}{*}{$250 \mathrm{ml}$} & \multirow[t]{2}{*}{159.05 hours } & \multirow[t]{2}{*}{$1.64 \times 10^{9}$} & \multirow[t]{2}{*}{$3.89 \times 10^{8}$} & \multirow[t]{2}{*}{$3.60 \times 10^{8}$} & $0.99 \times 10^{8}$ \\
\hline & & & & & & $1.05 \times 10^{8}$ \\
\hline \multirow[t]{2}{*}{ AMM09b-24 } & \multirow[t]{2}{*}{$245 \mathrm{ml}$} & \multirow[t]{2}{*}{165.75 hours } & \multirow[t]{2}{*}{$1.57 \times 10^{9}$} & \multirow[t]{2}{*}{$4.08 \times 10^{8}$} & \multirow[t]{2}{*}{$3.78 \times 10^{8}$} & $1.05 \times 10^{8}$ \\
\hline & & & & & & $1.09 \times 10^{8}$ \\
\hline AMM09b-25 & $240 \mathrm{ml}$ & 173.55 hours & Not Valid & Not Valid & Not Valid & Not Valid \\
\hline AMM09b-26 & $235 \mathrm{ml}$ & 181.35 hours & $1.67 \times 10^{9}$ & $4.21 \times 10^{8}$ & $3.90 \times 10^{8}$ & $1.12 \times 10^{8}$ \\
\hline \multirow[t]{2}{*}{ AMM09b-27 } & \multirow[t]{2}{*}{$235 \mathrm{ml}$} & \multirow[t]{2}{*}{189.15 hours } & $1.50 \times 10^{9}$ & $4.14 \times 10^{8}$ & $3.83 \times 10^{8}$ & \multirow[t]{2}{*}{$1.14 \times 10^{8}$} \\
\hline & & & $1.76 \times 10^{9}$ & $4.29 \times 10^{8}$ & $3.97 \times 10^{8}$ & \\
\hline AMM09b-28 & $235 \mathrm{ml}$ & 194.95 hours & $1.86 \times 10^{9}$ & $4.32 \times 10^{8}$ & $4.00 \times 10^{8}$ & $1.16 \times 10^{8}$ \\
\hline AMM09b-29** & $220 \mathrm{ml}$ & 200.55 hours & $2.04 \times 10^{9}$ & $4.69 \times 10^{8}$ & $4.34 \times 10^{8}$ & $1.24 \times 10^{8}$ \\
\hline \multirow[t]{2}{*}{ AMM09b-30 } & \multirow[t]{2}{*}{$220 \mathrm{ml}$} & \multirow[t]{2}{*}{207.55 hours } & $2.06 \times 10^{9}$ & $4.75 \times 10^{8}$ & $4.40 \times 10^{8}$ & $1.24 \times 10^{8}$ \\
\hline & & & $1.94 \times 10^{9}$ & $4.57 \times 10^{8}$ & $4.23 \times 10^{8}$ & $1.25 \times 10^{8}$ \\
\hline AMM09b-31 & $215 \mathrm{ml}$ & 214.8 hours & $2.05 \times 10^{9}$ & $4.73 \times 10^{8}$ & $4.38 \times 10^{8}$ & $1.24 \times 10^{8}$ \\
\hline AMM09d & $245 \mathrm{ml}$ & 6.3 hours & $4.87 \times 10^{7}$ & $1.11 \times 10^{7}$ & $1.03 \times 10^{7}$ & $1.24 \times 10^{8}$ \\
\hline
\end{tabular}

*Solution replenished with 5 Molar $\mathrm{HNO}_{3}$ to reach 250 milliliters. $* * \mathrm{CaF}_{2}$ added to solution. 
Table 12. Plutonium and Americium in AMM09a and AMM09c Solutions as a Function of Dissolution Time

\begin{tabular}{|c|c|c|c|c|c|c|}
\hline Experiment & $\begin{array}{c}\text { Time Sample } \\
\text { Taken }\end{array}$ & $\begin{array}{l}\text { Plutonium-241 } \\
\mathrm{g} / \mathrm{ml}\end{array}$ & $\begin{array}{l}\text { Americum-241 } \\
\mathrm{g} / \mathrm{ml}\end{array}$ & $\begin{array}{l}\text { Plutonium-238 } \\
\mathrm{g} / \mathrm{ml}\end{array}$ & $\begin{array}{l}\text { Plutonium-239 } \\
\mathrm{g} / \mathrm{ml}\end{array}$ & $\begin{array}{c}\text { Plutonium-240 } \\
\mathrm{g} / \mathrm{ml}\end{array}$ \\
\hline AMM09a-1 & 4.5 hours & $5.02 \times 10^{-6}$ & $1.07 \times 10^{-5}$ & $6.50 \times 10^{-7}$ & $5.66 \times 10^{-4}$ & $1.42 \times 10^{-4}$ \\
\hline AMM09a-2 & 12.2 hours & $6.38 \times 10^{-6}$ & $1.27 \times 10^{-5}$ & $8.37 \times 10^{-7}$ & $7.29 \times 10^{-4}$ & $1.83 \times 10^{-4}$ \\
\hline AMM09a-3 & 20.15 hours & $7.07 \times 10^{-6}$ & $1.39 \times 10^{-5}$ & $9.13 \times 10^{-7}$ & $7.96 \times 10^{-4}$ & $2.00 \times 10^{-4}$ \\
\hline AMM09a-4 & 28.35 hours & $7.73 \times 10^{-6}$ & $1.51 \times 10^{-5}$ & $1.00 \times 10^{-6}$ & $8.75 \times 10^{-4}$ & $2.20 \times 10^{-4}$ \\
\hline AMM09a-5 & 37.65 hours & $8.47 \times 10^{-6}$ & $1.62 \times 10^{-5}$ & $1.11 \times 10^{-6}$ & $9.69 \times 10^{-4}$ & $2.43 \times 10^{-4}$ \\
\hline AMM09a-6 & 45.65 hours & $9.08 \times 10^{-6}$ & $1.71 \times 10^{-5}$ & $1.18 \times 10^{-6}$ & $1.05 \times 10^{-3}$ & $2.57 \times 10^{-4}$ \\
\hline AMM09a-7 & 53.65 hours & $9.43 \times 10^{-6}$ & $1.79 \times 10^{-5}$ & $1.24 \times 10^{-6}$ & $1.08 \times 10^{-3}$ & $2.71 \times 10^{-4}$ \\
\hline AMM09a-8 & 59.65 hours & $9.74 \times 10^{-6}$ & $1.80 \times 10^{-5}$ & $1.27 \times 10^{-6}$ & $1.11 \times 10^{-3}$ & $2.79 \times 10^{-4}$ \\
\hline AMM09a-9 & 66.45 hours & $1.01 \times 10^{-5}$ & $1.92 \times 10^{-5}$ & $1.34 \times 10^{-6}$ & $1.17 \times 10^{-3}$ & $2.93 \times 10^{-4}$ \\
\hline AMM09a-10 & 74.2 hours & $1.05 \times 10^{-5}$ & $1.98 \times 10^{-5}$ & $1.41 \times 10^{-6}$ & $1.24 \times 10^{-3}$ & $3.08 \times 10^{-4}$ \\
\hline AMM09a-11* & 81 hours & $7.90 \times 10^{-6}$ & $1.48 \times 10^{-5}$ & $1.05 \times 10^{-6}$ & $9.14 \times 10^{-4}$ & $2.29 \times 10^{-4}$ \\
\hline AMM09a-12 & 90.6 hours & $8.38 \times 10^{-6}$ & $1.52 \times 10^{-5}$ & $1.10 \times 10^{-6}$ & $9.62 \times 10^{-4}$ & $2.41 \times 10^{-4}$ \\
\hline AMM09a-13 & 98.3 hours & $8.56 \times 10^{-6}$ & $1.58 \times 10^{-5}$ & $1.12 \times 10^{-6}$ & $9.76 \times 10^{-4}$ & $2.45 \times 10^{-4}$ \\
\hline AMM09a-14 & 105.55 hours & $9.00 \times 10^{-6}$ & $1.66 \times 10^{-5}$ & $1.18 \times 10^{-6}$ & $1.03 \times 10^{-3}$ & $2.58 \times 10^{-4}$ \\
\hline AMM09a-15 & 111.15 hours & $9.57 \times 10^{-6}$ & $1.84 \times 10^{-5}$ & $1.27 \times 10^{-6}$ & $1.11 \times 10^{-3}$ & $2.78 \times 10^{-4}$ \\
\hline AMM09a-16 & 118.55 hours & $9.34 \times 10^{-6}$ & $1.68 \times 10^{-5}$ & $1.24 \times 10^{-6}$ & $1.08 \times 10^{-3}$ & $2.71 \times 10^{-4}$ \\
\hline AMM09a-17 & 126.65 hours & $9.61 \times 10^{-6}$ & $1.76 \times 10^{-5}$ & $1.25 \times 10^{-6}$ & $1.09 \times 10^{-3}$ & $2.74 \times 10^{-4}$ \\
\hline AMM09a-18 & 134.75 hours & $9.83 \times 10^{-6}$ & $1.77 \times 10^{-5}$ & $1.29 \times 10^{-6}$ & $1.13 \times 10^{-3}$ & $2.83 \times 10^{-4}$ \\
\hline AMM09a-19 & 142.25 hours & $1.01 \times 10^{-5}$ & $1.87 \times 10^{-5}$ & $1.32 \times 10^{-6}$ & $1.15 \times 10^{-3}$ & $2.89 \times 10^{-4}$ \\
\hline AMM09a-20 & 142.25 hours & $9.26 \times 10^{-6}$ & $1.72 \times 10^{-5}$ & $1.22 \times 10^{-6}$ & $1.04 \times 10^{-3}$ & $2.61 \times 10^{-4}$ \\
\hline AMM09a-21 & 151.05 hours & $9.69 \times 10^{-6}$ & $1.88 \times 10^{-5}$ & $1.23 \times 10^{-6}$ & $1.07 \times 10^{-3}$ & $2.69 \times 10^{-4}$ \\
\hline AMM09a-22 & 159.05 hours & $9.78 \times 10^{-6}$ & $1.84 \times 10^{-5}$ & $1.32 \times 10^{-6}$ & $1.15 \times 10^{-3}$ & $2.90 \times 10^{-4}$ \\
\hline AMM09a-23* & 159.05 hours & $6.99 \times 10^{-6}$ & $1.30 \times 10^{-5}$ & $9.53 \times 10^{-3}$ & $8.30 \times 10^{-4}$ & $2.08 \times 10^{-4}$ \\
\hline AMM09a-24 & 165.75 hours & $7.25 \times 10^{-6}$ & $1.49 \times 10^{-5}$ & $9.87 \times 10^{-7}$ & $8.60 \times 10^{-4}$ & $2.16 \times 10^{-4}$ \\
\hline AMM09a-25 & 173.55 hours & $7.77 \times 10^{-6}$ & $1.47 \times 10^{-5}$ & $1.04 \times 10^{-6}$ & $9.05 \times 10^{-4}$ & $2.27 \times 10^{-4}$ \\
\hline AMM09a-26 & 181.35 hours & $7.64 \times 10^{-6}$ & $1.52 \times 10^{-5}$ & $1.08 \times 10^{-6}$ & $9.41 \times 10^{-4}$ & $2.37 \times 10^{-4}$ \\
\hline AMM09a-27 & 189.15 hours & $7.38 \times 10^{-6}$ & $1.54 \times 10^{-5}$ & $1.06 \times 10^{-6}$ & $9.25 \times 10^{-4}$ & $2.32 \times 10^{-4}$ \\
\hline AMM09a-28 & 194.95 hours & $6.81 \times 10^{-6}$ & $1.58 \times 10^{-5}$ & $1.04 \times 10^{-6}$ & $9.06 \times 10^{-4}$ & $2.28 \times 10^{-4}$ \\
\hline AMM09a-29** & 200.55 hours & $9.38 \times 10^{-6}$ & $1.77 \times 10^{-5}$ & $1.23 \times 10^{-6}$ & $1.07 \times 10^{-3}$ & $2.69 \times 10^{-4}$ \\
\hline AMM09a-30 & 207.55 hours & $8.78 \times 10^{-6}$ & $1.72 \times 10^{-5}$ & $1.11 \times 10^{-6}$ & $9.70 \times 10^{-4}$ & $2.43 \times 10^{-4}$ \\
\hline AMM09a-31 & 214.8 hours & $9.41 \times 10^{-6}$ & $1.77 \times 10^{-5}$ & $1.22 \times 10^{-6}$ & $1.07 \times 10^{-4}$ & $2.68 \times 10^{-4}$ \\
\hline AMM09c & 6.3 hours & $1.88 \times 10^{-7}$ & $3.34 \times 10^{-7}$ & $2.48 \times 10^{-8}$ & $2.16 \times 10^{-5}$ & $5.42 \times 10^{-6}$ \\
\hline
\end{tabular}

*Solution replenished with 5 Molar $\mathrm{HNO}_{3}$ to reach 250 milliliters. ${ }^{* *} \mathrm{CaF}_{2}$ added to solution. 
Table 13. Plutonium and Americium in AMM09b and AMM09d Solutions as a Function of Dissolution Time

\begin{tabular}{|c|c|c|c|c|c|c|}
\hline Experiment & $\begin{array}{c}\text { Time Sample } \\
\text { Taken }\end{array}$ & $\begin{array}{l}\text { Plutonium-241 } \\
\mathrm{g} / \mathrm{ml}\end{array}$ & $\begin{array}{c}\text { Americum-241 } \\
\mathrm{g} / \mathrm{ml}\end{array}$ & $\begin{array}{l}\text { Plutonium-238 } \\
\mathrm{g} / \mathrm{ml}\end{array}$ & $\begin{array}{l}\text { Plutonium-239 } \\
\mathrm{g} / \mathrm{ml}\end{array}$ & $\begin{array}{l}\text { Plutonium-240 } \\
\mathrm{g} / \mathrm{ml}\end{array}$ \\
\hline AMM09b-1 & 4.5 hours & $6.11 \times 10^{-6}$ & $1.22 \times 10^{-5}$ & $8.00 \times 10^{-7}$ & $6.97 \times 10^{-4}$ & $1.75 \times 10^{-4}$ \\
\hline AMM09b-2 & 12.2 hours & $7.25 \times 10^{-6}$ & $1.37 \times 10^{-5}$ & $9.31 \times 10^{-7}$ & $8.11 \times 10^{-4}$ & $2.04 \times 10^{-4}$ \\
\hline AMM09b-3 & 20.15 hours & $7.55 \times 10^{-6}$ & $1.46 \times 10^{-5}$ & $1.00 \times 10^{-6}$ & $8.73 \times 10^{-4}$ & $2.19 \times 10^{-4}$ \\
\hline AMM09b-4 & 28.35 hours & $8.65 \times 10^{-6}$ & $1.54 \times 10^{-5}$ & $1.00 \times 10^{-6}$ & $1.01 \times 10^{-3}$ & $2.53 \times 10^{-4}$ \\
\hline AMM09b-5 & 37.65 hours & $8.43 \times 10^{-6}$ & $1.67 \times 10^{-5}$ & $1.12 \times 10^{-6}$ & $9.77 \times 10^{-4}$ & $2.45 \times 10^{-4}$ \\
\hline AMM09b-6 & 45.65 hours & $9.26 \times 10^{-6}$ & $1.77 \times 10^{-5}$ & $1.20 \times 10^{-6}$ & $1.04 \times 10^{-3}$ & $2.62 \times 10^{-4}$ \\
\hline AMMO9b-7 & 53.65 hours & $9.61 \times 10^{-6}$ & $1.81 \times 10^{-5}$ & $1.25 \times 10^{-6}$ & $1.09 \times 10^{-3}$ & $2.73 \times 10^{-4}$ \\
\hline AMM09b-8 & 59.65 hours & $9.69 \times 10^{-6}$ & $1.81 \times 10^{-5}$ & $1.26 \times 10^{-6}$ & $1.10 \times 10^{-3}$ & $2.76 \times 10^{-4}$ \\
\hline AMM09b-9 & 66.45 hours & $1.01 \times 10^{-5}$ & $1.84 \times 10^{-5}$ & $1.33 \times 10^{-6}$ & $1.16 \times 10^{-3}$ & $2.90 \times 10^{-4}$ \\
\hline AMM09b-10 & 74.2 hours & $1.05 \times 10^{-5}$ & $1.94 \times 10^{-5}$ & $1.37 \times 10^{-6}$ & $1.19 \times 10^{-3}$ & $3.00 \times 10^{-4}$ \\
\hline AMM09b-11* & 81 hours & $8.30 \times 10^{-6}$ & $1.47 \times 10^{-5}$ & $1.10 \times 10^{-6}$ & $9.57 \times 10^{-4}$ & $2.40 \times 10^{-4}$ \\
\hline AMM09b-12 & 90.6 hours & $8.52 \times 10^{-6}$ & $1.56 \times 10^{-5}$ & $1.11 \times 10^{-6}$ & $9.70 \times 10^{-4}$ & $2.43 \times 10^{-4}$ \\
\hline AMM09b-13 & 98.3 hours & $9.04 \times 10^{-6}$ & $1.58 \times 10^{-5}$ & $1.21 \times 10^{-6}$ & $1.05 \times 10^{-3}$ & $2.64 \times 10^{-4}$ \\
\hline AMM09b-14 & 105.55 hours & $9.08 \times 10^{-6}$ & $1.60 \times 10^{-5}$ & $1.19 \times 10^{-6}$ & $1.04 \times 10^{-3}$ & $2.60 \times 10^{-4}$ \\
\hline AMMO9b-15 & 111.15 hours & $9.04 \times 10^{-6}$ & $1.63 \times 10^{-5}$ & $1.19 \times 10^{-6}$ & $1.04 \times 10^{-3}$ & $2.61 \times 10^{-4}$ \\
\hline AMM09b-16 & 118.55 hours & $9.17 \times 10^{-6}$ & $1.67 \times 10^{-5}$ & $1.20 \times 10^{-6}$ & $1.04 \times 10^{-3}$ & $2.62 \times 10^{-4}$ \\
\hline AMM09b-17 & 126.65 hours & $9.30 \times 10^{-6}$ & $1.67 \times 10^{-5}$ & $1.22 \times 10^{-6}$ & $1.07 \times 10^{-3}$ & $2.68 \times 10^{-4}$ \\
\hline AMM09b-18 & 134.75 hours & $9.30 \times 10^{-6}$ & $1.75 \times 10^{-5}$ & $1.20 \times 10^{-6}$ & $1.05 \times 10^{-3}$ & $2.63 \times 10^{-4}$ \\
\hline AMM09b-19 & 142.25 hours & $9.69 \times 10^{-6}$ & $1.77 \times 10^{-5}$ & $1.25 \times 10^{-6}$ & $1.09 \times 10^{-3}$ & $2.74 \times 10^{-4}$ \\
\hline AMM09b-20 & 142.25 hours & $8.53 \times 10^{6}$ & $1.68 \times 10^{-5}$ & $1.21 \times 10^{-6}$ & $1.06 \times 10^{-3}$ & $2.66 \times 10^{-4}$ \\
\hline AMM09b-21 & 151.05 hours & $8.65 \times 10^{-6}$ & $1.79 \times 10^{-5}$ & $1.26 \times 10^{-6}$ & $1.10 \times 10^{-3}$ & $2.76 \times 10^{-4}$ \\
\hline AMM09b-22 & 159.05 hours & $9.13 \times 10^{-6}$ & $1.71 \times 10^{-5}$ & $1.30 \times 10^{-6}$ & $1.13 \times 10^{-3}$ & $2.84 \times 10^{-4}$ \\
\hline AMM09b-23* & 159.05 hours & $7.15 \times 10^{-6}$ & $1.34 \times 10^{-5}$ & $9.63 \times 10^{-7}$ & $8.39 \times 10^{-4}$ & $2.11 \times 10^{-4}$ \\
\hline AMM09b-24 & 165.75 hours & $6.86 \times 10^{-6}$ & $1.41 \times 10^{-5}$ & $1.01 \times 10^{-6}$ & $8.80 \times 10^{-4}$ & $2.21 \times 10^{-4}$ \\
\hline AMM09b-25 & 173.55 hours & - & - & - & - & - \\
\hline AMM09b-26 & 181.35 hours & $7.29 \times 10^{-6}$ & $1.47 \times 10^{-5}$ & $1.04 \times 10^{-6}$ & $9.02 \times 10^{-4}$ & $2.26 \times 10^{-4}$ \\
\hline AMM09b-27 & 189.15 hours & $7.12 \times 10^{-6}$ & $1.50 \times 10^{-5}$ & $1.03 \times 10^{-6}$ & $8.98 \times 10^{-4}$ & $2.26 \times 10^{-4}$ \\
\hline AMM09b-28 & 194.95 hours & $8.12 \times 10^{-6}$ & $1.52 \times 10^{-5}$ & $1.06 \times 10^{-6}$ & $9.22 \times 10^{-4}$ & $2.32 \times 10^{-4}$ \\
\hline AMM09b-29** & 200.55 hours & $8.91 \times 10^{-6}$ & $1.63 \times 10^{-5}$ & $1.16 \times 10^{-6}$ & $1.01 \times 10^{-3}$ & $2.53 \times 10^{-4}$ \\
\hline AMM09b-30 & 207.55 hours & $8.74 \times 10^{-6}$ & $1.63 \times 10^{-5}$ & $1.14 \times 10^{-6}$ & $1.00 \times 10^{-3}$ & $2.51 \times 10^{-4}$ \\
\hline AMM09b-31 & 214.8 hours & $8.95 \times 10^{-6}$ & $1.64 \times 10^{-5}$ & $1.17 \times 10^{-6}$ & $1.02 \times 10^{-4}$ & $2.55 \times 10^{-4}$ \\
\hline AMM09d & 6.3 hours & $2.13 \times 10^{-7}$ & $4.02 \times 10^{-7}$ & $2.69 \times 10^{-8}$ & $2.34 \times 10^{-5}$ & $5.88 \times 10^{-6}$ \\
\hline
\end{tabular}

*Solution replenished with 5 Molar $\mathrm{HNO}_{3}$ to reach 250 milliliters. ** $\mathrm{CaF}_{2}$ added to solution. 
$0.15 \mathrm{M} \mathrm{KF}$ solution, the remaining plutonium and americium dissolved. A total of 0.37 grams of plutonium and americium dissolved. The amount of plutonium and americium in the initial Mark 42 reject compact material was calculated as 11 weight\% (3.4007 grams of Mark 42 reject compact material was dissolved.)

After about 91 hours, the plutonium and americium dissolution in AMM09b reached a plateau. The average amount of plutonium and americium dissolved was calculated using the sample results from 91 hours through 195 hours. The amount of plutonium and americium dissolved in AMM09b after 195 hours was calculated as 0.34 grams \pm 0.01 grams or $92 \%$ of the plutonium and americium. After the $\mathrm{CaF}_{2}$ was added to AMM09b to increase the fluoride concentration, the amount of plutonium and americium dissolved increased to 0.36 grams \pm 0.1 grams or $98 \%$ of the amount of plutonium and americium. After decanting the aluminum-laden solution and adding 250 milliliters of a $8 \mathrm{M} \mathrm{HNO}_{3} / 0.20 \mathrm{M} \mathrm{H}_{3} \mathrm{BO}_{3}$ / $0.15 \mathrm{M} \mathrm{KF}$ solution, the remaining plutonium and americium dissolved. A total of 0.36 grams of plutonium and americium dissolved. The amount of plutonium and americium in the initial Mark 42 reject compact material was calculated as 11 weight\% (3.3868 grams of Mark 42 reject compact material was dissolved.)

The progress of the dissolution of the plutonium and americium was calculated using the information in Table 12 and Table 13 with the volumes in Table 10 and Table 11 , respectively. The amounts of plutonium and americium that had dissolved at specific times during the dissolution are given in Table 14 and Table 15. Both the absolute amount and the fraction of the total plutonium and americium are given. The fraction of plutonium and americium was determined using the total plutonium and americium values from the AMM09a-31 and AMM09c solutions and from the AMM09b-31 and AMM09d solutions. As mentioned previously, the loss of plutonium and americium from the periodic sampling was incorporated into the calculation. A plot of the progress of the plutonium and americium dissolution in AMM09a is given in Figure 2 and for AMM09b in Figure 3.

The $\mathrm{x}$-ray diffraction analysis of the sample taken 54 hours at $85^{\circ} \mathrm{C}$ showed $\mathrm{PuO}_{2}$. A minor amount of vermiculite also was identified.

\subsubsection{Extended Dissolution Conclusions}

The extended dissolution tests indicate that neither $0.15 \mathrm{M}$ nor $0.20 \mathrm{M}$ fluoride solutions are sufficient to dissolve the $\mathrm{PuO}_{2}$ in the unirradiated Mark 42 fuel tubes. The aluminum:fluoride molar ratios for those two fluoride tests were 4.6 and 3.5, so it is not unexpected that $\mathrm{PuO}_{2}$ did not completely dissolve. Addition of $\mathrm{CaF}_{2}$ to the solutions to increase the fluoride concentrations to $0.25 \mathrm{M}$ and $0.30 \mathrm{M}$ did result in an increase in the dissolved $\mathrm{PuO}_{2}$ - up to $98 \%$. The corresponding aluminum:fluoride molar ratios would be 2.8 and 2.3 .

The promising results of the addition of $\mathrm{CaF}_{2}$ led to the next series of tests in which higher concentrations of fluoride were studied. Simultaneously, the proposed batching of the unirradiated Mark 42 fuel tubes was changed to a set of conditions that was more favorable for dissolution - fewer fuel tubes per batch. Use of $\mathrm{CaF}_{2}$ as the fluoride source has the advantage that higher fluoride concentrations can be used without the concern about boron salts precipitating, as is the case for $\mathrm{KF}$. A previous study reported the precipitation of a solids from a $0.75 \mathrm{M}$ fluoride $\left(0.375 \mathrm{M} \mathrm{CaF}_{2}\right) / 9.3 \mathrm{M} \mathrm{HNO}_{3} / 0.23 \mathrm{M}$ boron solution. ${ }^{9}$ The next series of tests for the Mark 42 flow sheet development examined much lower concentrations of $\mathrm{CaF}_{2}: 0.125$ to $0.15 \mathrm{M}$ (with corresponding to fluoride concentrations of 0.25 to $0.30 \mathrm{M}$ ).

\footnotetext{
.9 David G. Karraker et al, Flowsheet Modifications for Dissolution of Sand, Slag, and Crucible Residues in the F-Canyon Dissolvers, WSRC-TR-97-00395, December 1997.
} 
Table 14. Progress of Plutonium and Americium Dissolution in AMM09a Experiment

\begin{tabular}{|c|c|c|c|}
\hline Experiment & $\begin{array}{c}\text { Time Sample } \\
\text { Taken }\end{array}$ & $\begin{array}{l}\text { Plutonium and } \\
\text { Americium-241 in } \\
\text { Solution } \\
\text { (grams) }\end{array}$ & $\begin{array}{l}\text { Fraction of } \\
\text { Plutonium and } \\
\text { Americium }-241 \\
\text { in Solution }\end{array}$ \\
\hline AMM09a-1 & 4.5 hours & 0.17 & 0.45 \\
\hline AMM09a-2 & 12.2 hours & 0.22 & 0.58 \\
\hline AMM09a-3 & 20.15 hours & 0.23 & 0.63 \\
\hline AMM09a-4 & 28.35 hours & 0.24 & 0.66 \\
\hline AMM09a-5 & 37.65 hours & 0.26 & 0.72 \\
\hline AMM09a-6 & 45.65 hours & 0.28 & 0.76 \\
\hline AMM09a-7 & 53.65 hours & 0.29 & 0.78 \\
\hline AMM09a-8 & 59.65 hours & 0.28 & 0.75 \\
\hline AMM09a-9 & 66.45 hours & 0.31 & 0.85 \\
\hline AMM09a-10 & 74.2 hours & 0.31 & 0.83 \\
\hline AMM09a-11* & 81 hours & 0.31 & 0.83 \\
\hline AMM09a-12 & 90.6 hours & 0.32 & 0.85 \\
\hline AMM09a-13 & 98.3 hours & 0.32 & 0.87 \\
\hline AMM09a-14 & 105.55 hours & 0.33 & 0.90 \\
\hline AMM09a-15 & 111.15 hours & 0.35 & 0.94 \\
\hline AMM09a-16 & 118.55 hours & 0.33 & 0.90 \\
\hline AMM09a-17 & 126.65 hours & 0.33 & 0.90 \\
\hline AMM09a-18 & 134.75 hours & 0.34 & 0.91 \\
\hline AMM09a-19 & 142.25 hours & 0.34 & 0.91 \\
\hline AMM09a-20 & 142.25 hours & 0.32 & 0.88 \\
\hline AMM09a-21 & 151.05 hours & 0.34 & 0.92 \\
\hline AMM09a-22 & 159.05 hours & 0.33 & 0.90 \\
\hline AMM09a-23* & 159.05 hours & 0.32 & 0.87 \\
\hline AMM09a-24 & 165.75 hours & 0.33 & 0.88 \\
\hline AMM09a-25 & 173.55 hours & 0.33 & 0.91 \\
\hline AMM09a-26 & 181.35 hours & 0.34 & 0.92 \\
\hline AMM09a-27 & 189.15 hours & 0.34 & 0.91 \\
\hline AMM09a-28 & 194.95 hours & 0.33 & 0.90 \\
\hline AMM09a-29** & 200.55 hours & 0.37 & 1.0 \\
\hline AMM09a-30 & 207.55 hours & 0.34 & 0.93 \\
\hline AMM09a-31 & 214.8 hours & 0.37 & 1.0 \\
\hline AMM09c & 6.3 hours & 0.007 & 1.0 \\
\hline
\end{tabular}

*Solution replenished with 5 Molar $\mathrm{HNO}_{3}$ to reach 250 milliliters. ${ }^{* *} \mathrm{CaF}_{2}$ added to solution. 
Table 15. Progress of Plutonium and Americium Dissolution in AMM09b Experiment

\begin{tabular}{|c|c|c|c|}
\hline Experiment & $\begin{array}{c}\text { Time Sample } \\
\text { Taken }\end{array}$ & $\begin{array}{l}\text { Plutonium and } \\
\text { Americium-241 in } \\
\text { Solution } \\
\text { (grams) }\end{array}$ & $\begin{array}{c}\text { Fraction of } \\
\text { Plutonium and } \\
\text { Americium }-241 \\
\text { in Solution }\end{array}$ \\
\hline AMM09b - & 4.5 hours & 0.21 & 0.57 \\
\hline AMM09b-2 & 12.2 hours & 0.24 & 0.66 \\
\hline AMM09b-3 & 20.15 hours & 0.26 & 0.71 \\
\hline AMM09b-4 & 28.35 hours & 0.28 & 0.77 \\
\hline AMM09b-5 & 37.65 hours & 0.27 & 0.74 \\
\hline AMM09b-6 & 45.65 hours & 0.29 & 0.79 \\
\hline AMM09b-7 & 53.65 hours & 0.29 & 0.80 \\
\hline AMM09b-8 & 59.65 hours & 0.28 & 0.77 \\
\hline AMM09b-9 & 66.45 hours & 0.31 & 0.86 \\
\hline AMM09b-10 & 74.2 hours & 0.31 & 0.87 \\
\hline AMM09b-11* & 81 hours & 0.32 & 0.88 \\
\hline AMM09b-12 & 90.6 hours & 0.32 & 0.90 \\
\hline AMM09b-13 & 98.3 hours & 0.34 & 0.93 \\
\hline AMM09b-14 & 105.55 hours & 0.34 & 0.94 \\
\hline AMM09b-15 & 111.15 hours & 0.34 & 0.93 \\
\hline AMM09b-16 & 118.55 hours & 0.33 & 0.92 \\
\hline AMM09b-17 & 126.65 hours & 0.34 & 0.94 \\
\hline AMM09b-18 & 134.75 hours & 0.33 & 0.91 \\
\hline AMM09b-19 & 142.25 hours & 0.34 & 0.93 \\
\hline AMM09b-20 & 142.25 hours & 0.33 & 0.92 \\
\hline AMM09b-21 & 151.05 hours & 0.34 & 0.94 \\
\hline AMM09b-22 & 159.05 hours & 0.34 & 0.95 \\
\hline AMM09b-23* & 159.05 hours & 0.33 & 0.91 \\
\hline AMM09b-24 & 165.75 hours & 0.34 & 0.93 \\
\hline AMM09b-25 & 173.55 hours & - & - \\
\hline AMM09b-26 & 181.35 hours & 0.33 & 0.92 \\
\hline AMM09b-27 & 189.15 hours & 0.33 & 0.90 \\
\hline AMM09b-28 & 194.95 hours & 0.34 & 0.95 \\
\hline AMM09b-29** & 200.55 hours & 0.36 & 0.98 \\
\hline AMM09b-30 & 207.55 hours & 0.36 & 0.98 \\
\hline AMM09b-31 & 214.8 hours & 0.36 & 0.98 \\
\hline AMM09d & 6.3 hours & 0.007 & 1.0 \\
\hline
\end{tabular}

*Solution replenished with 5 Molar $\mathrm{HNO}_{3}$ to reach 250 milliliters. ${ }^{* *} \mathrm{CaF}_{2}$ added to solution. 
Figure 2. 215-Hour Dissolution with 0.15 M KF

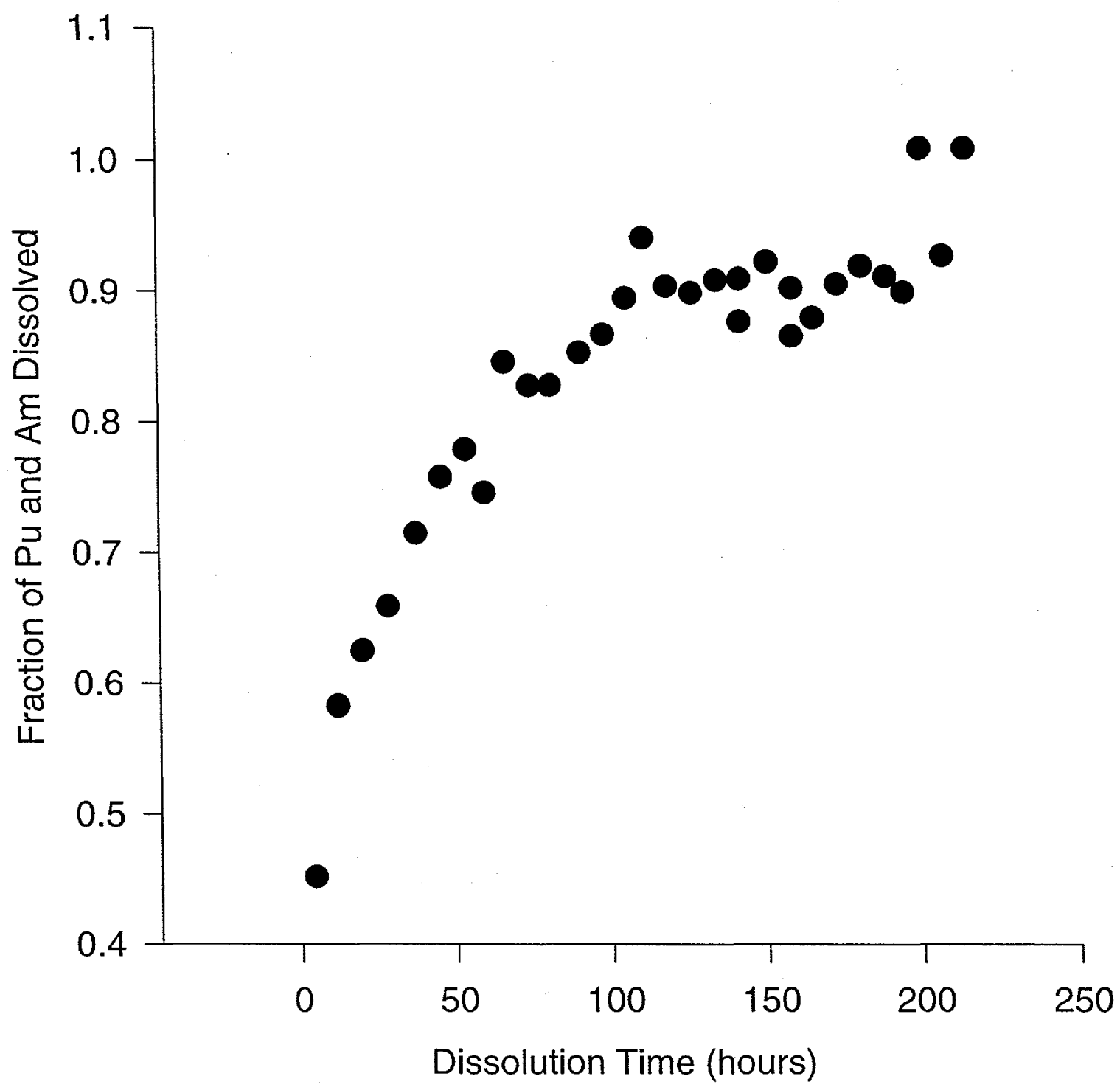




\section{Fraction of $\mathrm{Pu}$ and Am Dissolved}

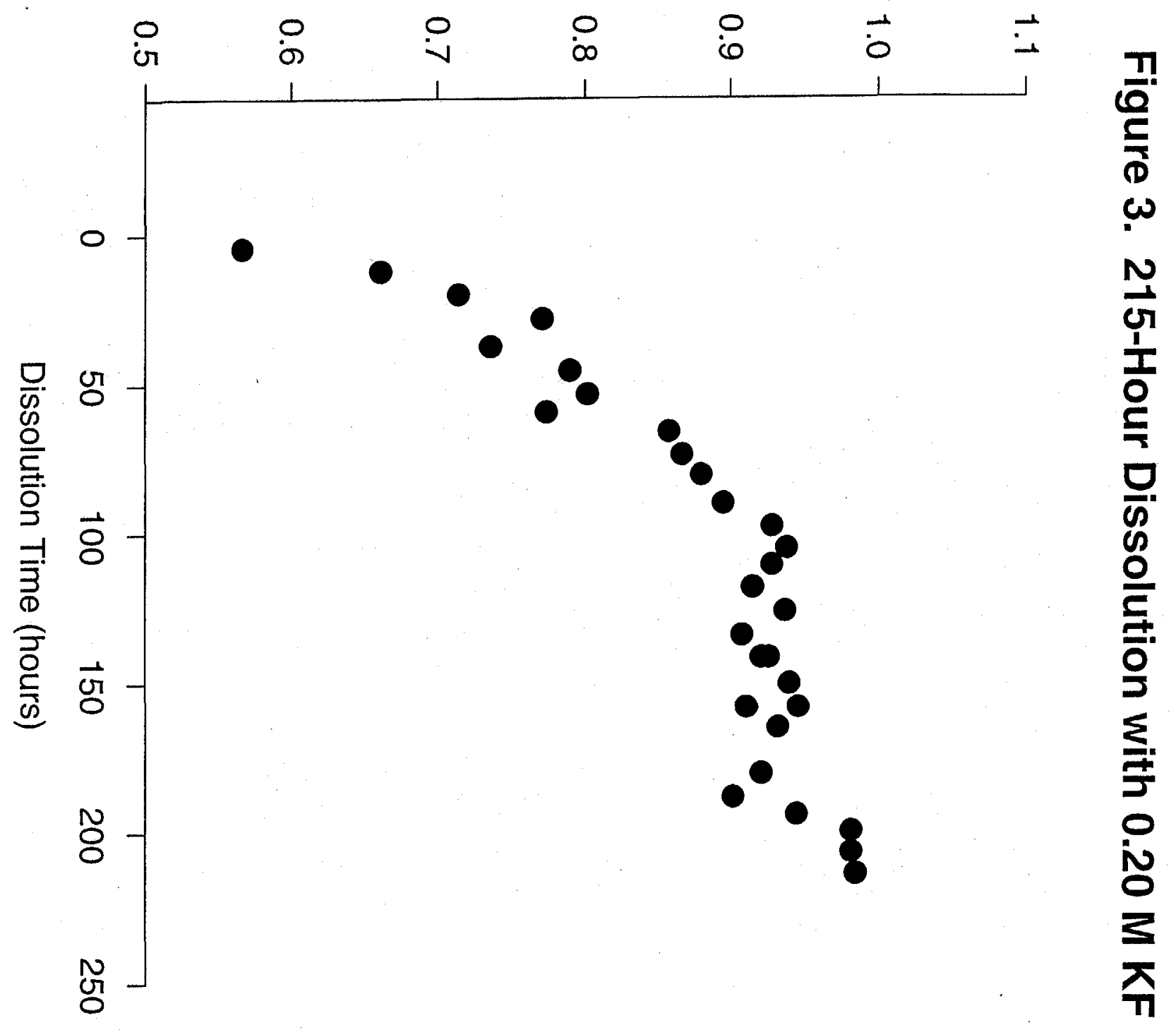




\section{2 $\mathrm{CaF}_{2}$ Dissolution Flow Sheet Development}

This series of tests examined the effect of higher fluoride concentrations on the dissolution of the Mark 42 reject compact material. Calcium fluoride was used as the fluoride source. Fluoride concentrations of $0.25 \mathrm{M}, 0.275 \mathrm{M}$, and $0.30 \mathrm{M}$ were tested (corresponding to $\mathrm{CaF}_{2}$ concentrations of $0.125 \mathrm{M}, 0.1375 \mathrm{M}$, and $0.15 \mathrm{M}$ respectively). At these $\mathrm{CaF}_{2}$ concentrations, no boron salts are expected to precipitate.

The amount of Mark 42 reject compact material used in the $\mathrm{CaF}_{2}$ experiments was based on a different charging plan than the plan used for the extended dissolution tests. The new charging plan had been developed in response to nuclear criticality safety concerns. In the new charging plan only one outer fuel tube or one middle fuel tube could be packaged per GPC. Two inner fuel tubes could be packaged together in a GPC. A worst case scenario for dissolution was developed in which two inner fuel tubes are packaged together. This scenario has the highest amount of plutonium and aluminum for the three possible packaging configurations. Four GPC would be dissolved in one batch. Based on that scenario, there would be about 6.2 kilograms of plutonium and 80.2 kilograms of aluminum.

For the $\mathrm{CaF}_{2}$ experiments, sufficient Mark 42 reject compact material and $\mathrm{ANN}$ were added to 250 milliliters of dissolver solution to duplicate the selected dissolution conditions. There were five $\mathrm{CaF}_{2}$ tests done. In two tests (AMM010a and AMM10b), $0.30 \mathrm{M}$ fluoride was tested with the concentrations of aluminum and $\mathrm{PuO}_{2}$ set for a dissolver solution with 6,500 liters and 10,000 liters. The AMM1 Ia and AMM1 $1 \mathrm{~b}$ tests examined $0.25 \mathrm{M}$ and $0.275 \mathrm{M}$ fluoride, respectively. Both AMM11a and AMM1 $1 \mathrm{~b}$ tests were based on a 6,500-liter dissolver solution. Aluminum nitrate nonahydrate was added to the AMM10 and AMM11 solutions to provide the aluminum expected from the dissolution of the cladding and the GPC.

The final test, AMM12, used a coupon of a GPC to provide the aluminum from the cladding and can. Once the coupon dissolved, the Mark 42 reject compact material was added. The fluoride concentration was $0.275 \mathrm{M}$ in the AMM12 solution.

The detailed description of the $\mathrm{CaF}_{2}$ test solutions is given in Table 16. All tests were done in $8 \mathrm{M} \mathrm{HNO}_{3}$ and 2.2 grams boron/liter solutions. The experiments were done in Teflon beakers. As a result, the progress of the dissolution only could be checked periodically as opposed to when glass beakers are used and the solutions and solids can be viewed continuously. The dissolution times in Table 16 are the times between the check when solids were last observed and the final check when no solids were observed.

Table 16. Experimental Conditions for the $\mathrm{CaF}_{2}$ Dissolution Flow Sheet Tests

\begin{tabular}{|l|c|c|c|c|c|}
\hline Test & $\begin{array}{c}\text { Mark 42 } \\
\text { Reject Compact }\end{array}$ & Fluoride & $\begin{array}{c}\text { Basis for } \\
\text { Dissolver } \\
\text { Solution }\end{array}$ & $\begin{array}{c}\text { Dissolution } \\
\text { Time at } 85^{\circ} \mathrm{C}\end{array}$ & Comments \\
\hline AMM10a & 2.33 grams & 0.30 Molar & 6,500 liters & $7-14$ hours & Solids dissolved \\
\hline AMM10b & 1.51 grams & 0.30 Molar & 10,000 liters & $1-6$ hours & Solids dissolved \\
\hline AMM11a & 2.33 grams & 0.275 Molar & 6,500 liters & $13-20$ hours & Solids dissolved \\
\hline AMM11b & 2.33 grams & 0.25 Molar & 6,500 liters & $18-25$ hours & Solids dissolved \\
\hline AMM12a & 2.34 grams & 0.275 Molar & 6,500 liters & $16-24$ hours & Solids dissolved \\
\hline
\end{tabular}

\subsubsection{AMM10 Tests}

The AMM10 tests used $0.30 \mathrm{M}$ fluoride with $\mathrm{CaF}_{2}$ as the fluoride source. Two tests were done based on different F-Canyon dissolver volumes. Tests AMM10a and AMM1Ob were based on 6,500 liters and 10,000 liters in the dissolver, respectively. 
After the first hour at $85^{\circ} \mathrm{C}$, no solids were observed in AMM10b. There were still solids present in AMM10a. Although there were no solids observed in AMM10b, that solution was heated for another 6.5 hours along with AMM10a to assure that indeed all of the solids had dissolved. Solution AMM10b was heated for an additional 6.5 hours after which no solids were observed.

\subsubsection{Analytical Results for AMM10 Experiments}

Samples were pulled for rad screen and gamma scan analyses periodically during the dissolution. The results of those analyses are given in Table 17. Total alpha activity (plutonium-238, plutonium-239, plutonium-240, and americium-241) and total beta activity (plutonium-241) were determined by rad screen. To determine the americium-241 contribution to the total alpha activity, gamma scans were done. The alpha activity results were corrected for the alpha-emitter counting efficiency as described in Sections 4.1.2.1 and 4.1.3.1.

Table 17. Rad Screen and Gamma Scan Results for AMM10 Solutions

\begin{tabular}{|c|c|c|c|c|c|c|}
\hline Experiment & $\begin{array}{c}\text { Volume of } \\
\text { Solution } \\
\text { Before } \\
\text { Sampling }\end{array}$ & $\begin{array}{c}\text { Time Sample } \\
\text { Taken }\end{array}$ & $\begin{array}{c}\text { Beta Activity } \\
\text { dpm/ml } \\
\text { assumed to } \\
\text { be Pu-241 }\end{array}$ & $\begin{array}{c}\text { Alpha } \\
\text { Activity } \\
\mathrm{dpm} / \mathrm{ml}\end{array}$ & $\begin{array}{c}\text { Corrected } \\
\text { Alpha } \\
\text { Activity } \\
\text { dpm/ml }\end{array}$ & $\begin{array}{c}\text { Americium- } \\
241 \\
\text { Alpha } \\
\text { Activity } \\
\text { dpm/ml }\end{array}$ \\
\hline AMM10a-2 & $245 \mathrm{ml}$ & 0.75 hours & Sample lost & Sample lost & - & Sample lost \\
\hline AMM10a-3 & $245 \mathrm{ml}$ & 7.15 hours & $1.29 \times 10^{9}$ & $2.99 \times 10^{8}$ & $2.77 \times 10^{8}$ & $8.51 \times 10^{7}$ \\
\hline AMM10a-4 & $245 \mathrm{ml}$ & 13.65 hours & $1.25 \times 10^{9}$ & $2.92 \times 10^{8}$ & $2.70 \times 10^{8}$ & $7.53 \times 10^{7}$ \\
\hline & & & & & & $8.76 \times 10^{7}$ \\
\hline AMM10b-2 & $245 \mathrm{ml}$ & 0.75 hours & $1.07 \times 10^{9}$ & $2.50 \times 10^{8}$ & $2.32 \times 10^{8}$ & $6.34 \times 10^{7}$ \\
\hline AMM10b-3 & $275 \mathrm{ml}$ & 7.15 hours & $1.04 \times 10^{9}$ & $2.42 \times 10^{8}$ & $2.24 \times 10^{8}$ & $6.32 \times 10^{7}$ \\
\hline
\end{tabular}

Samples were taken less frequently for the ICP/AES analyses for aluminum and boron, ion-selective electrode analysis for fluoride, and the analysis for total- and free-acid concentrations. Those results are discussed in Appendix B.

\subsubsection{Discussion of Results for AMM10 Experiments}

The grams of plutonium and of americium per liter were calculated using the information in Table 17 and those values are given in Table 18. The total amounts of plutonium and americium that had dissolved in the experiment were calculated as described in Sections 4.1.2.2 and 4.1.3.2. The total amounts dissolved in the solution were corrected for any plutonium and americium that was removed from the solution in samples. Those corrections were small. The corrected amounts are given in Table 19.

Table 18. Plutonium and Americium in AMM10 Solutions as a Function of Dissolution Time

\begin{tabular}{|c|c|c|c|c|c|c|}
\hline Experiment & $\begin{array}{c}\text { Time Sample } \\
\text { Taken }\end{array}$ & $\begin{array}{c}\text { Plutonium-241 } \\
\mathrm{g} / \mathrm{ml}\end{array}$ & $\begin{array}{c}\text { Americium- } \\
241 \\
\mathrm{~g} / \mathrm{ml}\end{array}$ & $\begin{array}{c}\text { Plutonium-238 } \\
\mathrm{g} / \mathrm{ml}\end{array}$ & $\begin{array}{c}\text { Plutonium-239 } \\
\mathrm{g} / \mathrm{ml}\end{array}$ & $\begin{array}{c}\text { Plutonium-240 } \\
\mathrm{g} / \mathrm{ml}\end{array}$ \\
\hline AMM10a-3 & 7.15 hours & $5.63 \times 10^{-6}$ & $1.14 \times 10^{-5}$ & $7.09 \times 10^{-7}$ & $6.17 \times 10^{-4}$ & $1.55 \times 10^{-4}$ \\
\hline AMM10a-4 & 13.65 hours & $5.46 \times 10^{-6}$ & $1.07 \times 10^{-6}$ & $7.27 \times 10^{-7}$ & $6.34 \times 10^{-4} \cdot$ & $1.59 \times 10^{-4}$ \\
\hline & & & & & & \\
\hline AMM10b-2 & 0.75 hours & $4.67 \times 10^{-6}$ & $8.33 \times 10^{-6}$ & $6.27 \times 10^{-7}$ & $5.46 \times 10^{-4}$ & $1.37 \times 10^{-4}$ \\
\hline AMM10b-3 & 7.15 hours & $4.54 \times 10^{-6}$ & $8.30 \times 10^{-6}$ & $6.00 \times 10^{-7}$ & $5.23 \times 10^{-4}$ & $1.31 \times 10^{-4}$ \\
\hline
\end{tabular}


WSRC-TR-98-00196

Table 19. Plutonium and Americium Dissolved in AMM10 Experiments

\begin{tabular}{|c|c|c|}
\hline Experiment & $\begin{array}{c}\text { Time Sample } \\
\text { Taken }\end{array}$ & $\begin{array}{c}\text { Plutonium and } \\
\text { Americum-241 } \\
\text { in Solution } \\
\text { (grams) }\end{array}$ \\
\hline AMM10a-3 & 7.15 hours & 0.19 \\
\hline AMM10a-4 & 13.65 hours & 0.20 \\
\hline & & \\
\hline AMM10b-2 & 0.75 hours & 0.17 \\
\hline AMM10b-3 & 7.15 hours & 0.18 \\
\hline
\end{tabular}

Using the information in Table 16 and Table 19, the amount of plutonium and americium in the Mark 42 reject compact material can be calculated. The AMM10a results indicate that the Mark 42 reject compact material is only 8.6 weight\% plutonium and americium whereas based on AMM10b, the Mark 42 reject compact material is 12 weight $\%$. The AMM10b result agrees with the MC\&A value (12.24 weight\%). The 8.6 weight\% value from the AMM10a experiment is lower than expected.

After dissolution was complete, it was observed that the volume of the AMM10b solution was about 275 milliliters. As the solution had been 245 milliliters the previous day, it was concluded that water (about 30 milliliters) from the condenser had splashed into the solution during sampling. Later tests (AMM11b) indicated that there was an actual leak in the condenser and that during the dissolution water was dripping into the solution. That dilution would result in the plutonium concentration being closer to an 11,000 -liter dissolver case as opposed to the 10,000-liter dissolver case. The fluoride would be diluted to $0.26 \mathrm{M}$. As most of the $\mathrm{PuO}_{2}$ had dissolved during the first hour at $85^{\circ} \mathrm{C}$, this dilution during the next 6.4 hours at $85^{\circ} \mathrm{C}$ probably did not have a significant effect on the dissolution of the remaining $\mathrm{PuO}_{2}$.

\subsubsection{AMM11 Tests}

The AMM11 tests examined the dissolution of the Mark 42 reject compact material with $0.25 \mathrm{M}$ and $0.275 \mathrm{M}$ fluoride in the dissolver solution with $\mathrm{CaF}_{2}$ as the fluoride source. The two tests were done based on an F-Canyon dissolver solution volume of 6,500 liters.

No solids were observed in AMM11a and AM11b after 20 hours and 25 hours, respectively, at $85^{\circ} \mathrm{C}$. The solutions were checked for solids after 5.2 hours, 13 hours, 17.8 hours, and 25 hours. Initial observations of the AMM11 a solution after 13 hours at $85^{\circ} \mathrm{C}$ indicated that there were no solids. However, further examination revealed that there were solids and that solution was heated for an additional seven hours.

\subsubsection{Analytical Results for AMM11 Experiments}

Samples were pulled for rad screen and gamma scan analyses periodically during the dissolution. The results of those analyses are given in Table 20. Total alpha activity (plutonium-238, plutonium-239, plutonium-240, and americium-241) and total beta activity (plutonium-241) were determined by rad screen. To determine the americium-241 contribution to the total alpha activity, gamma scans were done. The alpha activity results were corrected for the alpha-emitter counting efficiency as described in Sections 4.1:2.1 and 4.1.3.1. 
Table 20. Rad Screen and Gamma Scan Results for AMM11 Solutions

\begin{tabular}{|c|c|c|c|c|c|c|}
\hline Experiment & $\begin{array}{l}\text { Volume of } \\
\text { Solution } \\
\text { Before } \\
\text { Sampling }\end{array}$ & $\begin{array}{c}\text { Time Sample } \\
\text { Taken }\end{array}$ & $\begin{array}{c}\text { Beta Activity } \\
\text { dpm/ml } \\
\text { assumed to } \\
\text { be } \mathrm{Pu}-241\end{array}$ & $\begin{array}{l}\text { Alpha } \\
\text { Activity } \\
\text { dpm/ml }\end{array}$ & $\begin{array}{l}\text { Corrected } \\
\text { Alpha } \\
\text { Activity } \\
\text { dpm } / \mathrm{ml}\end{array}$ & $\begin{array}{c}\text { Americium- } \\
241 \\
\text { Alpha } \\
\text { Activity } \\
\text { dpm } / \mathrm{ml}\end{array}$ \\
\hline \multirow[t]{2}{*}{ AMM11a -2 } & \multirow[t]{2}{*}{$245 \mathrm{ml}$} & \multirow[t]{2}{*}{5.2 hours } & $1.86 \times 10^{9}$ & $4.36 \times 10^{8}$ & $4.04 \times 10^{8}$ & \multirow[t]{2}{*}{$1.09 \times 10^{8}$} \\
\hline & & & $1.75 \times 10^{9}$ & $4.16 \times 10^{8}$ & $3.85 \times 10^{8}$ & \\
\hline \multirow[t]{2}{*}{ AMM11a-3 } & \multirow[t]{2}{*}{$240 \mathrm{ml}$} & \multirow[t]{2}{*}{13 hours } & $1.66 \times 10^{9}$ & $4.09 \times 10^{8}$ & $3.79 \times 10^{8}$ & \multirow[t]{2}{*}{$1.11 \times 10^{8}$} \\
\hline & & & $1.78 \times 10^{9}$ & $4.18 \times 10^{8}$ & $3.87 \times 10^{8}$ & \\
\hline \multirow[t]{2}{*}{ AMM11a-4 } & \multirow[t]{2}{*}{$245 \mathrm{ml}$} & \multirow[t]{2}{*}{13 hours } & $1.83 \times 10^{9}$ & $4.28 \times 10^{8}$ & $3.96 \times 10^{8}$ & \multirow[t]{2}{*}{$1.08 \times 10^{8}$} \\
\hline & & & $1.77 \times 10^{9}$ & $4.20 \times 10^{8}$ & $3.89 \times 10^{8}$ & \\
\hline \multirow[t]{2}{*}{ AMM11a-5 } & \multirow[t]{2}{*}{$230 \mathrm{ml}$} & \multirow[t]{2}{*}{20 hours } & $1.65 \times 10^{9}$ & $3.83 \times 10^{8}$ & $3.55 \times 10^{8}$ & \multirow[t]{2}{*}{$1.12 \times 10^{8}$} \\
\hline & & & $3.09 \times 10^{9 *}$ & $7.20 \times 10^{8 *}$ & $6.67 \times 10^{8 *}$ & \\
\hline \multirow{2}{*}{ AMM11b-2 } & \multirow{2}{*}{$235 \mathrm{ml}$} & \multirow{2}{*}{5.2 hours } & & & & \multirow{2}{*}{$8.99 \times 10^{7}$} \\
\hline & & & $\frac{1.72 \times 10^{9}}{1.61 \times 10^{9}}$ & $\frac{4.04 \times 10^{\circ}}{3.78 \times 10^{8}}$ & $\frac{4.03 \times 10^{\circ}}{3.84 \times 10^{8}}$ & \\
\hline \multirow[t]{2}{*}{ AMM1 1b-3 } & \multirow{2}{*}{$\begin{array}{l}\text { Not taken, } \\
>250 \mathrm{ml}\end{array}$} & \multirow[t]{2}{*}{13 hours } & $1.47 \times 10^{9}$ & $3.40 \times 10^{8}$ & $3.15 \times 10^{8}$ & \multirow[t]{2}{*}{$8.60 \times 10^{7}$} \\
\hline & & & $1.48 \times 10^{9}$ & $3.51 \times 10^{8}$ & $3.25 \times 10^{8}$ & \\
\hline \multirow[t]{2}{*}{ AMM11b-4 } & \multirow{2}{*}{$\begin{array}{l}\text { Not taken, } \\
>250 \mathrm{ml}\end{array}$} & \multirow[t]{2}{*}{17.8 hours } & $1.39 \times 10^{9}$ & $3.24 \times 10^{8}$ & $3.00 \times 10^{8}$ & \multirow[t]{2}{*}{$8.89 \times 10^{7}$} \\
\hline & & & $1.47 \times 10^{9}$ & $3.46 \times 10^{8}$ & $3.20 \times 10^{8}$ & \\
\hline \multirow[t]{2}{*}{ AMM11b-5 } & \multirow[t]{2}{*}{$280 \mathrm{ml}$} & \multirow[t]{2}{*}{24.8 hours } & $1.28 \times 10^{9}$ & $3.00 \times 10^{8}$ & $2.78 \times 10^{8}$ & $8.08 \times 10^{7}$ \\
\hline & & & $1.51 \times 10^{9}$ & $3.58 \times 10^{8}$ & $3.32 \times 10^{8}$ & $9.43 \times 10^{7}$ \\
\hline
\end{tabular}

* Values not used in further calculations.

Samples were taken less frequently for the ICP/AES analyses for aluminum and boron, ion-selective electrode analysis for fluoride, and the analysis for total- and free-acid concentrations. Those results are discussed in Appendix B.

\subsubsection{Discussion of Results for AMM11 Experiments}

The grams of plutonium and of americium per liter were calculated using the information in Table 20 and those values are given in Table 21. The values for AMM11b-3 and AMM11b-4 were combined because they were duplicate samples. The amounts of plutonium and americium that had dissolved in the experiments were calculated as described in Sections 4.1.2.2 and 4.1.3.2. The total amounts dissolved in the solution were corrected for any plutonium and americium that was removed from the solution as samples. Those corrections were small. The corrected amounts are given in Table 22. No values for the total amount of plutonium and americium in AMM11b-3 and AMM11b-4 were obtained because the volumes of the solutions were not measured.

During the dissolution, it was observed that the volume of AMM11b was greater than 250 milliliters. The previous volume (after about 5 hours of heating) was 235 milliliters. This same phenomenon had been observed for AMM10b. At the time of the AMM10b observation, the increased volume was attributed to spillage from the condenser during the sampling. However, it is more likely that the condenser leaked. As a result, water was slowly added to the solution. After the Mark 42 reject compact material had dissolved and the solution had cooled, the volume of the solution was measured. The final volume was 280 milliliters, including the six milliliters that had been removed from samples. The new volume would correspond to about 11,000 liters in the F-Canyon dissolver with a fluoride concentration of $0.22 \mathrm{M}$. Although the volume change may have affected the equilibria among the various fluoride-complexing 
Table 21. Plutonium and Americium in AMM11 Solutions as a Function of Dissolution Time

\begin{tabular}{|c|c|c|c|c|c|c|}
\hline Experiment & $\begin{array}{c}\text { Time Sample } \\
\text { Taken }\end{array}$ & $\begin{array}{l}\text { Plutonium-241 } \\
\mathrm{g} / \mathrm{ml}\end{array}$ & $\begin{array}{c}\text { Americium- } \\
241 \\
\mathrm{~g} / \mathrm{ml}\end{array}$ & $\begin{array}{l}\text { Plutonium-238 } \\
\mathrm{g} / \mathrm{ml}\end{array}$ & $\begin{array}{l}\text { Plutonium-239 } \\
\mathrm{g} / \mathrm{ml}\end{array}$ & $\begin{array}{l}\text { Plutonium-240 } \\
\mathrm{g} / \mathrm{ml}\end{array}$ \\
\hline AMM1 1a-2 & 5.2 hours & $7.88 \times 10^{-6}$ & $1.43 \times 10^{-5}$ & $1.06 \times 10^{-6}$ & $9.27 \times 10^{-4}$ & $2.33 \times 10^{-4}$ \\
\hline AMM11a-3 & 13 hours & $7.51 \times 10^{-6}$ & $1.46 \times 10^{-5}$ & $1.01 \times 10^{-6}$ & $8.84 \times 10^{-4}$ & $2.22 \times 10^{-4}$ \\
\hline AMM1 la-4 & 13 hours & $7.86 \times 10^{-6}$ & $1.42 \times 10^{-5}$ & $1.06 \times 10^{-6}$ & $9.24 \times 10^{-4}$ & $2.32 \times 10^{-4}$ \\
\hline AMM11a-5 & 20 hours & $7.21 \times 10^{-6}$ & $1.48 \times 10^{-5}$ & $9.03 \times 10^{-7}$ & $7.87 \times 10^{-4}$ & $1.98 \times 10^{-4}$ \\
\hline AMM11b-2 & 5.2 hours & $7.27 \times 10^{-6}$ & $1.18 \times 10^{-5}$ & $9.98 \times 10^{-7}$ & $8.92 \times 10^{-4}$ & $2.24 \times 10^{-4}$ \\
\hline AMM11b-3/4 & 13 hours & $6.35 \times 10^{-6}$ & $1.15 \times 10^{-5}$ & $8.48 \times 10^{-7}$ & $7.39 \times 10^{-4}$ & $1.86 \times 10^{-8}$ \\
\hline AMM11b-5 & 24.8 hours & $5.59 \times 10^{-6}$ & $1.06 \times 10^{-5}$ & $7.34 \times 10^{-7}$ & $6.40 \times 10^{-4}$ & $1.61 \times 10^{-4}$ \\
\hline
\end{tabular}

species, it is expected that essentially the same amount of free fluoride was available to assist with the dissolution of the $\mathrm{PuO}_{2}$. Therefore, this volume change probably did not significantly change the dissolution time of the Mark 42 reject compact material.

Using the information in Table 16 and Table 22, the amount of plutonium and americium in the Mark 42 reject compact material can be calculated. The value of plutonium and americium in AMM11a-5 seems too low compared to the values obtained for AMM1 1a-2, AMM11-3, and AMM11a-4. There is no obvious explanation for the AMM11a-5 value. The volume of the final solution was rechecked and was 230 milliliters. Before sampling the volume would have been 235 milliliters, the value used in the calculations. Using the AMM1 1a-5 value, the plutonium and americium content of the Mark 42 reject compact material is about 10 weight \%. If the higher AMM11a-4 value is used, the plutonium and americium content of the Mark 42 reject compact material is 12 weight $\%$. The value for plutonium and americium content in Mark 42 reject compact material from AMM11b-5 is 11 weight\%. All three values are in agreement with the MC\&A value of 12.24 weight $\%$ and the values obtained in previous work. ${ }^{5}$

Table 22. Plutonium and Americium Dissolved in AMM11 Experiments

\begin{tabular}{|c|c|c|}
\hline Experiment & $\begin{array}{c}\text { Time Sample } \\
\text { Taken }\end{array}$ & $\begin{array}{c}\text { Plutonium and } \\
\text { Americum-241 } \\
\text { in Solution } \\
\text { (grams) }\end{array}$ \\
\hline AMM11a-2 & 5.2 hours & 0.28 \\
\hline AMM11a-3 & 13 hours & 0.27 \\
\hline AMM11a-4 & 13 hours & 0.29 \\
\hline AMM11a-5 & 20 hours & 0.24 \\
\hline & & 0.27 \\
\hline AMM11b-2 & 5.2 hours & 0.26 \\
\hline AMM11b-5 & 24.8 hours & \\
\hline
\end{tabular}

\subsubsection{AMM12 Tests}

In previous tests, ANN was added as a surrogate for the dissolved aluminum from the GPC and cladding of the unirradiated Mark 42 fuel tubes. As a result, the acid concentrations of the previous tests were higher than expected for the actual dissolution of the unirradiated Mark 42 fuel tubes because as the bulk aluminum (from the GPC and cladding) dissolves, it consumes acid. The only acid depletion in those 
previous tests was from the dissolution of the aluminum in the Mark 42 reject compact material (i.e., the fuel core). In the AMM12 test, an aluminum coupon from a GPC was added to the dissolver solution to test the dissolution of the Mark 42 reject compact material in the lower acid solution. Once the aluminum coupon had dissolved, the Mark 42 reject compact material was added. The fluoride concentration was $0.275 \mathrm{M}$ with $\mathrm{CaF}_{2}$ as the fluoride source. The test was done based on an F-Canyon dissoflver solution volume of 6,500 liters.

The aluminum coupon ( 1.21 grams) dissolved after 5.5 hours at $85^{\circ} \mathrm{C}$. The Mark 42 reject compact material was added to the cooled solution. Solids were observed after 7.6 hours and 16.3 hours at $85^{\circ} \mathrm{C}$. No solids were observed after 24.3 hours at $85^{\circ} \mathrm{C}$.

The only difference between AMM1 la and AMM12 was the way that aluminum was provided to the dissolver solution as a surrogate for the GPC and cladding. An aluminum coupon was used in AMM12 and ANN was used in AMM11a. The dissolution of the Mark 42 reject compact material was similar for the two experiments. In AMM11a, the material dissolved between 13 and 20 hours at $85^{\circ} \mathrm{C}$ and in $A M M 12$ the material dissolved between 16 and 24 hours at $85^{\circ} \mathrm{C}$. Thus, the dissolution of the Mark 42 reject compact material did not appear to be affected whether ANN or an aluminum coupon was used as surrogate for the GPC and cladding.

\subsubsection{Analytical Results for AMM12 Experiments}

Samples were pulled for rad screen and gamma scan analyses periodically during the dissolution. The results of those analyses are given in Table 23. Total alpha activity (plutonium-238, plutonium-239, plutonium-240, and americium-241) and total beta activity (plutonium-241) were determined by rad screen. To determine the americium- 241 contribution to the total alpha activity, gamma scans were done. The alpha activity results were corrected for the alpha-emitter counting efficiency as described in Sections 4.1.2.1 and 4.1.3.1.

Table 23. Rad Screen and Gamma Scan Results for AMM12 Solution

\begin{tabular}{|c|c|c|c|c|c|c|}
\hline Experiment & $\begin{array}{c}\text { Volume of } \\
\text { Solution } \\
\text { Before } \\
\text { Sampling }\end{array}$ & $\begin{array}{c}\text { Time Sample } \\
\text { Taken }\end{array}$ & $\begin{array}{c}\text { Beta Activity } \\
\text { dpm/ml } \\
\text { assumed to } \\
\text { be Pu-241 }\end{array}$ & $\begin{array}{c}\text { Alpha } \\
\text { Activity } \\
\mathrm{dpm} / \mathrm{ml}\end{array}$ & $\begin{array}{c}\text { Corrected } \\
\text { Alpha } \\
\text { Activity } \\
\mathrm{dpm} / \mathrm{ml}\end{array}$ & $\begin{array}{c}\text { Americium- } \\
241 \\
\text { Alpha } \\
\text { Activity } \\
\text { dpm/ml }\end{array}$ \\
\hline AMM12-3 & $220 \mathrm{ml}$ & 7.6 hours & $1.61 \times 10^{9}$ & $3.78 \times 10^{8}$ & $3.50 \times 10^{8}$ & $1.00 \times 10^{8}$ \\
\hline AMM12-4 & $220 \mathrm{ml}$ & 16.3 hours & $1.46 \times 10^{9}$ & $3.38 \times 10^{8}$ & $3.13 \times 10^{8}$ & $1.05 \times 10^{8}$ \\
\hline AMM12-5 & $220 \mathrm{ml}$ & 24.3 hours & $1.71 \times 10^{9}$ & $3.95 \times 10^{8}$ & $3.66 \times 10^{8}$ & $1.02 \times 10^{8}$ \\
\hline
\end{tabular}

Samples were taken less frequently for the ICP/AES analyses for aluminum and boron, ion-selective electrode analysis for fluoride, and the analysis for total- and free-acid concentrations. Those results are discussed in Appendix B.

\subsubsection{Discussion of Results for AMM12 Experiment}

The grams of plutonium and of americium per liter were calculated using the information in Table 23 and those values are given in Table 24. The total amounts of plutonium and americium that had dissolved in the experiment were calculated as described in Sections 4.1.2.2 and 4.1.3.2. The total amounts dissolved in the solution were corrected for any plutonium and americium that was removed from the solution as samples. Those corrections were small. The corrected amounts are given in Table 25 . The values for AMM12-3 and AMM12-4 are not in agreement with the progress of the dissolution. Either the value for AMM12-3 is too high or the value for AMM12-4 is too low. 
Table 24. Plutonium and Americium in AMM12 Solution as a Function of Dissolution Time

\begin{tabular}{|c|c|c|c|c|c|c|}
\hline Experiment & $\begin{array}{c}\text { Time Sample } \\
\text { Taken }\end{array}$ & $\begin{array}{c}\text { Plutonium-241 } \\
\mathrm{g} / \mathrm{ml}\end{array}$ & $\begin{array}{c}\text { Americium- } \\
241 \\
\mathrm{~g} / \mathrm{ml}\end{array}$ & $\begin{array}{c}\text { Plutonium-238 } \\
\mathrm{g} / \mathrm{ml}\end{array}$ & $\begin{array}{c}\text { Plutonium-239 } \\
\mathrm{g} / \mathrm{ml}\end{array}$ & $\begin{array}{c}\text { Plutonium-240 } \\
\mathrm{g} / \mathrm{ml}\end{array}$ \\
\hline AMM12-3 & 7.6 hours & $7.03 \times 10^{-6}$ & $1.31 \times 10^{-5}$ & $932 \times 10^{-7}$ & $8.12 \times 10^{-4}$ & $2.04 \times 10^{-4}$ \\
\hline AMM12-4 & 16.3 hours & $6.38 \times 10^{-6}$ & $1.37 \times 10^{-5}$ & $7.77 \times 10^{-7}$ & $6.77 \times 10^{-4}$ & $1.70 \times 10^{-4}$ \\
\hline AMM12-5 & 24.3 hours & $7.47 \times 10^{-6}$ & $1.34 \times 10^{-5}$ & $9.83 \times 10^{-7}$ & $8.57 \times 10^{-4}$ & $2.15 \times 10^{-4}$ \\
\hline
\end{tabular}

Table 25. Plutonium and Americium Dissolved in AMM12 Experiments

\begin{tabular}{|c|c|c|}
\hline Experiment & $\begin{array}{c}\text { Time Sample } \\
\text { Taken }\end{array}$ & $\begin{array}{c}\text { Plutonium and } \\
\text { Americum-241 } \\
\text { in Solution } \\
\text { (grams) }\end{array}$ \\
\hline AMM12-3 & 0.75 hours & 0.23 \\
\hline AMM12-4 & 7.15 hours & 0.19 \\
\hline AMM12-5 & 13.65 hours & 0.24 \\
\hline
\end{tabular}

Using the information in Table 16 and Table 25, the amount of plutonium and americium in the Mark 42 reject compact material can be calculated. The calculated amount of plutonium and americium in the Mark 42 reject compact material was 10 weight\%. That value agrees with the MC\&A (12.24 weight\%) value, other values obtained in this set of experiments, and values obtained in previous work. ${ }^{5}$

\subsection{4 $\mathrm{CaF}_{2}$ Dissolution Conclusions}

The $\mathrm{CaF}_{2}$ dissolution experiments demonstrated that fluoride concentrations between $0.25 \mathrm{M}$ and $0.30 \mathrm{M}$ can be used to dissolve the Mark 42 reject compact material with the new batching scenario. The most effective of the tested fluoride concentrations for dissolution was $0.30 \mathrm{M}$ (AMM10a and AMM10b). That result is not surprising because the aluminum:fluoride mole ratios were 1.5 and 1 , respectively. Previous tests ${ }^{5}$ had shown aluminum:fluoride ratios of less that 1.3 were successful in dissolving Mark 42 reject compact material in about 4 hours. Those tests also included an aluminum:fluoride mole ratio of 1.5 . That material was not dissolved within six hours and for AMM10a almost 14 hours were required for dissolution of the solids. As the fluoride concentration was decreased, the dissolution time increased (AMM1 1a and AMM11b). The use of ANN or an aluminum coupon (AMM12) as a source of GPC and cladding aluminum did not seem to affect the dissolution of the Mark 42 reject compact material.

\subsection{Dissolution of 6063-Aluminum Coupons}

As mentioned previously, no mercury was added to the crushed Mark 42 reject compact material to assist with the dissolution of aluminum. Initially, the enhanced dissolution rate was observed in this study was attributed to the larger surface area of the crushed material compared to bulk aluminum. Larger surface areas usually promote dissolution. However, recent work at Idaho National Engineering and Environmental Laboratory has identified another reason that the aluminum dissolution proceeded so readily. Anderson and Christian reported that $\mathrm{HBF}_{4}$ behaves similarly to the $\mathrm{Hg}\left[\mathrm{NO}_{3}\right]_{2}$ catalyst for dissolving aluminum. ${ }^{10}$ It is reasonable to expect $\mathrm{HBF}_{4}$ in the dissolution solutions in equilibria with $\mathrm{H}_{3} \mathrm{BO}_{3}, \mathrm{HNO}_{3}$, and $\mathrm{KF}$ or $\mathrm{CaF}_{2}$.

\footnotetext{
${ }^{10}$ Philip A. Anderson and Jerry D. Christian, Journal of Materials Research, 13(1), 68 (1998).
} 
The aim of this study was to compare the dissolution of aluminum coupons in representative solutions. In one solution, $\mathrm{HBF}_{4}$ was added to an $\mathrm{HNO}_{3}$ solution. A second solution had a composition similar to the solutions used for the dissolution of Mark 42 reject compact material $\left(8 \mathrm{M} \mathrm{HNO}_{3} / 0.20 \mathrm{M} \mathrm{H}_{3} \mathrm{BO}_{3}\right.$ I $0.1375 \mathrm{CaF}_{2}$ ). The third solution was simply an $\mathrm{HNO}_{3}$ solution without any boron. If the $\mathrm{HBF}_{4}$ species was present in the dissolver solution, then the dissolution of aluminum coupon in the $8 \mathrm{M} \mathrm{HNO}_{3} / 0.20 \mathrm{M}$ $\mathrm{H}_{3} \mathrm{BO}_{3} / 0.1375 \mathrm{CaF}_{2}$ solution should be better than the dissolution in the $8 \mathrm{M} \mathrm{HNO}_{3}$ solution. Of particular interest was the comparison of the dissolution in the two solutions containing boron.

Three solutions were made up as described below:

Solution A: $\quad 0.2036 \mathrm{M} \mathrm{HBF}_{4} / 8 \mathrm{M} \mathrm{HNO}_{3}$

Solution B: $\quad 0.2036 \mathrm{M} \mathrm{H}_{3} \mathrm{BO}_{3} / 0.1375 \mathrm{M} \mathrm{CaF}_{2} / 8 \mathrm{M} \mathrm{HNO}_{3}$

Solution C: $\quad 8 \mathrm{M} \mathrm{HNO}_{3}$.

Aluminum coupons $(\sim 3.1$ grams) from a GPC were added to the solutions. Once the aluminum dissolved, the aluminum concentration would be $0.46 \mathrm{M}$, the aluminum concentration for AMM1 1a (6,500 liter case). The solutions were heated to $85^{\circ} \mathrm{C}$ with a maximum of $95^{\circ} \mathrm{C}$ being reached during the aluminum dissolution because of the exothermicity of that reaction. Evaporation from the solutions was minimized by use of an ice-cooled condenser watch glass.

The aluminum dissolution in Solutions $A$ and $B$ proceeded more vigorously than the dissolution in Solution $\mathrm{C}$. Dark orange $\mathrm{NO}_{\mathrm{x}}$ fumes evolved from Solutions $\mathrm{A}$ and $\mathrm{B}$, evidence of the oxidation of the aluminum by $\mathrm{HNO}_{3}$. Only a trace of $\mathrm{NO}_{\mathrm{x}}$ fumes was observed from Solution $\mathrm{C}$. As expected, the aluminum coupon in Solution A dissolved most rapidly, after 1.5 hours at $85^{\circ} \mathrm{C}$. The aluminum coupon in Solution B needed four hours for dissolution. After 10 hours, the aluminum coupon in Solution $C$ had not dissolved. Furthermore, a visual inspection of the coupon in Solution $\mathrm{C}$ indicated that very little of the aluminum coupon had dissolved.

These results are promising for developing a flow sheet that does not require mercury to catalyze the dissolution of bulk aluminum. The actual function of the $\mathrm{HBF}_{4}$ on the aluminum is not known. The $\mathrm{HBF}_{4}$ could be consumed as the aluminum is dissolved or it may be catalytic. It may be advantageous to explore the ability of $\mathrm{HBF}_{4}$ to promote aluminum dissolution because if $\mathrm{HBF}_{4}$ did promote the aluminum dissolution in a satisfactory manner, then mercury would not be needed. The disuse of mercury in the dissolution of bulk aluminum materials at SRS would be an important waste and hazard minimization step.

\section{Summary}

The extended dissolution tests (AMM08 and AMM09) were not successful. Solutions of crushed Mark 42 reject compact material were heated at $85^{\circ} \mathrm{C}$ for up to 195 hours without complete dissolution of the $\mathrm{PuO}_{2}$. Those tests used $0.15 \mathrm{M}$ and $0.20 \mathrm{M}$ fluoride and were premised on a flow sheet in which 10.3 kilograms of plutonium and 96.3 kilograms from the unirradiated Mark 42 fuel tubes were added to 6,500 liters of dissolver solution per batch.

The $\mathrm{CaF}_{2}$ dissolution tests (AMM10, AMM11, and AMM12) were successful because all of the crushed Mark 42 reject compact material was dissolved within seven to 24 hours depending on the fluoride concentration. The most effective fluoride concentration was $0.30 \mathrm{M}$ (AMM10a and AMM10b). The flow sheet for these tests was based on the addition of 6.2 kilograms of plutonium and 80.2 kilograms from the unirradiated Mark 42 fuel tubes to the dissolver solution per batch. Dissolver solution volumes of 6,500 and 10,000 liters were tested. The dissolution in the larger volume (AMM10b) was completed in the shortest amount of time because it had the smallest aluminum:fluoride molar ratio (1:1).

The corrosive effect of the higher-fluoride concentrations is important to the acceptance of those fluoride concentrations for F-Canyon processing solutions. A study is being done by the Materials Applications and Technology Group to determine the corrosion effects of fluoride concentrations in the range of 0.2 to $0.4 \mathrm{M}$ using the Mark 42 dissolution flow sheet. Those results will be published in a separate report. As part of that study, the effective free-fluoride concentrations will be measured. 
Scoping tests indicate that use of mercury to promote the dissolution of bulk aluminum may not be necessary in solutions in which boron and fluoride are present. The $\mathrm{HBF}_{4}$ species may serve a similar catalytic role in the dissolution of aluminum as mercury serves. Further testing is recommended.

$\therefore \ldots$ 
WSRC-TR-98-00196

\section{Appendix A \\ Estimate of Amount of Aluminum in Mark 42 Fuel Tube Cladding}

The information in the NMP-SRB-92-0048 was used to estimate the quantity of aluminum in the cladding of the Mark 42 fuel tubes. ${ }^{7}$ These estimates are based on the specification for the Mark 42 fuel tube. It is important to note that the reject mark 42 fuel tubes did not meet the plutonium density specifications. Therefore, the aluminum content of the reject fuel tubes is different. Based on Frontroth's report, 'the reject inner fuel tube may have about $5 \%$ less aluminum than required by the specification. Although the following calculations may over- or under estimate the amount of aluminum in the reject fuel core with a corresponding under- or over estimate of the aluminum in the cladding, the total aluminum that will be dissolved is known from Beckum's report. ${ }^{\text {? }}$

Inner Fuel Tube

According to that report, there are five bundles of Mark 42 fuel that each contains two inner tubes. The plutonium content is given as 0.78 kilograms per inner tube in the report. The inner tube core has a plutonium content of 18.7 weight $\%$. Therefore, the amount of aluminum in each inner fuel tube core is 3.29 kilograms. The total aluminum content of the bundle (core + cladding + GPC) with two inner tubes is given as 20.04 kilograms in the report. There are 6.67 kilograms of aluminum in each GPC. Therefore, the amount of aluminum in the cladding of each inner fuel tube is 3.40 kilograms.

\section{Middle Fuel Tube}

One bundle is listed in the report as containing only one fuel tube, a middle fuel tube. The amount of plutonium in the fuel tube core is given as 1.51 kilograms. Using the middle tube core composition of 21.8 weight\% plutonium, the amount of aluminum in the middle tube core is 5.20 kilograms. The total aluminum content of the bundle (core + cladding + GPC) is given as 15.09 kilograms in the report. There are 6.67 kilograms of aluminum in each GPC. Therefore, the amount of aluminum in the cladding of the middle fuel tube is 3.23 kilograms.

\section{Outer Fuel Tube}

The amount of aluminum in the outer tube's cladding had to be estimated indirectly because there was no information on individual outer tubes. According to the report, there are several bundles that contain the complete fuel tube assembly (i.e., outer, middle, and inner fuel tubes). The plutonium content in the outer fuel tube core is given as 1.06 kilograms. With a plutonium content of 15.4 weight $\%$, the outer fuel tube core has 5.68 kilograms of aluminum. The total aluminum in the bundle is 30.75 kilograms. Subtracting the contributions by the GPC (6.67 kilograms), the fuel cores (5.68 kilograms -outer, 5.20 kilograms middle, and 3.29 kilograms - inner), the inner fuel tube cladding (3.40 kilograms), and the middle fuel tube cladding ( 3.23 kilograms), the cladding on the outer fuel tube is estimated at 3.29 kilograms.

Table Al summarizes the composition of the fuel tubes.

Table A1. Composition of Mark 42 Fuel Tubes (in kilograms)

\begin{tabular}{|l|c|c|c|c|}
\hline Fuel tube & Plutonium & $\mathrm{PuO}_{2}$ & $\begin{array}{c}\text { Aluminum in } \\
\text { Cermet (Core) }\end{array}$ & $\begin{array}{c}\text { Aluminum in } \\
\text { Cladding }\end{array}$ \\
\hline Inner Tube & 0.78 & 0.88 & 3.29 & 3.40 \\
\hline Middle Tube & 1.51 & 1.71 & 5.20 & 3.23 \\
\hline Outer Tube & 1.06 & 1.20 & 5.68 & 3.29 \\
\hline
\end{tabular}


WSRC-TR-98-00196

\section{Appendix B}

Results of Fluoride Concentration Analyses, Acid Concentration Analyses, and ICP/AES Analyses

\section{AMM08 Tests}

The aluminum and boron concentrations in the solutions were determined with ICP/AES. The results of those analyses are given in Table B1. Initial and final sets of samples were taken from the AMM08a and AMM08b solutions. The first set of samples was taken after the ANN had been added but before the Mark 42 reject compact material had been added. The second set of samples was taken after 48 hours of dissolution. One set of samples was from the AMM08c and AMM08d solutions. Those samples were taken after the solids had dissolved.

Table B1. ICP/AES Results for Aluminum and Boron for AMM08 Solutions

\begin{tabular}{|l|c|c|c|c|c|}
\hline Experiment & $\begin{array}{c}\text { Time into } \\
\text { Dissolution } \\
\text { Sample Taken }\end{array}$ & $\begin{array}{c}\text { Aluminum } \\
\text { mg/liter }\end{array}$ & $\begin{array}{c}\text { \% Aluminum } \\
\text { as ANN } \\
\text { Added }\end{array}$ & $\begin{array}{c}\text { Boron } \\
\text { mg/liter }\end{array}$ & $\begin{array}{c}\% \text { Boron } \\
\text { Added }\end{array}$ \\
\hline AMM08a-0 & 0 hours & 7,800 & $97 \%$ & 2,200 & $101 \%$ \\
\hline AMM08b-0 & 0 hours & 7,800 & $96 \%$ & 2,220 & $102 \%$ \\
\hline AMM08a-7 & 48 hours & 31,500 & - & 3,340 & $81 \%$ \\
\hline AMM08b-7 & 48 hours & 28,200 & - & 3,160 & $94 \%$ \\
\hline AMM08c & 8 hours & 9,200 & - & 420 & None Added \\
\hline AMM08d & 8 hours & 1,900 & - & 240 & None Added \\
\hline
\end{tabular}

The ICP/AES data were expected to help with a material balance and to establish the amount of aluminum in the Mark 42 reject compact material. The boron results would confirm the amount of boron that was used in the experiments. The aluminum and boron results for AMM08a-0 and AMM08b-0 did correspond to the amount of aluminum in ANN and the amount of boron in the $\mathrm{H}_{3} \mathrm{BO}_{3}$ that were added to the AMM08a and AMM08b solutions.

The results for AMM08a-7 and AMM08b-7 cannot be used for a material balance of the Mark 42 reject compact material because of the precipitation of solids as the solutions evaporated during the 48 hours at temperature. The $\mathrm{x}$-ray diffraction analyses of the solids showed that both $\mathrm{ANN}$ and $\mathrm{H}_{3} \mathrm{BO}_{3}$ were present. Thus, the total amount of aluminum dissolved from the Mark 42 reject compact material could not be determined.

According to the literature, ${ }^{11}$ at $25^{\circ} \mathrm{C}$ the solubility of $\mathrm{H}_{3} \mathrm{BO}_{3}$ decreases in $\mathrm{HNO}_{3}$ solutions as the $\mathrm{HNO}_{3}$ concentration increases. For example the $\mathrm{H}_{3} \mathrm{BO}_{3}$ solubility in $4.698 \mathrm{M} \mathrm{HNO}_{3}$ is given as 27 grams per liter and 18.31 grams per liter in $8.410 \mathrm{M} \mathrm{HNO}_{3}$. Solutions $8 \mathrm{a}$ and $8 \mathrm{~b}$ were initially $8 \mathrm{M}$ nitric acid/ $/ 0.20 \mathrm{M}$ boron (close to the solubility limit of $\mathrm{H}_{3} \mathrm{BO}_{3}$ ). After 48 hours at $85^{\circ} \mathrm{C}$, sufficient solution had evaporated to increase the free-acid concentrations to about $9.7 \mathrm{M}$. The precipitation of $\mathrm{H}_{3} \mathrm{BO}_{3}$ from the solutions at higher acid concentrations is not surprising.

Milligan ${ }^{12}$ reported the solubility of aluminum nitrate $\left(\mathrm{Al}\left(\mathrm{NO}_{3}\right)_{3}\right)$ in $\mathrm{HNO}_{3}$ solutions as a function of $\mathrm{HNO}_{3}$ concentration and temperature. The solubility of $\mathrm{Al}\left(\mathrm{NO}_{3}\right)_{3}$ decreased in $\mathrm{HNO}_{3}$ solutions as the $\mathrm{HNO}_{3}$ concentration increased. Therefore, the precipitation of ANN from the evaporated solutions is not unexpected because the free-acid concentration had increased to $9.7 \mathrm{M}$.

The precipitation of ANN does explain why aluminum was found by the ICP/AES analyses of samples from the AMM08c and AMM08d solutions. Very little aluminum, if any, was expected in those two solutions because all of the aluminum in the Mark 42 reject compact material should have dissolved in the

\footnotetext{
"Atherton Seidel, "Solubilities of Inorganic and Metal Organic Compounds", D. Van Nostrand Company, New York, 1940.

${ }^{12}$ Lowell H. Milligan, Journal of the American Chemical Society, 44, (1922), 567.
} 
first hours of the dissolution (i.e., the AMM008a and AMM08b solutions). However, any precipitated ANN present in the solids remaining after the AMM08a and AMM08b solutions were decanted would have been redissolved in AMM08c and AMM08d, respectively. Similarly, no boron was expected in the AMM08c and AMM08d solutions because no $\mathrm{H}_{3} \mathrm{BO}_{3}$ had been added to the solutions. The ICP/AES analyses of samples from AMM08c and AMM08d found 420 and 240 milligrams of borofi per liter, respectively. That boron must have been from precipitated $\mathrm{H}_{3} \mathrm{BO}_{3}$ in the solid residue left after the AMM08a and AMM08b solutions had been decanted.

The total- and free-acid concentrations were measured for the solutions. Those results are given in Table B2. The interference from complexing metal ions (e.g., aluminum) is removed in the free-acid concentration analysis while the total-acid concentration analysis includes the metal ion effects. The totaland free-acid concentrations confirm that the evaporation of the solutions resulted in increased acid concentration. Typically, after the Mark 42 reject compact material dissolved, the acid concentration decreased from about $8 \mathrm{M}$ to $6 \mathrm{M}$ because of the aluminum dissolution.

Table B2. Total- and Free-Acid Concentrations and Fluoride Concentration for AMM008 Solutions

\begin{tabular}{|l|c|c|c|}
\hline Experiment & $\begin{array}{c}\text { Free Acid } \\
\text { (Molar) }\end{array}$ & $\begin{array}{c}\text { Total Acid } \\
\text { (Molar) }\end{array}$ & $\begin{array}{c}\text { Fluoride } \\
\text { (ppm) }\end{array}$ \\
\hline AMM08a-0 & 7.32 & 8.66 & 1,250 \\
\hline AMM08b-0 & 7.52 & 8.78 & 1,690 \\
\hline AMM08a-7 & 10.13 & 11.6 & 1,510 \\
\hline AMM08b-7 & 9.32 & 11.31 & 1,460 \\
\hline AMM08c & 7.46 & 8.66 & 814 \\
\hline AMM08d & 7.81 & 8.26 & 818 \\
\hline
\end{tabular}

The dissolution of the $\mathrm{PuO}_{2}$ is dependent on the availability of free-fluoride ions. If complexing ions are present in the solution, e.g., boron or aluminum, the amount of free fluoride ions is expected to be reduced. The fluoride-ion concentration was measured with an ion-selective electrode. In general, that analysis is a measure of total fluoride-ion concentration. However, the analysis does not provide the free-fluoride concentration for these samples because the analysis is not calibrated to provide the free-fluoride value in the presence of complexing agents (e.g., boron and aluminum). Thus, this analysis provides qualitative information on the free-fluoride ions in the solution. The results are presented in Table B2.

The AMM08a-0 and AMM08b-0 samples were taken of the dissolver solution after the addition of ANN but before the addition of the Mark 42 reject compact material. Based on the initial fluoride concentrations of the solutions, the expected results were 2,850 ppm and 3,800 ppm for AMM08a and AMM08b, respectively. The analytical results indicate that some of the fluoride is being complexed by the aluminum and boron.

The results from AMM08a-7 and AMM08b-7 cannot be interpreted easily. Typically, the fluoride concentration from the initial solution could be compared with the fluoride concentration from the final solution to see the effect of the aluminum dissolution from the Mark 42 reject compact material. However, because $\mathrm{ANN}$ and $\mathrm{H}_{3} \mathrm{BO}_{3}$ precipitated, the resulting fluoride complexing equilibria have shifted. It is not possible to draw any conclusions from the results regarding the effect of the aluminum from the dissolved Mark 42 reject compact material on the fluoride concentration. 
The fluoride concentration results from the AMM08c and AMM08d samples are unexpected. Based on the ICP/AES results, those solutions had significantly less aluminum and boron available for complexation than the AMM08a-0 and AMM08b-0 solutions. However, for the same fluoride concentration $(0.15 \mathrm{M})$, the fluoride concentration results indicate there are more complexing reagents available in AMM08c compared to AMM08a-0.

\section{AMM09}

Table B3 contains the ICP/AES results for aluminum, boron, and calcium for the AMM09 experiments. In addition to providing material balance information, it was expected that the ICP/AES analyses would help monitor the effect of the periodic additions of the 5 Molar nitric acid to the solutions. For example, the samples for AMM09a-23 and AMM09b-23 were taken immediately after the $5 \mathrm{M} \mathrm{HNO}_{3}$ solution was added to replenish solutions AMM09a and AMM09b to 250 milliliters. Thus, a dilution factor should relate the results of those two samples to the results from samples AMM09a-22 and AMM09b-22, respectively.

Table B3. ICP/AES Results for Aluminum, Boron, and Calcium for AMM09 Solutions

\begin{tabular}{|l|c|c|c|c|}
\hline \multicolumn{1}{|c|}{ Experiment } & $\begin{array}{c}\text { Time into } \\
\text { Dissolution } \\
\text { Sample Taken }\end{array}$ & $\begin{array}{c}\text { Aluminum } \\
\text { mg/liter }\end{array}$ & $\begin{array}{c}\text { Boron } \\
\mathrm{mg} / \text { liter }\end{array}$ & $\begin{array}{c}\text { Calcium } \\
\mathrm{mg} / \mathrm{liter}\end{array}$ \\
\hline AMM09a-0 & 0 hours & 7,500 & 2,010 & - \\
\hline AMM09a-6 & 45.65 hours & 19,400 & 2,110 & - \\
\hline AMM09a-11* & 74.2 hours & 15,800 & 1,770 & - \\
\hline AMM09a-22 & 159.05 hours & 19,700 & 2,160 & - \\
\hline AMM09a-23* & 159.05 hours & 14,000 & 1,540 & - \\
\hline AMM09a-28 & 194.95 hours & 16,700 & 1,830 & - \\
\hline AMM09a-31 $* *$ & 214.8 hours & 18,500 & 1,980 & 2,570 \\
\hline AMM09c & 6.3 hours & 235 & 2,170 & - \\
\hline & & & & - \\
\hline AMM09b-0 & 0 hours & 7,330 & 1,960 & - \\
\hline AMM09b-6 & 45.65 hours & 21,600 & 2,300 & - \\
\hline AMM09b-11* & 74.2 hours & 16,600 & 1,810 & - \\
\hline AMM09b-22 & 159.05 hours & 19,900 & 2,130 & - \\
\hline AMM09b-23* & 159.05 hours & 14,700 & 1,580 & - \\
\hline AMM09b-28 & 194.95 hours & 15,600 & 1,660 & - \\
\hline AMM09b-31** & 214.8 hours & 18,300 & 1,920 & 2,550 \\
\hline AMM09d & 6.3 hours & 370 & 2,190 & - \\
\hline
\end{tabular}

Replenished dissolver solution to 250 milliliters with $5 \mathrm{M} \mathrm{HNO}_{3}$

** $\mathrm{CaF}_{2}$ added to the AMM09-29 solutions

Typically, the amount of aluminum in the Mark 42 reject compact material can be calculated as the difference between the amount of the aluminum from the ANN and the total amount of aluminum in solution based on the ICP/AES results. The ICP/AES results for boron are used as a check because the boron quantity is not expected to change during the dissolution. To use the ICP/AES data for material balance, the effect of the cumulative removal of the rad screen/gamma scan samples needed to be included. Each one-milliliter sample for the rad screen/gamma scan analyses removed some of the aluminum and boron from the solution, as well as plutonium and americium. The amounts of aluminum and boron in the solutions based on the ICP/AES data are given in Table B4. Both the amounts based on the raw data and the corrected amounts are given in Table B4. 
Table B4. Total Aluminum and Boron in AMM09 Solutions Based on ICP/AES Data

\begin{tabular}{|c|c|c|c|c|c|c|c|c|c|}
\hline \multirow[t]{2}{*}{ Experiment } & \multirow{2}{*}{$\begin{array}{c}\text { Time into } \\
\text { Dissolution } \\
\text { Sample Taken }\end{array}$} & \multicolumn{2}{|c|}{$\begin{array}{l}\text { Aluminum } \\
\text { grams }\end{array}$} & \multirow{2}{*}{$\begin{array}{c}\% \\
\text { Aluminum } \\
\text { Added } \\
\end{array}$} & \multicolumn{2}{|c|}{$\begin{array}{l}\text { Boron } \\
\text { grams }\end{array}$} & \multirow[t]{2}{*}{$\begin{array}{l}\% \text { Boron } \\
\text { Added }\end{array}$} & \multirow[t]{2}{*}{$\begin{array}{l}\text { Calcium } \\
\text { grams }\end{array}$} & \multirow[t]{2}{*}{$\begin{array}{c}\text { \% Calcium } \\
\text { Added }\end{array}$} \\
\hline & & raw & cort & & raw & corr & & & \\
\hline AMM09a-0 & 0 hours & 2.03 & $N / A$ & 100 & 0.54 & N/A & 100 & - & - \\
\hline AMM09a-6 & 45.65 hours & 4.08 & 4.14 & - & 0.44 & 0.45 & 85 & - & - \\
\hline AMM09a-11* & 74.2 hours & 3.79 & 4.07 & - & 0.42 & .48 & 91 & - & 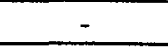 \\
\hline AMM09a-22 & 159.05 hours & 3.84 & 4.39 & - & 0.42 & 0.49 & 92 & - & - \\
\hline AMM09b-23a* & 159.05 hours & 3.49 & 4.10 & - & 0.39 & 0.47 & 89 & - & - \\
\hline AMM09a-28 & 194.95 hours & 3.84 & 4.68 & - & 0.42 & 0.51 & 96 & - & - \\
\hline AMM09a-31** & 214.8 hours & 3.88 & 4.92 & - & 0.43 & 0.54 & 102 & 0.54 & 108 \\
\hline AMM09c & 6.3 hours & 0.06 & $\mathrm{~N} / \mathrm{A}$ & - & 0.55 & $\mathrm{~N} / \mathrm{A}$ & 101 & - & - \\
\hline AMM09b-0 & 0 hours & 1.98 & $\mathrm{~N} / \mathrm{A}$ & 97 & 0.53 & N/A & 98 & - & - \\
\hline AMM09b-6 & 45.65 hours & 4.53 & 4.61 & - & 0.48 & 0.49 & 92 & - & - \\
\hline AMM09b-11* & 74.2 hours & 3.98 & 4.28 & - & 0.43 & 0.47 & 89 & - & - \\
\hline AMM09b-22 & 159.05 hours & 4.09 & 4.69 & - & 0.44 & 0.51 & 96 & - & - \\
\hline AMM09b-23b* & 159.05 hours & 3.68 & 4.34 & - & 0.40 & 0.48 & 91 & - & - \\
\hline AMM09b-28 & 194.95 hours & 3.66 & 4.46 & - & 0.39 & 0.49 & 92 & - & - \\
\hline AMM09b-31** & 214.8 hours & 3.93 & 5.00 & - & 0.42 & 0.11 & 98 & 0.55 & 110 \\
\hline AMM09d & 6.3 hours & 0.09 & N/A & - & 0.54 & $\mathrm{~N} / \mathrm{A}$ & 97 & - & - \\
\hline
\end{tabular}

Replenished dissolver solution to 250 milliliters with $5 \mathrm{M} \mathrm{HNO}_{3}$

$* * \mathrm{CaF}_{2}$ added to the AMM09-29 solutions

As can be seen, the value for the percent of boron added is not constant. It varies from 85 to $102 \%$. Initially that discrepancy was attributed to error in the ICP/AES sample preparation prior to the submission of the samples to the Analytical Development Section (ADS). ${ }^{13}$ For the ICP/AES sample, a one-milliliter aliquot of the solution was pulled and diluted into ten milliliters of $5 \mathrm{M} \mathrm{HNO}_{3}$. If that dilution was not done accurately, then the ICP/AES results will be inaccurate. That assertion is supported by the results of the AMM09-22 and AMM09-23 analyses. Those samples were taken before and after the addition of $5 \mathrm{M}$ $\mathrm{HNO}_{3}$ to the dissolver solutions. The amount of boron should not be affected and yet for AMM09b-22 and AMM9b-23 the boron values are 0.51 and 0.48 grams, respectively.

One way to estimate the amount of aluminum in Mark 42 reject compact material is adjust the aluminum values by the factor that adjusts the boron values to their correct value. For example, in AMM06a the boron value needs to be multiplied by 1.17 to give the amount of boron added to the solution. If that factor is applied to the aluminum value ( 4.14 grams), the new aluminum value is 4.84 grams. Subtracting the amount of ANN aluminum, gives 2.85 grams as the amount of aluminum from the Mark 42 reject compact material. Based on the 2.85 grams, aluminum is $84 \%$ of the Mark 42 reject compact material. Considering the corrections for the samples and the adjustment for the boron value, that is a reasonable value for the aluminum content. Similar adjustments were made to the other aluminum values and the calculated aluminum contents of the Mark 42 reject compact material are given in Table B5 along with the calculated aluminum contents without the boron adjustment.

The average value for the aluminum content of the Mark 42 reject compact material was calculated using the adjusted values given in Table B4. It was assumed that all of the aluminum dissolved immediately and all of the ICP/AES values could be averaged. For AMM09a, the calculated aluminum content of the Mark 42 reject compact material was $80 \% \pm 4 \%$ by weight. The calculated aluminum content of the Mark 42

\footnotetext{
${ }^{13}$ Results from the AMM10, AMM11, and AMM12 ICP/AES samples (both diluted and undiluted) indicate that the error may be due to sample preparation errors in ADS or instrument drift.
} 
Table B5. Calculated Aluminum Content of Mark 42 Reject Compact Material Based on ICP/AES Data

\begin{tabular}{|c|c|c|c|c|c|}
\hline \multirow[t]{2}{*}{ Experiment } & \multicolumn{2}{|c|}{$\begin{array}{c}\text { Aluminum Based on } \\
\text { Data Corrected for } \\
\text { Sample Removal } \\
\end{array}$} & \multirow[t]{2}{*}{$\begin{array}{c}\text { Boron } \\
\text { Adjustment }\end{array}$} & \multicolumn{2}{|c|}{$\begin{array}{l}\text { Aluminum with } \\
\text { Adjustment }\end{array}$} \\
\hline & grams & $\% *$ & & grams & $\% *$ \\
\hline AMM09a-0 & \multicolumn{2}{|c|}{ No Mark 42} & & \multicolumn{2}{|c|}{ No Mark 42} \\
\hline AMM09a-6 & 4.14 & 63 & 1.17 & 4.84 & 85 \\
\hline AMM09a-11** & 4.07 & 61 & 1.10 & 4.49 & 74 \\
\hline AMM09a-22 & 4.39 & 71 & 1.08 & 4.74 & 81 \\
\hline AMM09b-23a** & 4.10 & 62 & 1.12 & 4.60 & 77 \\
\hline AMM09a-28 & 4.68 & 79 & 1.04 & 4.86 & 85 \\
\hline \multirow{2}{*}{ AMM09a-31*** } & \multirow[t]{2}{*}{4.92} & \multirow[t]{2}{*}{86} & 0.98 & 4.82 & 83 \\
\hline & & & 0.93 (from Ca) & 4.58 & 76 \\
\hline AMM09b-0 & \multicolumn{2}{|c|}{ No Mark 42} & & \multicolumn{2}{|c|}{ No Mark 42} \\
\hline AMM09b-6 & 4.53 & 77 & 1.08 & 4.98 & 88 \\
\hline AMM09b-11** & 4.28 & 68 & 1.12 & 4.81 & 83 \\
\hline AMM09b-22 & 4.69 & 80 & 1.04 & 4.88 & 85 \\
\hline AMM09b-23b** & 4.34 & 70 & 1.10 & 4.77 & 82 \\
\hline AMM09b-28 & 4.46 & 73 & 1.09 & 4.86 & 85 \\
\hline \multirow[t]{2}{*}{ AMM09b-31*** } & 5.00 & 89 & 1.02 & 5.10 & 92 \\
\hline & & & 0.91 (from Ca) & 4.55 & 76 \\
\hline
\end{tabular}

* The amount of aluminum from the ANN (2.03 grams) is subtracted before \% is calculated.

**Replenished dissolver solution to 250 milliliters with $5 \mathrm{M} \mathrm{HNO}_{3}$

*** $\mathrm{CaF}_{2}$ added to the AMM09-29 solutions

reject compact material was $84.5 \% \pm 3 \%$ by weight for AMM09b. The error is probably more on the order of $10 \%$ based on the number of corrections applied to the ICP/AES data. Both of those values are in agreement with the values determined in previous experiments. ${ }^{5}$

The total- and free-acid concentrations were measured for the solutions. Those results are given in Table B6. The interference from complexing metal ions (e.g., aluminum) is removed in the free-acid concentration analysis while the total-acid concentration analysis includes the metal ion effects. The change in free-acid concentration between the AMM09-0 and AMM09-6 samples shows that as the aluminum the Mark 42 reject compact material dissolved, $\mathrm{HNO}_{3}$ was consumed.

Overall, the results of the analyses for total-and free-acid concentrations were as expected. As the solutions evaporated, the acid concentrations increased and after the replenishment to bring the solutions back to 250 milliliters, the acid concentrations decreased. The AMM09a-11 result for the free-acid concentration seems to be an anomalous result because the sample was obtained after the solution was replenished to 250 milliliters and the AMM09a-11 value should be less than the value for AMM09a-6. The AMM09a-6 sample was taken from the solution at 210 milliliters.

The dissolution of the $\mathrm{PuO}_{2}$ is dependent on the availability of free-fluoride ions. If complexing ions are present in the solution, e.g., boron or aluminum, the amount of free-fluoride ions is expected to be reduced. The fluoride-ion concentration was measured with an ion-selective electrode. In general, that analysis is a measure of total fluoride-ion concentration. However, the analysis does not provide the free-fluoride concentration for these samples because the analysis is not calibrated to provide the free-fluoride value in the presence of complexing agents (e.g., boron and aluminum). Thus, this analysis provides qualitative information on the free-fluoride ions in the solution. The results are presented in Table B6. 
Table B6. Total- and Free-Acid Concentrations and Fluoride Concentration for AMM09 Solutions

\begin{tabular}{|l|c|c|c|}
\hline Experiment & $\begin{array}{c}\text { Free Acid } \\
\text { (Molar) }\end{array}$ & $\begin{array}{c}\text { Total Acid } \\
\text { (Molar) }\end{array}$ & $\begin{array}{c}\text { Fluoride } \\
\text { (ppm) }\end{array}$ \\
\hline AMM09a-0 & 7.12 & 8.07 & 920 \\
\hline AMM09a-6 & 6.33 & 8.86 & 320 \\
\hline AMM09a-11* & 6.78 & 8.32 & 650 \\
\hline AMM09a-22 & 6.84 & 9.23 & 780 \\
\hline AMM09a-23* & 6.25 & 8.40 & 650 \\
\hline AMM09a-28 & 7.20 & 9.30 & 730 \\
\hline AMM09a-29** & Not Taken & Not Taken & 1,260 \\
\hline AMM09a-30 & Not Taken & Not Taken & 1,310 \\
\hline AMM09a-31 & 7.41 & 9.31 & 1,190 \\
\hline AMM09c & 8.12 & 8.02 & 2,120 \\
\hline & & & \\
\hline AMM09b-0 & 7.11 & 7.17 & 1,100 \\
\hline AMM09b-6 & 6.06 & 8.52 & 220 \\
\hline AMM09b-11* & 6.48 & 8.01 & 800 \\
\hline AMM09b-22 & 6.84 & 9.78 & 830 \\
\hline AMM09b-23* & 5.96 & 8.17 & 830 \\
\hline AMM09b-28 & 6.52 & 8.69 & 900 \\
\hline AMM09b-29** & Not Taken & Not Taken & 1,260 \\
\hline AMM09b-30 & Not Taken & Not Taken & 1,370 \\
\hline AMM09b-31 & 6.78 & 8.82 & 1,250 \\
\hline AMM09d & 8.09 & 8.11 & 1,930 \\
\hline
\end{tabular}

* Solutions replenished with $5 \mathrm{M} \mathrm{HNO}_{3}$ to reach 250 milliliters. ${ }^{* *} \mathrm{CaF}_{2}$ added to solutions.

The initial AMM09a and AMM09b solutions should have fluoride concentrations of $2850 \mathrm{ppm}$ and 3800 ppm, respectively. The measured values were 920 ppm (AMM09a-0) and 1,100 ppm (AMM09b-0). The lower than expected values indicate that the aluminum and boron in the solutions are complexing with the fluoride ions. The fluoride-ion concentration decreased as the aluminum from the Mark 42 reject compact material dissolved. The increase in fluoride concentrations from the AMM09-6 to the AMM09-11 samples was not expected. The solution volumes when the AMM09-11 samples were taken were 250 milliliters while the solution volumes when the AMM09-6 samples were taken were less than 200 milliliters. The fluoride concentrations in the AMM09-29 solutions were larger than the concentrations in the AMM09-28 solutions because $\mathrm{CaF}_{2}$ had been added. The fluoride concentrations in the AMM09c and AMM09d solutions were expected to be $2850 \mathrm{ppm}$ based on the amount of $\mathrm{KF}$ added to the solutions. The lower measured fluoride concentration was due to the effect of the boron in the solutions because no ANN was added. The effect of the ANN can be seen by comparing the measured fluoride concentrations of solutions AMM09a, AMM09c, and AMM09d. Those three solutions were made to be $0.15 \mathrm{M} \mathrm{KF}$. The AMM09c and AMM09d values are higher than the AMM09a-0 values because the aluminum from the ANN in AMM09a complexes with the fluoride ions and interferes with the analysis.

\section{AMM10, AMM11, and AMM12}

The results from the ICP/AES, total- and free-acid concentrations, and fluoride analyses for AMM10, AMM11, and AMM12 will be discussed together because those sets of experiments were conducted similarly. Table B7 contains the ICP/AES results for aluminum, boron, and calcium for those experiments. The ICP/AES results were expected to provide information regarding the amount of aluminum in the Mark 42 reject compact material. 
WSRC-TR-98-00196

Table B7. ICP/AES Results for Aluminum, Boron, and Calcium for AMM10, AMM11, and AMM12 Solutions

\begin{tabular}{|l|c|c|c|c|c|c|}
\hline Experiment & $\begin{array}{c}\text { Aluminum } \\
\text { mg/liter }\end{array}$ & $\begin{array}{c}\% \text { Aluminum } \\
\text { Added as } \\
\text { ANN }\end{array}$ & $\begin{array}{c}\text { Boron } \\
\text { mg/liter }\end{array}$ & $\begin{array}{c}\text { \% Boron } \\
\text { Added }\end{array}$ & $\begin{array}{c}\text { Calcium } \\
\text { mg/liter }\end{array}$ & $\begin{array}{c}\text { \% Calcium } \\
\text { Added }\end{array}$ \\
\hline AMM10a-1 & 4,600 & 100 & 2,100 & 100 & 5,800 & 100 \\
\hline AMM10a-3 & 11,300 & - & 1,900 & $87^{*}$ & 5,000 & 83 \\
\hline & & & & & & \\
\hline AMM10b-1 & 3,100 & 99 & 2,150 & 100 & 5,800 & 98 \\
\hline AMM10b-3 & 6,500 & - & 1,800 & $91^{*}$ & 4,600 & $86^{*}$ \\
\hline & & & & & & \\
\hline AMM11a-1 & 4,400 & 95 & 2,200 & 104 & 5,000 & 95 \\
\hline AMM11a-3 & 12,000 & - & 2,100 & $95^{*}$ & 5,000 & $90^{*}$ \\
\hline AMM11a-5 & 10,200 & - & 1,800 & $80^{*}$ & 4,400 & $77^{*}$ \\
\hline & & & & & & \\
\hline AMM11b-1 & 4,600 & 97 & 2,300 & 105 & 4,700 & 95 \\
\hline AMM11b-5 & 11,300 & - & 2,000 & 104 & 4,300 & 100 \\
\hline & & & & & & \\
\hline AMM12-1 & 1,000 & None added & 2,400 & 108 & 5,300 & 97 \\
\hline AMM12-2 & 4,900 & 95 & 2,250 & $98^{*}$ & 5,300 & $93^{*}$ \\
\hline AMM12-5 & 13,900 & - & 2,300 & $97^{*}$ & 5,400 & $93^{*}$ \\
\hline
\end{tabular}

*Corrected for removal of samples.

Samples for the ICP/AES analyses were obtained from the initial solution before the addition of the Mark 42 reject compact material and after all of the solids had dissolved. An intermediate ICP/AES sample was taken from AMM11a-3 and AMM12-2. The sample results were corrected for the removal of the initial and any intermediate samples, e.g., rad screen/gamma scan samples.

The percent of added material was based on the amounts of $\mathrm{ANN}$ (for aluminum), $\mathrm{H}_{3} \mathrm{BO}_{3}$ (for boron), and $\mathrm{CaF}_{2}$ (for fluoride) that were added to the initial solutions. The results for the initial solutions agree within ten percent of the amounts of $\mathrm{ANN}, \mathrm{H}_{3} \mathrm{BO}_{3}$, and $\mathrm{CaF}_{2}$ that were added to the solutions. The values for the other AMM10 and AMM1 1a samples are low. Initially, the low values were attributed to dilution errors in the preparation of the samples prior to sending them to the ADS for analysis. Another set of ICP/AES samples were obtained from the AMM10a, AMM10b, AMM11a, AMM11b, and AMM12 final solutions and were sent to ADS without any dilution. The results of those new analyses are given in Table B8, Table $\mathrm{B} 9$, and Table B10 for aluminum, boron, and calcium, respectively. Those three tables also contain the results of recheck analyses on the original samples from AMM11a and AMM11b.

As can be seen in Table B8, the aluminum values from the rechecks for the original samples are slightly lower than the values from the first analyses. For both the AMM11a and AMM11b, the aluminum values from the rechecks are about $5 \%$ lower than the first values. The aluminum results of the additional samples agree with the results from the original sample with the exception of the aluminum results from the AMM1 1a additional sample. That agreement indicates that there was no dilution error in the preparation of the original sample from AMM10a, AMM10b, AMM11b, and AMM12. The results for the additional sample from AMM11a are about $20 \%$ higher than the results for the original sample, thus indicating that there might have been a dilution problem.

Using the aluminum values from the ICP/AES data, the percent of aluminum in the Mark 42 reject compact material was calculated. The values for AMM11b and AMM12 (81\% and 82\%, respectively) agree with results from the previous report. ${ }^{5}$ The other three values are about $15 \%$ lower at about 70 weight $\%$ aluminum. This discrepancy in the measured aluminum content cannot be explained. It is probably due to 
Table B8. Additional ICP/AES Results for Aluminum for AMM10, AMM11, and AMM12 Solutions

\begin{tabular}{|c|c|c|c|c|c|c|c|}
\hline Experiment & & & $\begin{array}{l}\text { Aluminum } \\
\text { mg/liter }\end{array}$ & & & $\begin{array}{c}\text { Total } \\
\text { Aluminum }\end{array}$ & $\begin{array}{c}\text { Mark } 42 \\
\text { Aluminum }\end{array}$ \\
\hline & $\begin{array}{l}\text { Original } \\
\text { Sample }\end{array}$ & $\begin{array}{l}\text { Original } \\
\text { Recheck-1 }\end{array}$ & $\begin{array}{l}\text { Original } \\
\text { Recheck } \\
\text { Duplicate }\end{array}$ & $\begin{array}{l}\text { Additional } \\
\text { Sample }\end{array}$ & $\begin{array}{l}\text { Additional } \\
\text { Sample - } \\
\text { Duplicate }\end{array}$ & & \\
\hline AMM10a-1 & 4,600 & - & - & - & - & $1.20 *$ & - \\
\hline AMM10a-3 & 11,300 & - & - & 11,200 & 11,700 & $2.83 * *$ & $1.62 / 69 \%$ \\
\hline AMM10b-1 & 3,100 & - & - & - & - & $0.78^{*}$ & - \\
\hline AMM10b-3 & 6,500 & - & - & 6,400 & 6,500 & $1.80^{* *}$ & $1.01 / 67 \%$ \\
\hline AMM11a-1 & 4,400 & - & - & - & - & $1.16^{*}$ & $\overline{-}$ \\
\hline AMM11a-3 & 12,000 & 11,600 & 11,700 & - & - & $2.85 * *$ & $1.63 / 70 \%$ \\
\hline AMM11a-5 & 10,200 & 9,700 & 9,800 & 12,300 & 12,600 & $2.62 / 2.98 * * *$ & $\begin{array}{l}1.40 / 60 \% \\
1.76 / 76 \%\end{array}$ \\
\hline AMM11b-1 & 4,600 & - & - & - & - & - & - \\
\hline AMM11b-5 & 11,300 & 10,700 & 10,800 & 11,000 & 10,700 & $3.10^{* *}$ & $1.88 / 81 \%$ \\
\hline AMM12-1 & 1,000 & - & - & - & - & - & - \\
\hline AMM12-2 & 4,900 & - & $=$ & - & - & $1.16^{*}$ & - \\
\hline AMM12-5 & 13,900 & - & - & 14,300 & 13,900 & $3.14 * *$ & $1.92 / 82 \%$ \\
\hline
\end{tabular}

* Initial solution, only source of aluminum is the ANN (or GPC coupon for AMM12)

** Corrected for removal of samples

*** Corrected for removal of samples and second number is based only on the ICP/AES results for the additional sample

sample preparation errors or instrument drift. However, to determine if there was a systematic error, the boron and calcium ICP/AES values were examined because both of those elements can be considered as internal standards.

The boron and calcium values are given in TableB9 and Table B10 for the original analyses, recheck analyses, and additional sample analyses. The boron and calcium values seem to be low by a similar factor as the aluminum values. Using an average of the boron and calcium factors, an adjusted value for the aluminum can be calculated, and that adjusted value can be used to estimate the amount of aluminum in the Mark 42 reject compact material. The adjusted values for AMM10a-3, AMM10b-3, AMM11a-3, AMM1 1a-5, AMM11b-5, and AMM12-5 are given in Table B11. Based on the adjusted values, the average aluminum content for the Mark 42 reject compact material is $86 \pm 3$ weight $\%$. That value agrees with the 86 weight\% expected from the MC\&A 12.24 weight\% value for the plutonium. The 86 weight\% is higher than the 80 weight\% value obtained in earlier experiments. ${ }^{5}$ However, there was no attempt to use the boron in those earlier experiments as an internal standard to correct the aluminum ICP/AES values $\left(\mathrm{CaF}_{2}\right.$ was not used as a fluoride source in those experiments; $\mathrm{KF}$ was used as the fluoride source.). 
Table B9. Additional ICP/AES Results for Boron for AMM10, AMM11, and AMM12 Solutions

\begin{tabular}{|l|c|c|c|c|c|c|}
\hline Experiment & \multicolumn{5}{|c|}{$\begin{array}{c}\text { Boron } \\
\text { mg/liter }\end{array}$} & $\begin{array}{c}\text { Boron } \\
\text { (grams/\%) }\end{array}$ \\
\hline & $\begin{array}{c}\text { Original } \\
\text { Sample }\end{array}$ & $\begin{array}{c}\text { Original } \\
\text { Recheck-1 }\end{array}$ & $\begin{array}{c}\text { Original } \\
\text { Recheck } \\
\text { Duplicate }\end{array}$ & $\begin{array}{c}\text { Additional } \\
\text { Sample }\end{array}$ & $\begin{array}{c}\text { Additional } \\
\text { Sample - } \\
\text { Duplicate }\end{array}$ & \\
\hline AMM10a-1 & 2,100 & - & - & - & - & $0.55 / 100 \%$ \\
\hline AMM10a-3 & 1,900 & - & - & 1,900 & 2,000 & $0.48 / 87 \%^{*}$ \\
\hline & & & & & & \\
\hline AMM10b-1 & 2,150 & - & - & - & - & $0.55 / 100 \%$ \\
\hline AMM10b-3 & 1,800 & - & - & 1,700 & 1,700 & $0.49 / 89 \%^{*}$ \\
\hline & & & & & & \\
\hline AMM11a-1 & 2,200 & - & - & - & - & $0.57 / 104 \%$ \\
\hline AMM11a-3 & 2,100 & 2,000 & 2,000 & - & - & $0.51 / 92 \%^{*}$ \\
\hline AMM11a-5 & 1,800 & 1,700 & 1,700 & 2,100 & 2,200 & $0.46 / 84 \%$ \\
\hline & & & & & & $0.52 / 95 \% * *$ \\
\hline AMM11b-1 & 2,300 & - & - & - & - & $0.58 / 105 \%$ \\
\hline AMM11b-5 & 2,000 & 1,850 & 1,900 & 1,900 & 1,800 & $0.54 / 98 \% *$ \\
\hline & & & & & & \\
\hline AMM12-1 & 2,400 & - & - & - & - & $0.59 / 108 \%$ \\
\hline AMM12-2 & 2,250 & - & - & - & - & $0.54 / 98 \% \%^{*}$ \\
\hline AMM12-5 & 2,300 & - & - & 2,300 & 2,300 & $0.53 / 97 \%^{*}$ \\
\hline
\end{tabular}

* Corrected for removal of samples

** Corrected for removal of samples and the second number is based only on the ICP/AES results for the additional sample

The total- and free-acid concentrations were measured for the solutions. Those results are given in Table B12. The interference from complexing metal ions (e.g., aluminum) is removed in the free-acid concentration analysis while the total-acid concentration analysis includes the metal ion effects. The results for AMM12-5 indicate that the dissolution of the aluminum coupon resulted in a lower free-acid concentration compared to providing the aluminum as ANN (AMM11a-5) in a solution with similar fluoride, aluminum, and plutonium concentrations, $5.6 \mathrm{M}$ and $6.8 \mathrm{M}$, respectively.

The dissolution of the $\mathrm{PuO}_{2}$ is dependent on the availability of free-fluoride ions. If complexing ions are present in the solution, e.g., boron or aluminum, then the amount of free-fluoride ions is expected to be reduced. The fluoride-ion concentration was measured with an ion-selective electrode. In general, that analysis is a measure of total fluoride-ion concentration. However, the analysis does not provide the freefluoride concentration for these samples because the analysis is not calibrated to provide the free-fluoride value in the presence of complexing agents (e.g., boron and aluminum). Thus, this analysis provides qualitative information on the free-fluoride ions in the solution. The results are presented in Table B12. The corrosion study being conducted by the Materials Applications and Technology Group includes the measurement of effective free-fluoride concentrations in the $\mathrm{CaF}_{2}$ solutions that are proposed for the flow sheet for the dissolution of the unirradiated Mark 42 fuel tubes. ${ }^{14}$

\footnotetext{
${ }^{14}$ The report on the corrosion studies being performed by John Mickalonis will include fluoride-ion concentrations that are more representative of the effective free-fluoride concentration in the dissolver solutions.
} 
Table B10. Additional ICP/AES Results for Calcium for AMM10, AMM11, and AMM12 Solutions

\begin{tabular}{|c|c|c|c|c|c|c|}
\hline \multirow[t]{2}{*}{ Experiment } & \multicolumn{5}{|c|}{$\begin{array}{l}\text { Calcium } \\
\text { mg/liter }\end{array}$} & \multirow[t]{2}{*}{$\begin{array}{c}\text { Calcium } \\
\text { (grams } / \% \text { ) }\end{array}$} \\
\hline & $\begin{array}{c}\text { Original } \\
\text { Sample }\end{array}$ & $\begin{array}{c}\text { Original } \\
\text { Recheck-1 }\end{array}$ & $\begin{array}{l}\text { Original } \\
\text { Recheck } \\
\text { Duplicate }\end{array}$ & $\begin{array}{l}\text { Additional } \\
\text { Sample }\end{array}$ & $\begin{array}{l}\text { Additional } \\
\text { Sample - } \\
\text { Duplicate }\end{array}$ & \\
\hline AMM10a-1 & 5,800 & - & - & - & $=$ & $1.5 / 100 \%$ \\
\hline AMM10a-3 & 5,000 & - & - & 4,950 & 5,100 & $1.3 / 84 \% *$ \\
\hline AMM10b-1 & 5,800 & - & - & - & - & $1.5 / 98 \%$ \\
\hline AMM10b-3 & 4,600 & - & - & 4,500 & 4,500 & $1.3 / 85 \% *$ \\
\hline & & & & & & \\
\hline & & & & & & \\
\hline$\frac{\text { AMM11a-3 }}{\text { AMM11a-5 }}$ & 5,000 & 4,800 & 4,800 & - & - & $1.2 / 87 \% *$ \\
\hline & & 4,000 & 4,100 & 5,150 & 5,300 & $\begin{array}{c}1.1 / 81 \% \\
1.3 / 92 \% * *\end{array}$ \\
\hline AMM11b-1 & 4,650 & - & - & - & - & $1.2 / 95 \%$ \\
\hline AMM11b-5 & 4,300 & 4,050 & 4,100 & 4,200 & 4,100 & $1.2 / 95 \%$ \\
\hline AMM12-1 & 5,300 & - & - & - & - & $1.3 / 97 \%$ \\
\hline AMM12-2 & 5,300 & - & - & - & - & $1.3 / 93 \%$ \\
\hline AMM12-5 & 5,400 & - & - & 5,500 & 5,450 & $1.3 / 93 \%$ \\
\hline
\end{tabular}

* Corrected for removal of samples

** Corrected for removal of samples and the second number is based only on the ICP/AES results for the additional sample

Table B11. Calculated Aluminum Content of Mark 42 Reject Compact Material Based on ICP/AES Data

\begin{tabular}{|c|c|c|c|l|c|c|c|}
\hline \multirow{2}{*}{ Experiment } & \multicolumn{3}{|c|}{ Aluminum** } & Boron/ & \multicolumn{3}{|c|}{ Aluminum with Adjustment** } \\
\cline { 7 - 8 } & $\begin{array}{c}\text { Total } \\
\text { grams }\end{array}$ & $\begin{array}{c}\text { Mark 42 } \\
\text { grams }\end{array}$ & $\begin{array}{c}\text { Mark 42 } \\
\%\end{array}$ & $\begin{array}{l}\text { Calcium } \\
\text { Adjustment }\end{array}$ & $\begin{array}{c}\text { Total } \\
\text { grams }\end{array}$ & $\begin{array}{c}\text { Mark 42 } \\
\text { grams }\end{array}$ & $\begin{array}{c}\text { Mark 42 } \\
\%\end{array}$ \\
\hline AMM10a-3 & 2.83 & 1.62 & 69 & 1.17 & 3.31 & 2.10 & 90 \\
\hline AMM10b-3 & 1.80 & 0.79 & 67 & 1.15 & 2.08 & 1.29 & 86 \\
\hline AMM11a-3 & 2.85 & 1.63 & 70 & 1.12 & 3.19 & 1.97 & 84 \\
\hline AMM11a-5 & $2.62 / 2.98^{*}$ & $1.40 / 1.76$ & $60 / 76$ & $1.21 / 1.07$ & $3.17 / 3.20^{*}$ & $1.95 / 1.98$ & $84 / 85$ \\
\hline AMM11b-5 & 3.10 & 1.88 & 81 & 1.03 & 3.21 & 1.99 & 85 \\
\hline AMM12-5 & 3.14 & 1.92 & 82 & 1.05 & 3.31 & 2.09 & 89 \\
\hline
\end{tabular}

* Corrected for removal of samples and second number is based only on the ICP/AES results for the additional sample

** Corrected for removal of samples 
Table B12. Total- and Free-Acid Concentrations and Fluoride Concentration for AMM10, AMM11 and AMM12 Solutions

\begin{tabular}{|l|c|c|c|}
\hline Experiment & $\begin{array}{c}\text { Free Acid } \\
\text { (Molar) }\end{array}$ & $\begin{array}{c}\text { Total Acid } \\
\text { (Molar) }\end{array}$ & $\begin{array}{c}\text { Fluoride } \\
\text { (ppm) }\end{array}$ \\
\hline AMM010a-1 & 6.54 & 7.8 & - \\
\hline AMM010a-3 & 6.10 & 7.56 & 1,360 \\
\hline & & & \\
\hline AMM10b-1 & 6.58 & 7.5 & - \\
\hline AMM10b-3 & 5.84 & 6.50 & 1,220 \\
\hline & & & \\
\hline AMM11a-1 & 7.01 & 7.9 & - \\
\hline AMM11a-3 & 6.72 & 7.98 & 1,360 \\
\hline AMM11a-5 & 6.76 & 8.14 & 1,350 \\
\hline & & & \\
\hline AMM11b-1 & 6.96 & 8.40 & - \\
\hline AMM11b-3 & 5.95 & 7.01 & 1,240 \\
\hline & & & \\
\hline AMM12-1 & 7.32 & 7.55 & 3,750 \\
\hline AMM12-2 & 7.09 & 7.67 & 1,270 \\
\hline AMM12-5 & 5.62 & 7.69 & 1,350 \\
\hline
\end{tabular}

The fluoride concentrations for the initial samples of AMM10 and AMM11 were not measured. Based on the amounts of $\mathrm{CaF}_{2}$ added to the solutions the fluoride concentrations were expected to be $5,700 \mathrm{ppm}$ (AMM10a and AMM10b), 5,230 ppm (AMM11a) and 4,750 ppm (AMM11b). The measured fluoride concentrations are about one-fourth of the expected amount. Thus, the aluminum and boron are complexing with the fluoride ions. Another mechanism for the reduction of available fluoride is the $\mathrm{CaF}_{2}$ equilibrium with fluoride ions and the $\mathrm{CaF}^{+1}$ species. ${ }^{9}$

The initial AMM12 solution only contains boron to complex with the fluoride. However, as mentioned previously, the dissolved $\mathrm{CaF}_{2}$ exists in equilibrium with fluoride ions and the $\mathrm{CaF}^{+1}$ species.? $\mathrm{Based}$ on the amount of $\mathrm{CaF}_{2}$ added to the AMM12 solution, the fluoride concentrations should be $5,230 \mathrm{ppm}$. The measured value was $3,750 \mathrm{ppm}$ (AMM12-1). After the aluminum coupon was added and allowed to dissolve, the fluoride concentration was measured again (AMM12-2). That value was $1,270 \mathrm{ppm}$. A value of $1,350 \mathrm{ppm}$ was measured after the Mark 42 material was added and dissolved. It was expected that the measured fluoride concentration of AMM12-5 should be less than that of AMM12-2 because more aluminum was dissolved. 